Balanceamento de linhas de produção com trabalhadores deficientes e máquinas paralelas 
SERVIÇO DE PÓS-GRADUAÇÃO DO ICMC-USP

Data de Depósito: 23/05/2011

Assinatura:

\section{Balanceamento de linhas de produção com trabalhadores deficientes e máquinas paralelas}

\section{Felipe Francisco Bezerra Araújo}

Orientador: Prof. Dr. Alysson Machado Costa

Dissertação apresentada ao Instituto de Ciências Matemáticas e de Computação - ICMC-USP, como parte dos requisitos para obtenção do título de Mestre em Ciências - Ciências de Computação e Matemática Computacional. VERSÃO REVISADA.

USP - São Carlos

Maio/2011 
Ficha catalográfica elaborada pela Biblioteca Prof. Achille Bassi e Seção Técnica de Informática, ICMC/USP, com os dados fornecidos pelo(a) autor(a)

Araújo, Felipe Francisco Bezerra
Balanceamento de linhas de produção com
trabalhadores deficientes e máquinas paralelas /
Felipe Francisco Bezerra Araújo; orientador Alysson
Machado Costa -- São Carlos, 2011.
123 p.
Tese (Doutorado - Programa de Pós-Graduação em
Ciências de Computação e Matemática Computacional) --
Instituto de Ciências Matemáticas e de Computação,
Universidade de São Paulo, 2011.
Lormulação. 4. Programação matemática. I. Costa,
Alysson Machado, orient. II. Título.




\section{Agradecimentos}

Ao Prof. Alysson, orientador desta dissertação, cujo apoio, competência e exigência permitiram a conclusão deste trabalho.

Ao Prof. Dr. Reinaldo Morabito e à Profa. Dra. Franklina Maria Bragion de Toledo, que participaram da banca de meu exame de qualificação, na qual propuseram ótimas ideias que foram de grande ajuda para este trabalho.

Aos membros do Laboratório de Otimização (LOt), pela disposição em ajudar sempre que possível.

Aos meus familiares que sempre me apoiaram e mesmo à distância continuam me dando apoio.

Aos meus amigos, que sempre estiveram presentes nos momentos felizes e nas horas difíceis.

Ao CNPq e à FAPESP, financiadores desta pesquisa através dos processos 561672/20083 (CNPq), 2009/02894-3 e 2009/07812-5 (FAPESP).

A todas as pessoas que, direta ou indiretamente, contribuíram para a realização deste trabalho. 



\section{Resumo}

O problema de balanceamento de linhas de produção e designação de trabalhadores (ALWABP, do inglês Assembly Line Worker Assignment and Balancing Problem) é uma extensão do problema simples de balanceamento de linhas na qual os tempos de execução de tarefas são dependentes dos trabalhadores. Este problema tem sua motivação prática oriunda de linhas de produção com trabalhadores deficientes. Neste trabalho, focamos em uma extensão para o problema que permite lidar com a possibilidade de layouts de linhas com estações em paralelo. Além disso, estudamos uma segunda variante do problema que permite que os trabalhadores colaborem uns com os outros em uma mesma estação. Apresentamos formulações matemáticas para ambas as versões do problema. Adicionalmente, a partir de adaptações de métodos existentes para o ALWABP serial, desenvolvemos heurísticas construtivas para o ALWABP paralelo e ALWABP colaborativo. Testes computacionais em instâncias da literatura e uma análise detalhada dos resultados são apresentados.

Palavras-chave: Linhas de produção, máquinas paralelas, formulação, programação matemática 



\section{Abstract}

The assembly line and worker assignment balancing problem is an extension of the classical simple assembly line balancing problem where task execution times are workerdependent. This problem is motivated by the situation faced when balancing assembly lines with disabled workers. In this study, we focus on an extension for the problem with the goal of including the possibility of having layouts with parallel workstations. We also study a second variation for this problem that allows workers collaborating with each other. We present mathematical formulations for both problems. Moreover, constructive heuristics are developed, based on heuristic methods for the serial assembly line worker assignment and balancing problem. Computational tests on literature instances and a detailed analysis of the results are reported.

Keywords: Assembly lines, parallel workstations, linear formulation, mathematical programming 



\section{Sumário}

\section{Lista de Figuras}

Lista de Tabelas

Índice de Siglas

p. 19

1 Introdução

p. 1

2 Descrição dos problemas $\quad$ p. 5

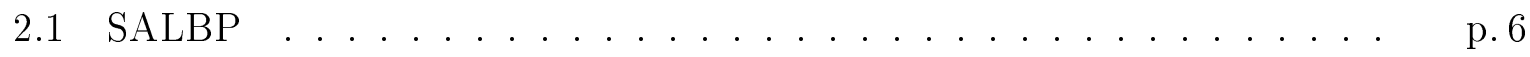

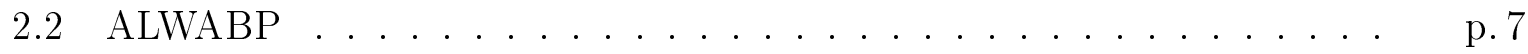

2.3 ALWABP com estações em paralelo . . . . . . . . . . . . . . p 9

2.4 ALWABP colaborativo . . . . . . . . . . . . . . . p. 13

3 Revisão Bibliográfica $\quad$ p. 15

4 Formulações Matemáticas $\quad$ p. 19

4.1 Formulação para o SALBP . . . . . . . . . . . . . . . . . . . p. 19

4.2 Formulação para o ALWABP . . . . . . . . . . . . . p. 20

4.3 Formulação para o ALBP com estações em paralelo . . . . . . . . . . p. 22

4.4 Formulação para o ALWABP com estações em paralelo . . . . . . . . . p. 23

4.5 Formulação para o ALWABP colaborativo . . . . . . . . . . p. 27

5 Heurística Construtiva $\quad$ p. 29

5.1 Heurística para o SALBP-2 . . . . . . . . . . . . . . p. 29 
5.2 Heurística para o ALWABP . . . . . . . . . . . p. 31

5.3 Heurística para o ALWABP com estações em paralelo . . . . . . . . . p. 33

5.3.1 Adaptação do custo de adição de uma tarefa . . . . . . . . . . . p. 35

5.3.2 Adaptação das regras de seleção de trabalhadores . . . . . . . . p. 36

5.3 .3 Modificações na heurística . . . . . . . . . . . . . . . . p. 37

5.4 Heurística para o ALWABP colaborativo . . . . . . . . . . . p. 38

5.4 .1 Modificações na heurística . . . . . . . . . . . . . . p. 38

6 Testes Computacionais p. 39

6.1 Testes com os modelos . . . . . . . . . . . . . . . . . . . p. 40

6.2 Testes com as heurísticas construtivas . . . . . . . . . . . . p. 44

6.2.1 Heurística para o ALWABP com estações em paralelo . . . . . . p p. 44

6.2.1.1 Testes com as heurísticas modificadas . . . . . . . . p. 46

6.2.2 Heurística para o ALWABP colaborativo . . . . . . . . . p. 46

6.2.2.1 Testes com as heurísticas modificadas . . . . . . . . p. 47

6.2.3 Comentários gerais sobre os resultados . . . . . . . . . p. 48

7 Conclusões e Passos futuros $\quad$ p. 51

7.1 Trabalhos futuros . . . . . . . . . . . . . . . p. p 52

Referências Bibliográficas p. 55

Apêndice A - Resultados detalhados dos testes computacionais $\quad$ p. 59

A.1 Heurística para o ALWABP com estações em paralelo . . . . . . . . . p. 59

A.1.1 Testes com as heurísticas modificadas . . . . . . . . . . p 69

A.2 Heurística para o ALWABP colaborativo . . . . . . . . . . p p. 92

A.2.1 Testes com as heurísticas modificadas . . . . . . . . . . . . p. 102 


\section{Lista de Figuras}

1 Exemplo de Grafo de Precedência . . . . . . . . . . . p. 5

2 Exemplo de Solução para o SALBP . . . . . . . . . . . . . . p. 7

3 Exemplo de Solução para o ALWABP . . . . . . . . . . . . . p. 8

4 Exemplo de Solução para o ALBP utilizando estações paralelas . . . . . $\quad$ p. 10

5 Exemplo de Solução para o ALWABP utilizando estações paralelas . . . $\quad$ p. 11

6 Exemplo de execução para o ALWABP com estações em paralelo . . . . p p. 13

7 Exemplo de Solução para o ALWABP colaborativo . . . . . . . . . . . p 14 



\section{Lista de Tabelas}

Tempos de execução das tarefas para o SALBP . . . . . . . . . $\quad$ p. 6

2 Tempos de execução das tarefas para o ALWABP $\ldots \ldots \ldots \ldots$ p. . . . . 8

3 Resultados para a família Heskia . . . . . . . . . . . . . p. p. 41

4 Resultados para a família Roszieg . . . . . . . . . . . . . . p. 42

$5 \quad$ Resultados para a família Heskia mod $1 \ldots \ldots$. . . . . . . . 42

6 Resultados para a família Roszieg $\bmod 1 \ldots \ldots$. . . . . . . . . 42

$7 \quad$ Resultados para a família $\operatorname{Roszieg} \bmod 2 \ldots \ldots$. . . . . . . . 42

8 Resultados para a família Heskia $\bmod 2 \ldots \ldots \ldots$ p. 42

9 Características das instâncias f. . . . . . . . . . . p. p. 44

10 Resultados dos testes com a heurística para o ALWABP com estações em paralelo utilizando $K_{\text {Max }}=2 \ldots \ldots \ldots \ldots$. . . . . . . . . . . . . . . .

11 Resultados dos testes com a heurística para o ALWABP com estações em paralelo utilizando $K_{\text {Max }}=3 \ldots \ldots \ldots$. . . . . . . . . . 45

12 Resultados dos testes com as heurísticas modificadas para o ALWABP com estações em paralelo utilizando $K_{\operatorname{Max}}=2 \ldots \ldots$ p. 46

13 Resultados dos testes com as heurísticas modificadas para o ALWABP com estações em paralelo utilizando $K_{\text {Max }}=3 \ldots \ldots$. . . . . . . . . 46

14 Resultados dos testes com a heurística para o ALWABP colaborativo utilizando $K_{\text {Max }}=2 \ldots \ldots \ldots \ldots \ldots$ p. 47

15 Resultados dos testes com a heurística para o ALWABP colaborativo utilizando $K_{\text {Max }}=3 \ldots \ldots \ldots \ldots \ldots \ldots \ldots$ p. . . . . . . . . . . . . .

16 Resultados dos testes com as heurísticas modificadas para o ALWABP colaborativo utilizando $K_{M a x}=2 \ldots \ldots \ldots \ldots \ldots$ p. 48 
17 Resultados dos testes com as heurísticas modificadas para o ALWABP colaborativo utilizando $K_{\text {Max }}=3 \ldots \ldots \ldots \ldots$ p. 48

18 Resultados da heurística para o ALWABP com estações em paralelo para a família Roszieg . . . . . . . . . . . . . . . . . . p. 60

19 Resultados da heurística para o ALWABP com estações em paralelo para a família Heskia . . . . . . . . . . . . . . . . . . . . . . p. p 61

20 Resultados da heurística para o ALWABP com estações em paralelo para a família Tonge . . . . . . . . . . . . . . . . . . . . . . . p. 62

21 Resultados da heurística para o ALWABP com estações em paralelo para a família Wee-mag . . . . . . . . . . . . . . . p. 63

22 Resultados da heurística para o ALWABP com estações em paralelo para a família Roszieg $\bmod 1 \ldots$. . . . . . . . . . . . . . . . . . p. 64

23 Resultados da heurística para o ALWABP com estações em paralelo para a família $\operatorname{Roszieg} \bmod 2 \ldots$. . . . . . . . . . . . . . . p. 65

24 Resultados da heurística para o ALWABP com estações em paralelo para a família Heskia $\bmod 1 \ldots \ldots$. . . . . . . . . . . . . . . 66

25 Resultados da heurística para o ALWABP com estações em paralelo para a família Heskia mod $2 \ldots \ldots$. . . . . . . . . . . . . 67

26 Resultados da heurística P1 para a família Roszieg . . . . . . . . . . p. 70

27 Resultados da heurística P2 para a família Roszieg . . . . . . . . . . p. 70

28 Resultados da heurística PS para a família Roszieg . . . . . . . . . . p. 71

29 Resultados da heurística PW para a família Roszieg . . . . . . . . . . . p p.71

30 Resultados da heurística P1 para a família Heskia . . . . . . . . . p. 73

31 Resultados da heurística P2 para a família Heskia . . . . . . . . . p. 73

32 Resultados da heurística PS para a família Heskia . . . . . . . . . . . p. 74

33 Resultados da heurística PW para a família Heskia . . . . . . . . . p 74

34 Resultados da heurística P1 para a família Tonge $\ldots \ldots$. . . . . . p 76

35 Resultados da heurística P2 para a família Tonge . . . . . . . . . p. 76

36 Resultados da heurística PS para a família Tonge . . . . . . . . . . p. 77 
37 Resultados da heurística PW para a família Tonge . . . . . . . . . p. 77

38 Resultados da heurística P1 para a família Wee-mag . . . . . . . . . p. 79

39 Resultados da heurística P2 para a família Wee-mag . . . . . . . . p. 79

40 Resultados da heurística PS para a família Wee-mag . . . . . . . p p 80

41 Resultados da heurística PW para a família Wee-mag . . . . . . . . p. 80

42 Resultados da heurística P1 para a família Roszieg mod 1 . . . . . . . p p. 82

43 Resultados da heurística P2 para a família Roszieg mod $1 \ldots$. . . . . p. 82

44 Resultados da heurística PS para a família Roszieg mod 1 . . . . . . p p. 83

45 Resultados da heurística PW para a família Roszieg mod $1 \ldots$. . . . . p. 83

46 Resultados da heurística P1 para a família Roszieg mod $2 \ldots$. . . . p. 85

47 Resultados da heurística P2 para a família Roszieg mod $2 \ldots$. . . . p. 85

48 Resultados da heurística PS para a família Roszieg mod $2 \ldots \ldots$. . . . 86

49 Resultados da heurística PW para a família Roszieg mod $2 \ldots$. . . . p. 86

50 Resultados da heurística P1 para a família Heskia mod $1 \ldots$. . . . p. 87

51 Resultados da heurística P2 para a família Heskia mod $1 \ldots$. . . . p. 87

52 Resultados da heurística PS para a família Heskia mod $1 \ldots$. . . . . p. 88

53 Resultados da heurística PW para a família Heskia mod $1 \ldots$. . . . p. 88

54 Resultados da heurística P1 para a família Heskia mod $2 \ldots \ldots$ p. . . . 90

55 Resultados da heurística P2 para a família Heskia mod $2 \ldots$. . . . p. 90

56 Resultados da heurística PS para a família Heskia mod $2 \ldots$. . . . p. 91

57 Resultados da heurística PW para a família Heskia mod $2 \ldots$. . . . p. 91

58 Resultados da heurística para o ALWABP colaborativo para a família

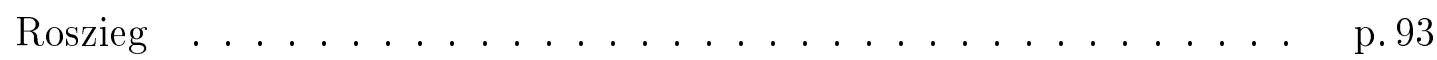

59 Resultados da heurística para o ALWABP colaborativo para a família Heskia . . . . . . . . . . . . . . . . . . p. 94

60 Resultados da heurística para o ALWABP colaborativo para a família

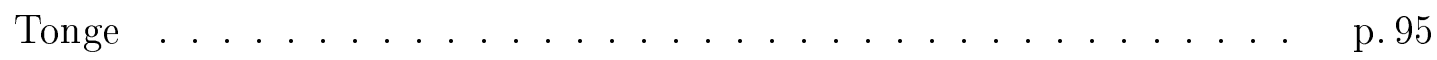


61 Resultados da heurística para o ALWABP colaborativo para a família Wee-mag . . . . . . . . . . . . . . . . p. 96

62 Resultados da heurística para o ALWABP colaborativo para a família Roszieg $\bmod 1 \ldots \ldots \ldots$ p. 97

63 Resultados da heurística para o ALWABP colaborativo para a família Roszieg $\bmod 2 \ldots \ldots \ldots \ldots$ p. 98

64 Resultados da heurística para o ALWABP colaborativo para a família Heskia $\bmod 1 \ldots \ldots \ldots$. . . . . . . . . . . . . . . . . . . . . . . .

65 Resultados da heurística para o ALWABP colaborativo para a família

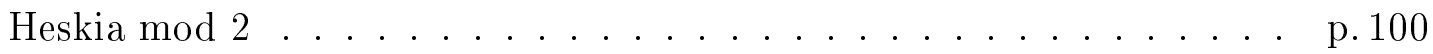

66 Resultados da heurística C1 para a família Roszieg . . . . . . . . . . p. 103

67 Resultados da heurística C2 para a família Roszieg . . . . . . . . . . . p. 103

68 Resultados da heurística CS para a família Roszieg . . . . . . . . . . p. 104

69 Resultados da heurística CW para a família Roszieg . . . . . . . . . . . p. 104

70 Resultados da heurística C1 para a família Heskia . . . . . . . . . p. 106

71 Resultados da heurística C2 para a família Heskia . . . . . . . . . p. 106

72 Resultados da heurística CS para a família Heskia . . . . . . . . . p. 107

73 Resultados da heurística CW para a família Heskia . . . . . . . . . p. 107

74 Resultados da heurística C1 para a família Tonge . . . . . . . . . . . p. 108

75 Resultados da heurística C2 para a família Tonge . . . . . . . . . p. 108

76 Resultados da heurística CS para a família Tonge . . . . . . . . . . p. 109

77 Resultados da heurística CW para a família Tonge . . . . . . . . . . . p. 109

78 Resultados da heurística C1 para a família Wee-mag . . . . . . . . . p. 111

79 Resultados da heurística C2 para a família Wee-mag . . . . . . . . p. 111

80 Resultados da heurística CS para a família Wee-mag . . . . . . . . . p. 112

81 Resultados da heurística CW para a família Wee-mag . . . . . . . . . p. 112

82 Resultados da heurística C1 para a família Roszieg mod 1 . . . . . p. 113

83 Resultados da heurística C2 para a família Roszieg mod 1 . . . . . . p. 113 
84 Resultados da heurística CS para a família Roszieg mod 1 . . . . . . . p. 114

85 Resultados da heurística CW para a família Roszieg mod 1 . . . . . . p. 114

86 Resultados da heurística C1 para a família Roszieg Mod 2 . . . . . . . p. 116

87 Resultados da heurística C2 para a família Roszieg Mod 2 . . . . . . p. 116

88 Resultados da heurística CS para a família Roszieg Mod 2 . . . . . . p. 117

89 Resultados da heurística CW para a família Roszieg Mod 2 . . . . . . p. 117

90 Resultados da heurística C1 para a família Heskia Mod 1 . . . . . . . p. 119

91 Resultados da heurística C2 para a família Heskia Mod 1 . . . . . . . p. 119

92 Resultados da heurística CS para a família Heskia Mod 1 . . . . . . p. 120

93 Resultados da heurística CW para a família Heskia Mod 1 . . . . . . p. 120

94 Resultados da heurística C1 para a família Heskia Mod 2 . . . . . . . p. 122

95 Resultados da heurística C2 para a família Heskia Mod 2 . . . . . . . p. 122

96 Resultados da heurística CS para a família Heskia Mod 2 . . . . . . . p. 123

97 Resultados da heurística CW para a família Heskia Mod 2 . . . . . . . p. 123 



\section{Indice de Siglas}

- CTD - centro de trabalho para deficientes

- ALWABP - problema de balanceamento e designação de trabalhadores (do inglês assembly line worker assignment and balancing problem)

- ALBP - problema de balanceamento de linhas de produção (do inglês assembly line balancing problem)

- SALBP - problema simples de balanceamento de linhas de produção (do inglês simples assembly line balancing problem)

- GALBP - problema geral de balanceamento de linhas de produção (do inglês general assembly line balancing problem)

- MALBP - problema de balanceamento de linhas de produção multi-modelo (do inglês mixed-model assembly line balancing problem) 


\section{Introdução}

A Organização Mundial de Saúde estima que 650 milhões de pessoas no mundo possuem algum tipo de deficiência. Segundo o Censo Demográfico 2000, no Brasil este número chega a 24,5 milhões de pessoas, o que corresponde a cerca de 14,5\% da população brasileira. Destes, apenas 537 mil estão no mercado formal de trabalho, representando 2,05\% do total de empregados ${ }^{[1]}$.

Simonelli et al. ${ }^{[2]}$ e Simonelli ${ }^{[3]}$ analisam as políticas e práticas de inclusão de pessoas portadoras de deficiência no mercado de trabalho brasileiro. Uma das constatações interessantes destes estudos foi o fato da grande maioria de vagas existentes para trabalhadores portadores de deficiências se encontrarem em contextos produtivos. Esta conclusão é condizente com a iniciativa de diversos países com altos índices de desenvolvimento humano tais como Espanha, Inglaterra e Japão, que promovem a manutenção de Centros de Trabalho para Deficientes (CTD's) com linhas produtivas.

CTD's são organizações que oferecem emprego para trabalhadores deficientes, muitas vezes em linhas de montagem terceirizadas de grandes empresas. Assim como qualquer outra empresa, os CTD's precisam competir com o mercado, com a diferença de que são organizações sem fins lucrativos. Desta forma, potenciais lucros que poderiam ser obtidos podem ser convertidos em mais empregos.

Miralles et al. ${ }^{[4]}$ identificaram as seguintes características em CTD's:

- Os tempos de execução de cada tarefa costumam ser bastante diferentes entre os trabalhadores.

- Em muitos casos, alguns trabalhadores não conseguem executar certas tarefas.

- Por motivos terapêuticos, algumas designações de tarefas para determinados trabalhadores devem ser consideradas a priori.

- Não é possível dividir os trabalhadores em lentos e rápidos. Um trabalhador pode 
ser muito lento em certas tarefas, ou mesmo incapaz de executá-las, mas muito eficiente em outras.

- Algumas deficiências requerem a designação destes trabalhadores a determinadas posições (estágios) da linha. Por exemplo, trabalhadores com deficiência auditiva trabalham melhor na primeira ou última estação, uma vez que as estações intermediárias requerem um nível maior de coordenação e comunicação.

- O objetivo principal dos CTD's é incentivar o desenvolvimento das capacidades dos trabalhadores deficientes, buscando integrá-los, assim que possível, ao mercado de trabalho. Logo, é comum que vários trabalhadores deixem o CTD ao alcançar níveis satisfatórios de produtividade e passem a trabalhar em empresas convencionais.

- Trabalhadores deficientes costumam ter mais problemas de saúde e, portanto, costumam faltar com mais frequência ao trabalho.

- Além disso, acompanhamento psicológico é essencial em um CTD.

Estes três últimos ítens fazem com que a linha de montagem tenha que ser constantemente replanejada, pois resultam em constantes ausências ou mudanças de trabalhadores

Neste trabalho propomos dois modelos matemáticos para o problema de balanceamento e designação de trabalhadores em linhas de produção (ALWABP, do inglês Assembly Line Worker Assignment and Balancing Problem), estendendo o modelo introduzido por Miralles et al. ${ }^{[4]}$. O primeiro modelo permite o projeto de linhas com estações de trabalho em paralelo, indicando que trabalhadores diferentes executam o mesmo conjunto de tarefas em produtos diferentes. O segundo modela a situação em que dois trabalhadores podem atuar colaborativamente no mesmo produto.

As duas extensões propostas proporcionam uma maior flexibilidade para o problema. Com isto, podemos encontrar soluções mais eficientes (em termos de produtividade) do que aquelas que conseguimos com o modelo serial. Além disso, o ALWABP com estações em paralelo tem a vantagem adicional de permitir tarefas cujo tempo de execução seja maior que o tempo de ciclo. O uso de paralelismo permite também um maior aproveitamento de cada estágio, que pode executar mais tarefas sem prejudicar o desempenho da linha de produção. Já o ALWABP colaborativo possui a vantagem de não exigir que um trabalhador execute todas as tarefas alocadas a um estágio. Isto permite que os trabalhadores executem combinações de tarefas que eles não seriam capazes de executar no ALWABP serial ou com estações em paralelo. 
Este trabalho está organizado da seguinte forma: no Capítulo 2 são descritos o problema simples de balanceamento de linhas de produção (SALBP, do inglês Simple Assembly Line Balancing Problem), bem como as modificações necessárias em ambos os problemas para a utilização das duas extensões propostas. No Capítulo 3 apresentamos uma revisão bibliográfica para o problema. No Capítulo 4, são apresentadas uma formulação para o ALWABP, uma formulação para o problema de balanceamento de linhas de produção (ALBP, do inglês, Assembly Line Balancing Problem) que utiliza estações paralelas e as duas formulações desenvolvidas - para o ALWABP com estações paralelas e para o ALWABP colaborativo. No Capítulo 5 descrevemos duas heurísticas construtivas, adaptadas daquela descrita por Moreira et al. ${ }^{[5]}$, para os dois problemas tratados nesse trabalho. No Capítulo 6 apresentamos os resultados obtidos com testes realizados. Por fim, o capítulo 7 apresenta algumas conclusões, bem como propostas de trabalhos futuros. 


\section{Descrição dos problemas}

Uma linha de montagem é constituída de um conjunto finito e conhecido de tarefas e um conjunto de estações de trabalho nas quais estas tarefas devem ser executadas. Cada tarefa possui um tempo de processamento e um conjunto de relações de precedência. As relações de precedência entre as tarefas podem ser representadas por um grafo de precedência. Os nós do grafo representam as tarefas e os arcos representam as relações de precedência. Um arco partindo de um nó 1 para um nó 2 indica que a tarefa 2 só pode ser executada depois que a tarefa 2 for concluída. A Figura 1 mostra um exemplo de grafo de precedência.

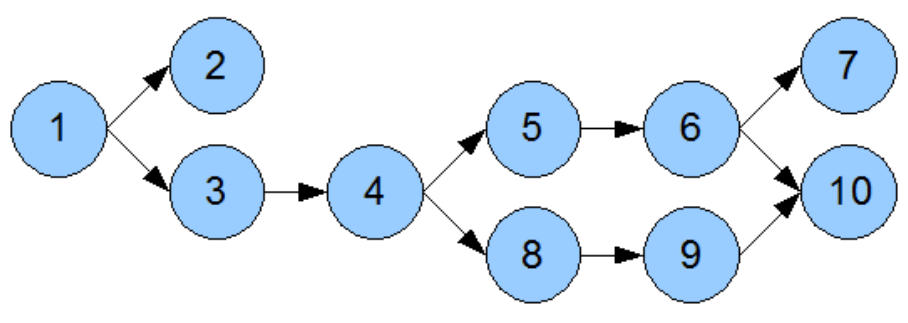

Figura 1: Exemplo de Grafo de Precedência

Para que um produto seja completado todas as tarefas referentes à montagem daquele produto devem ser realizadas. Assim, em uma linha de montagem, o processo de fabricação do produto é dividido em diversos estágios. Em cada estágio um subconjunto das tarefas necessárias para a fabricação deste produto é realizado. Em linhas seriais, cada estágio corresponde a uma estação de trabalho. A velocidade da linha é limitada pela velocidade do estágio mais lento. Logo, definimos o tempo de ciclo da linha de montagem como o tempo de execução do estágio mais carregado. O tempo de execução de uma estação corresponde à soma dos tempos de execução das tarefas alocadas a esta estação. Desta forma, o tempo de ciclo é uma medida da velocidade de produção da linha.

O problema de balanceamento de linhas de produção (ALBP, do inglês assembly line balancing problem) consiste em alocar a estações de trabalho de modo a otimizar certa característica do problema. Caso desejemos minimizar o número de estações dado um 
determinado tempo de ciclo, temos o ALBP-1. Caso o número de estações seja fixo e desejemos minimizar o tempo de ciclo, temos o ALBP-2. Se desejamos minimizar o produto entre o número de estações e o tempo de ciclo, temos o ALBP-E. Por fim, se tanto o tempo de ciclo quanto o número de estações são fixos e desejamos saber se existe uma solução viável para o problema, temos o ALBP-F.

Nesta seção, apresentamos dois problemas de balanceamento de linhas de produção: o clássico SALBP e o recente ALWABP, nosso problema em estudo. Também analisamos como a introdução de layouts com máquinas paralelas pode afetar ambos os problemas. Além disso analisamos também uma nova variante do ALWABP, denominada ALWABP colaborativo.

\section{$2.1 \quad \mathrm{SALBP}$}

O SALBP corresponde à versão mais simplificada do ALBP. No SALBP os tempos de execução das tarefas são fixos, conhecidos e independentes da estação de trabalho escolhida. Cada tarefa deve ser alocada a exatamente um estágio e cada estágio pode ter uma ou mais tarefas. Cada estágio contém uma estação de trabalho, na qual são executadas as tarefas a ele atribuídas. Além disso, supomos que a linha de produção é ritmada, isto é, o produto fica disponível durante a mesma quantidade de tempo em cada estágio da linha.

A Figura 2 mostra uma possível solução para o SALBP, utilizando o grafo de precedência da Figura 1 e os tempos de execução da tabela 1. $T_{1}, T_{2}, T_{3}$ e $T_{4}$ representam quatro estágios da linha de montagem, nesta ordem.

Tabela 1: Tempos de execução das tarefas para o SALBP

\begin{tabular}{|c|c|c|c|c|c|c|c|c|c|c|}
\hline Tarefas & 1 & 2 & 3 & 4 & 5 & 6 & 7 & 8 & 9 & 10 \\
\hline Tempos(s) & 4 & 3 & 9 & 5 & 9 & 4 & 8 & 7 & 5 & 1 \\
\hline
\end{tabular}

Nesta solução, temos 4 estações, cada uma com um trabalhador. Os tempos de execução obtidos em cada estação foram, respectivamente, 16s, 14s, 12s e 13s. O tempo de ciclo desta configuração é de 16s, ou seja, o tempo do estágio mais lento. Assim, a cada $16 \mathrm{~s}$, temos uma unidade completa produzida.

À medida em que modificamos as especificações do SALBP obtemos novos problemas, capazes de se adequar melhor a diferentes casos práticos. Becker e Scholl ${ }^{[6]}$ destacam as seguintes variações para o problema: 


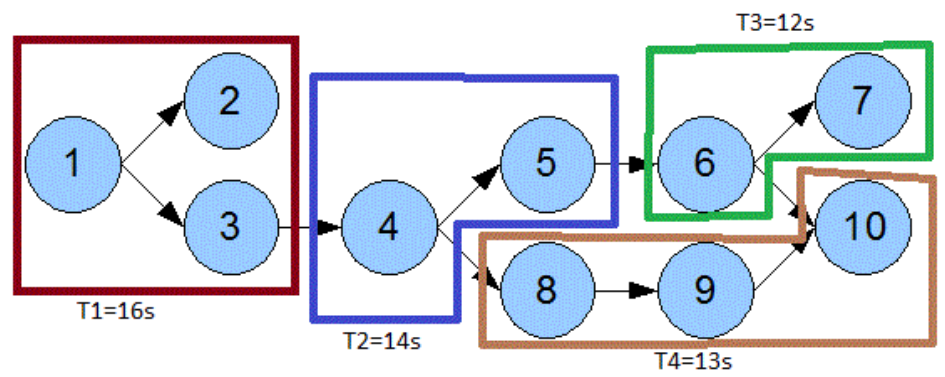

Figura 2: Exemplo de Solução para o SALBP

- Quanto ao número de modelos produzidos: modelo único, multi-modelos

- Quanto à forma de controle da linha: ritmada, arritmada síncrona e arritmada assíncrona

- Quanto ao nível de automação: linhas manuais e linhas automatizadas

- Quanto à frequência: instalação e reconfiguração

- Quanto ao formato da linha: serial, em U, múltiplos Us (n-U)

- Quanto ao uso de paralelismo: sem paralelismo, paralelismo de linhas, estações, tarefas e áreas de trabalho

- Quanto aos tempos das tarefas: fixos, estocásticos e dependentes da estação

- Outras configurações adicionais: uso de buffers, feeders, mudanças no posicionamento de equipamento, posicionamento e dimensionamento de material, entre outros

Neste projeto nos interessamos pela variação do SALBP em que os tempos das tarefas dependem do trabalhador ao qual elas são alocadas. Este problema, conhecido na literatura como ALWABP, é descrito na seção seguinte.

\subsection{ALWABP}

Em CTD's o tempo de execução de cada tarefa, apesar de ser conhecido, pode ser diferente dependendo do trabalhador escolhido. Não é possível, entretanto, categorizar os trabalhadores em lentos e rápidos. Um trabalhador pode ser muito lento em uma tarefa, mas ser muito eficiente em outra. Além disso, dependendo das deficiências que o trabalhador possui, podem existir tarefas que o mesmo não é capaz de executar. 
O SALBP não modela adequadamente esta situação. Em vista disto, Miralles et al. ${ }^{[4]}$ propuseram o ALWABP, uma extensão do SALBP capaz de lidar com diferentes tempos de execução para uma mesma tarefa, de acordo com o trabalhador escolhido. Desta forma, além de determinar quais tarefas devem ser executadas em cada estágio, devemos também determinar qual trabalhador deverá executar estas tarefas.

Da mesma forma que o ALBP, o ALWABP pode ser categorizado em ALWABP-1, ALWABP-2, ALWABP-E, de acordo com a função objetivo a otimizar, ou ALWABP-F, se o problema consiste em verificar a existência de uma solução viável dados um tempo de ciclo e um número de estações. Em CTD's, desejamos maximizar a eficiência da linha de produção empregando todos os trabalhadores disponíveis. Portanto, este trabalho se interessa, em particular, pelo ALWABP-2.

A figura 3 mostra uma possível solução para o ALWABP, utilizando o grafo de precedência da figura 1 e os tempos de execução da tabela 2 , em que $W_{1}, W_{2}, W_{3}$ e $W_{4}$ representam quatro trabalhadores.

Tabela 2: Tempos de execução das tarefas para o ALWABP

\begin{tabular}{|c|c|c|c|c|c|c|c|c|c|c|c|}
\hline \multicolumn{2}{|c|}{ Tarefas } & 1 & 2 & 3 & 4 & 5 & 6 & 7 & 8 & 9 & 10 \\
\hline Tempos(s) & $W_{1}$ & 4 & 3 & 9 & 5 & 9 & 4 & 8 & 7 & 5 & 1 \\
& $W_{2}$ & - & 1 & 2 & 3 & 4 & 4 & - & 4 & 2 & 1 \\
& $W_{3}$ & 4 & 3 & 9 & 5 & 2 & 2 & 5 & 3 & 2 & 2 \\
& $W_{4}$ & 4 & 1 & 5 & 1 & 2 & 3 & 4 & 2 & - & 1 \\
\hline
\end{tabular}

Neste exemplo, ao contrário do anterior, os tempos das tarefas podem variar de acordo com o trabalhador que a executa. A tarefa 3, por exemplo, é executada em 9s pelos trabalhadores $W_{1}$ e $W_{3}$, 2s pelo trabalhador $W_{2}$ e em 5 s pelo trabalhador $W_{4}$. Além disto, o trabalhador $W_{2}$ não pode executar as tarefas 1 e 7 , enquanto que o trabalhador $W_{4}$ não pode executar a tarefa 9 .

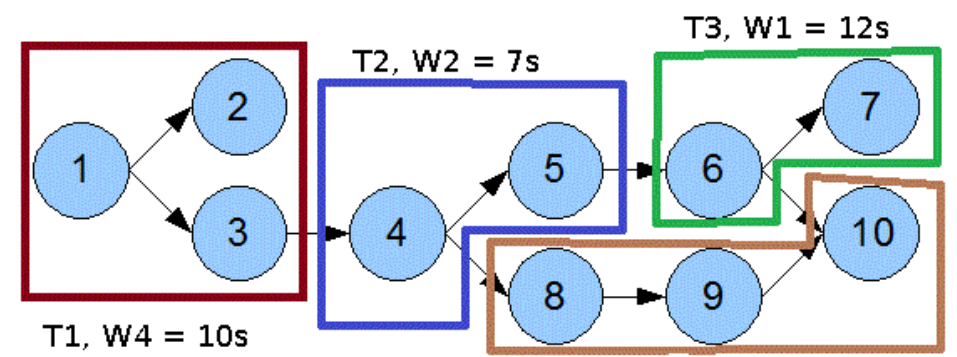

$\mathrm{T} 4, \mathrm{~W} 3=7 \mathrm{~s}$

Figura 3: Exemplo de Solução para o ALWABP

Nesta figura temos uma configuração com quatro estágios, em que a cada estágio está 
alocado um trabalhador. No primeiro estágio está alocado o trabalhador $W_{4}$, cuja carga alocada é de 10s. No segundo, o trabalhador $W_{2}$, que executa as tarefas 4 e 5 em $7 \mathrm{~s}$. O trabalhador $W_{1}$ está alocado no terceiro estágio, com tempo de execução de $12 \mathrm{~s}$. No último estágio temos o trabalhador $W_{3}$, com tempo de execução de $7 \mathrm{~s}$. O tempo de ciclo da linha é, portanto, de 12s.

Diferente do caso anterior, trocar dois trabalhadores de lugar pode alterar totalmente a solução. Por exemplo, se fizermos o trabalhador $W_{2}$ ir para o primeiro estágio e o trabalhador $W_{4}$ para o segundo, esta solução se torna inviável, pois o trabalhador $W_{2}$ não pode executar a tarefa 1 .

\subsection{ALWABP com estações em paralelo}

Nos casos anteriores, cada estágio possui apenas uma estação de trabalho. O uso de estações paralelas permite que o conjunto de tarefas alocado a um estágio seja executado em duas ou mais estações de trabalho. Isto resulta em uma maior flexibilidade da linha de produção, o que pode melhorar consideravelmente sua eficiência.

Uma das vantagens de se utilizar paralelismo é que ele permite tarefas com tempo de execução maiores que o tempo de ciclo. No modelo serial, se uma tarefa tem tempo de execução muito grande, o estágio à qual esta for alocado pode ter um tempo de execução muito maior que os demais. No modelo paralelo, isto pode ser evitado, bastando adicionar mais estações àquele estágio. Isto é especialmente interessante no caso do ALWABP, uma vez que permite que trabalhadores executem tarefas para os quais não são muito eficientes, possibilitando uma maior variedade de configurações da linha de montagem.

O uso de paralelismo permite também um maior aproveitamento de cada estágio. No modelo serial, a adição de muitas tarefas a um mesmo estágio pode prejudicar o tempo de ciclo. No modelo paralelo, no entanto, a adição de mais estações de trabalho a este estágio reduz o tempo total de execução. Assim, temos um maior número de tarefas executando em um estágio sem redução da taxa de produção.

Em contrapartida, a execução das mesmas tarefas em várias estações aumenta o custo total dos equipamentos a serem adquiridos, uma vez que o equipamento necessário para a execução de uma dada tarefa deverá ser replicado em cada estação de trabalho pertencente ao estágio onde a tarefa se encontra alocada. Além disso, o espaço disponível no local de trabalho pode restringir o número máximo de estações em paralelo. 
A taxa de execução de um estágio é dada pela soma das taxas de execução das estações que o compõem. Logo, o tempo de ciclo de um estágio corresponde ao inverso da soma dos inversos dos tempos de execução de cada estação. Para o ALBP, uma vez que as estações são idênticas, este cálculo pode ser efetuado de uma maneira mais simples, bastando dividir o tempo total das tarefas pelo número de estações neste estágio. Por exemplo, se uma máquina executa um conjunto de tarefas em 60 segundos, ou seja, o conjunto de tarefas é completado uma vez a cada minuto, três máquinas similares executarão o mesmo conjunto de tarefas, em média, três vezes por minuto, o que equivale a um tempo de ciclo de 20 segundos.

A figura 4 mostra uma solução para o ALBP com estações paralelas, utilizando o grafo de precedência da figura 1 os tempos de execução da tabela 1.

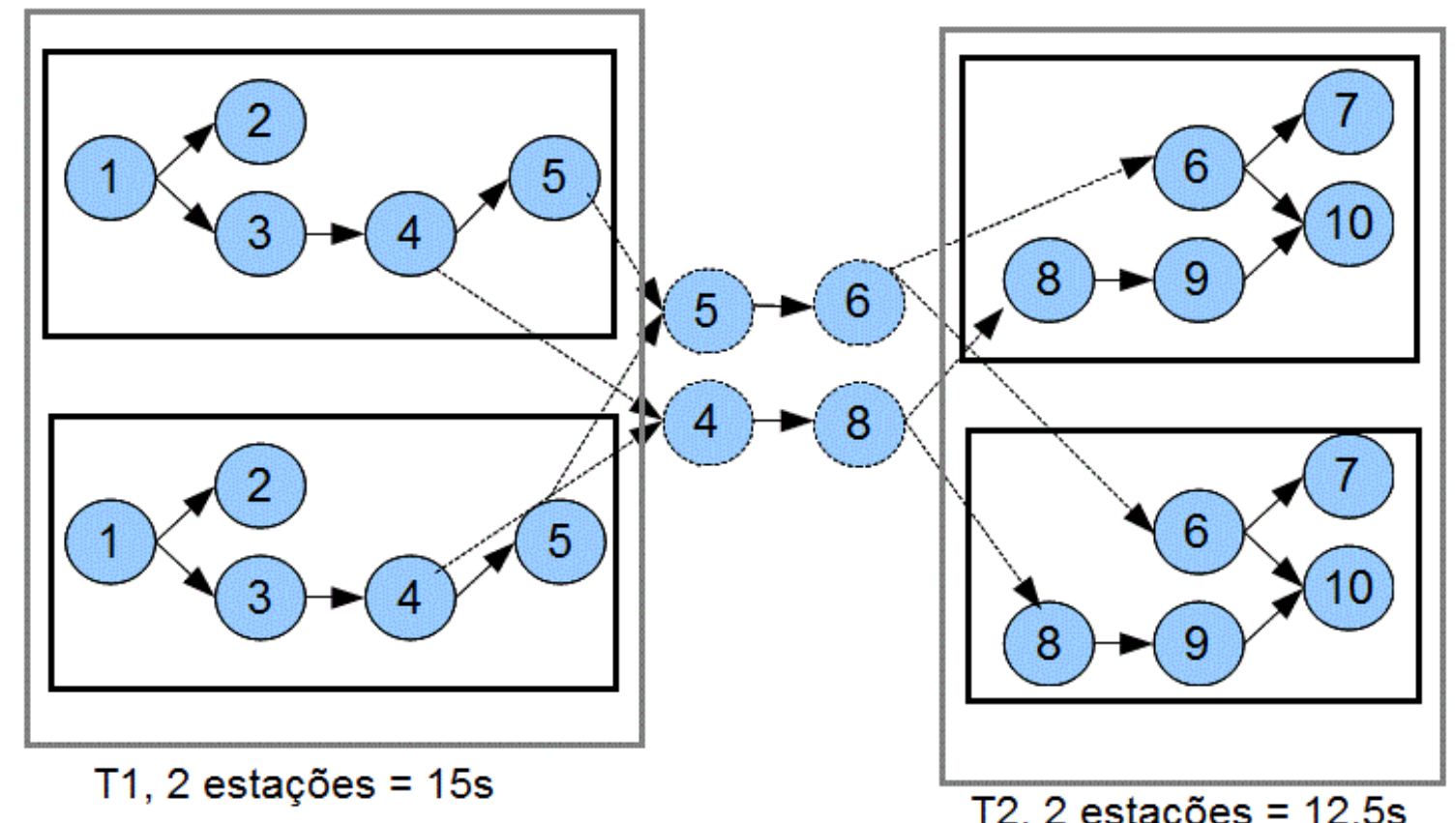

Figura 4: Exemplo de Solução para o ALBP utilizando estações paralelas

Nesta solução, temos dois estágios, cada um com dois trabalhadores. Para facilitar a visualização, as relações de precedência entre os estágios foi representada por cópias das tarefas 4, 5, 6 e 8. Cada um dos dois trabalhadores do primeiro estágio executa as tarefas em 30s. Desta forma, trabalhando juntos, eles executam estas mesmas tarefas, em média, a cada 15s. Da mesma forma, os dois trabalhadores do segundo estágio executariam suas tarefas em $25 \mathrm{~s}$, mas trabalhando juntos equivalem a um único trabalhador executando estas tarefas em $12,5 \mathrm{~s}$.

Observe que podemos efetivamente produzir um produto a cada 15 segundos se in- 
troduzirmos um atraso em um dos trabalhadores do primeiro estágio. Se o primeiro trabalhador iniciar sua produção no tempo 0 e o segundo trabalhador esperar 15 segundos para iniciar a sua produção, teremos um produto finalizado a cada 15 segundos. De fato, isto pode ser extendido para qualquer estágio em que o tempo total das tarefas é $T$ e que possui $n$ trabalhadores. Se fizermos o primeiro trabalhador iniciar sua produção normalmente e, para cada trabalhador subsequente, esperarmos $\frac{T}{n}$ para iniciarmos a produção, conseguiremos organizar o estágio de tal forma que não seja necessário o uso de buffers.

No ALWABP, uma vez que os tempos das tarefas podem variar dependendo do trabalhador que as executa, o cálculo do tempo de ciclo torna-se mais complexo. Se um trabalhador executa um conjunto de tarefas em 40 segundos (1,5 vezes por minuto) e outro executa as mesmas tarefas em 60 segundos ( 1 vez por minuto), trabalhando em paralelo estes dois trabalhadores executariam estas tarefas, em média, 2,5 vezes por minuto, o que corresponde a um tempo de ciclo de 24 segundos.

A figura 5 mostra uma solução para o ALWABP com estações paralelas, utilizando o grafo de precedência da figura 1 os tempos de execução da tabela 2.

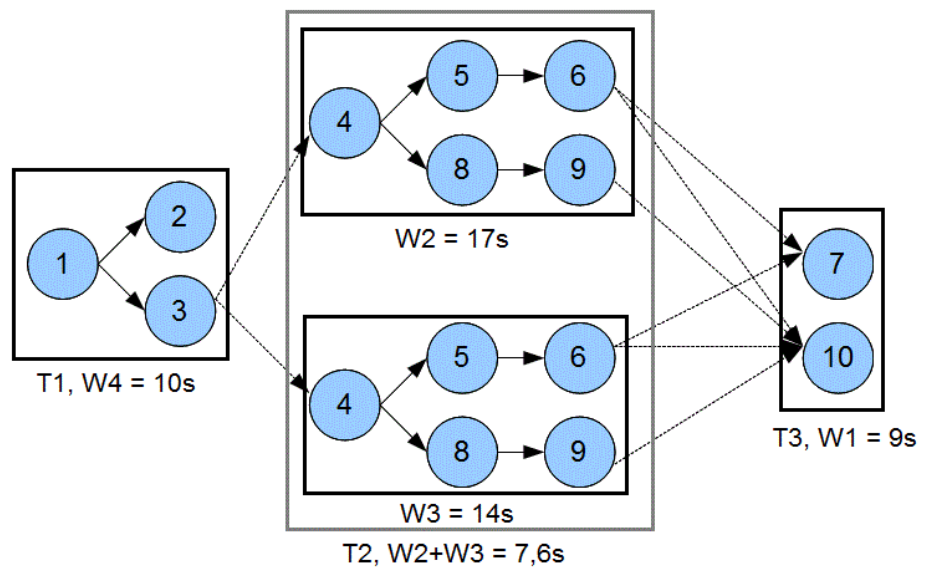

Figura 5: Exemplo de Solução para o ALWABP utilizando estações paralelas

Nesta solução, o trabalhador $W_{4}$ está no primeiro estágio, os trabalhadores $W_{2}$ e $W_{3}$ estão juntos no segundo estágio e o trabalhador $W_{1}$ está no último estágio. O trabalhador $W_{2}$ executa as tarefas 4, 5, 6, 8 e $9 \mathrm{em} 17 \mathrm{~s}$, enquanto que o trabalhador $W_{3}$ executa estas mesmas tarefas em 14s. Trabalhando em paralelo, o tempo de execução destes dois trabalhadores é de $\frac{1}{\frac{1}{17}+\frac{1}{14}}=7,6 s$. Com isto, conseguimos um tempo de ciclo de 10 s para esta configuração da linha de produção.

Sejam $t_{1}, t_{2}, \ldots, t_{i}, \ldots, t_{n}$ os tempos de execução de $n$ trabalhadores para um mesmo 
conjunto de tarefas, o tempo de execução $T$ destes trabalhadores em paralelo é dado por

$$
\begin{aligned}
& \frac{1}{T}=\frac{1}{t_{1}}+\frac{1}{t_{2}}+\ldots+\frac{1}{t_{i}}+\ldots+\frac{1}{t_{n}}>\frac{1}{t_{i}} . \text { Logo, } \\
& \frac{1}{T}>\frac{1}{t_{i}} \rightarrow T<t_{i} .
\end{aligned}
$$

Ou seja, o tempo de execução de dois ou mais trabalhadores em paralelo é sempre menor que o tempo de execução de cada um destes trabalhadores, executando as mesmas tarefas. Analogamente, podemos mostrar que a adição de um trabalhador a um estágio sempre melhora o tempo de execução deste estágio. Esta característica proporciona uma grande vantagem ao uso de estações paralelas para o ALWABP caso desejemos adicionar um novo trabalhador à linha de produção que seja pouco eficiente em relação aos demais.

Diferentemente do ALBP com estações em paralelo, caso os tempos dos trabalhadores sejam diferentes, não é possível produzir os itens a uma taxa constante usando paralelismo. Em vista disso, para linhas ritmadas, esta adaptação exige o uso de buffers nos estágios que usam paralelismo. Cada item cujo processamento seja concluído nesses estágios será colocado em um buffer. Quando um item for solicitado no estágio seguinte este item deverá ser retirado do buffer.

É possível iniciar a produção com um número suficiente de itens no buffer de tal forma que a produção nunca seja interrompida pela falta de itens a serem processados. Sejam dois trabalhadores $A$ e $B$, cujos tempos de execução para um certo conjunto de tarefas são $T_{A}$ e $T_{B}$, respectivamente. O tempo de execução $T$ de um estágio com estes dois trabalhadores em paralelo é dado por

$$
\frac{1}{T}=\frac{1}{T_{A}}+\frac{1}{T_{B}}=\frac{T_{A}+T_{B}}{T_{A} T_{B}} \rightarrow T=\frac{T_{A} T_{B}}{T_{A}+T_{B}}
$$

A expressão acima indica que, em $T_{A} T_{B}$ segundos são produzidos $T_{A}+T_{B}$ itens neste estágio. Observe que, após $T_{A} T_{B}$ segundos, ambos os trabalhadores terão concluído o processamento de um item e estarão prontos para começar a processar um novo item. Desta forma, supondo que este estágio corresponde ao gargalo da linha de produção, se iniciarmos o buffer com $T_{A}+T_{B}$ itens, temos a garantia de que sempre haverá itens no buffer para os estágios seguintes. Este cálculo pode ser estendido para qualquer número de trabalhadores.

O cálculo acima estabelece um limite superior para o número de itens necessários no buffer. No entanto, este número tende a ser menor. Por exemplo, sejam $A$ e $B$ dois trabalhadores, cujos tempos de execução para um certo conjunto de tarefas são respectivamente 10 s e 20 s. O tempo de execução $T$ de um estágio com esses trabalhadores em paralelo corresponde a 6,7s. Assuma que este é o tempo de ciclo da linha. A Figura 
6 ilustra o funcionamento deste estágio.

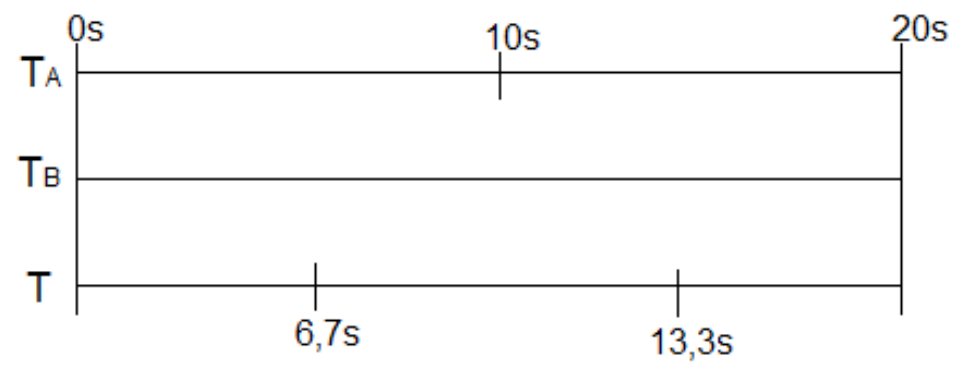

Figura 6: Exemplo de execução para o ALWABP com estações em paralelo

Em $t=6,7 \mathrm{~s}$, o primeiro item é solicitado pelo estágio seguinte. Porém, os trabalhadores $A$ e $B$ ainda não terminaram de processar nenhum item. Em $t=10 \mathrm{~s}$ o trabalhador $A$ termina de processar seu primeiro item e o coloca no buffer. Em $t=13,3 s$ o item que está no buffer é solicitado pelo estágio seguinte. Por fim, em $t=20 \mathrm{~s}$ ambos os trabalhadores terminam um item cada. Um destes itens é recolhido para o estágio seguinte. Como podemos ver, apenas no tempo $t=6,7 \mathrm{~s}$ uma demanda não foi atendida. Desta forma, se iniciarmos esta linha de produção com um item no buffer temos a garantia de que a demanda dos estágios sempre será atendida.

No problema encontrado em CTD's, geralmente se deseja incluir no processo produtivo todos os trabalhadores disponíveis. A configuração serial apresenta uma grande dificuldade, pois a presença de um trabalhador lento em todas ou quase todas as tarefas pode resultar em uma solução ótima pior que a solução sem este trabalhador. Já no caso com estações em paralelo, podemos fazer com que o novo trabalhador execute tarefas juntamente com outro já existente. Conforme demonstrado, o tempo de execução deste estágio será melhor que o tempo de execução do trabalhador que já estava atuando na linha de produção. Portanto, a nova configuração da linha de produção será pelo menos tão produtiva quanto a configuração original.

\subsection{ALWABP colaborativo}

Além do ALWABP com estações paralelas, outra variação estudada neste projeto é o ALWABP colaborativo. Neste problema, assim como no ALWABP com estações paralelas, cada estágio pode ter um ou mais trabalhadores. No entanto, no ALWABP colaborativo os trabalhadores alocados a um estágio executarão tarefas sobre o mesmo produto. Cada tarefa alocada em um estágio será executada pelo trabalhador alocado àquele estágio que 
for mais rápido na execução desta tarefa.

Em relação ao tempo de execução, esta abordagem só é vantajosa caso os tempos de execução dos trabalhadores sejam diferentes. Além disso, uma vez que um trabalhador não precisa executar todas as tarefas alocadas a um estágio, O ALWABP colaborativo pode ajudar a contornar alguns problemas, como tarefas que um dos trabalhadores não pode executar ou para as quais ele é pouco eficiente.

A figura 7 representa uma solução para o ALWABP colaborativo, utilizando o grafo de precedência da figura 1 os tempos de execução da tabela 2.

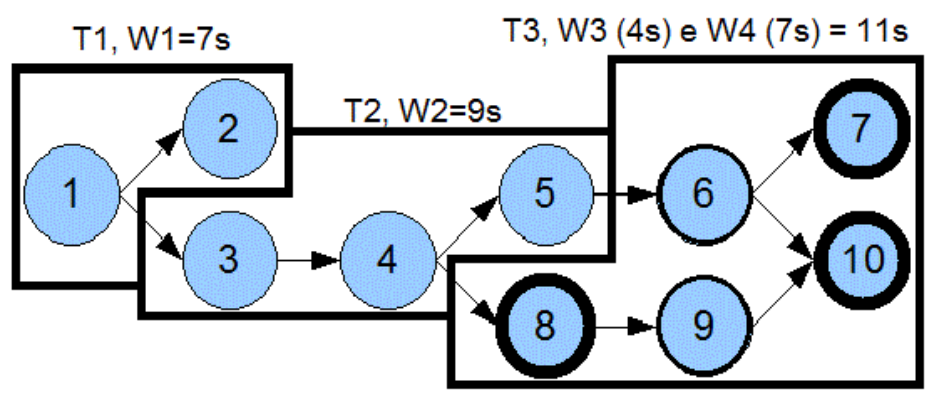

Figura 7: Exemplo de Solução para o ALWABP colaborativo

Neste exemplo, o trabalhador W4 é o mais eficiente na execução da tarefa 8 e também é bastante eficiente na execução da tarefa 10. No entanto, uma vez que este trabalhador não consegue executar a tarefa 9, para o ALWABP serial e com estações paralelas este trabalhador não pode executar as tarefas 8 e 10 em um mesmo estágio. No entanto, usando o ALWABP colaborativo, fazemos com que o trabalhador W3 execute a tarefas 9, o que permite que o trabalhador W4 execute a tarefa 10. Dessa forma, nesta configuração da linha de produção, o trabalhador W1 está alocado no estágio T1, enquanto que o trabalhador W2 está alocado ao estágio T2 e os trabalhadores W3 e W4 estão alocados ao estágio T3. O trabalhador W3 executa as tarefas 6 e $9 \mathrm{em} 4 \mathrm{~s}$ enquanto que o trabalhador W4 executa as tarefas 7, 8 e $10 \mathrm{em} \mathrm{7s.} \mathrm{Assim,} \mathrm{o} \mathrm{tempo} \mathrm{de} \mathrm{execução} \mathrm{do} \mathrm{estágio} \mathrm{T3,} \mathrm{bem}$ como o tempo de ciclo dessa configuração da linha de produção, corresponde à soma dos tempos de execução dos trabalhadores W3 e W4, isto é, 11s. 


\section{Revisão Bibliográfica}

O SALBP é um problema clássico da área de pesquisa operacional, tendo sido arduamente estudado por várias décadas. Diversas extensões para o problema foram propostas, tentando se adequar aos mais diferentes casos possíveis e proporcionar maior flexibilidade ao problema.

Baybars ${ }^{[7]}$ apresenta a primeira revisão bibliográfica para o SALBP. A revisão discute diversos métodos exatos e problemas relacionados ao SALBP. São excluídos, no entanto, métodos aproximados e algoritmos para o GALBP (general assembly line balancing problem).

Becker e Scholl ${ }^{[6]}$ apresentam uma revisão mais recente para o GALBP. Este trabalho identifica diversas extensões para o problema, como modelos orientados a custo e lucro, seleção de equipamentos, alternativas de processamento, uso de estações e tarefas em paralelo, linhas de produção em U, restrições relacionadas ao posicionamento dos equipamentos, às estações, tarefas e trabalhadores, tempos estocásticos e produção de diversos tipos de produtos diferentes.

Boysen et al. ${ }^{[8]}$ apresentam uma classificação para problemas de balanceamento de linhas de produção. A classificação utiliza como base características do grafo de precedência, características das estações e da linha de produção, e o objetivo do modelo.

Boysen et al. ${ }^{[9]}$ apresentam uma classificação para diversos artigos relacionados ao ALBP. A classificação apresentada leva em consideração o número de modelos a serem produzidos e a forma como esta produção é feita, o tipo de controle da linha (ritmada, arritmada síncrona e arritmada assíncrona), frequência de utilização (instalação e reconfiguração), nível de automação e aplicações específicas.

Para o caso onde se deseja minimizar os custos associados à linha de produção, podemos citar os trabalhos de Amen ${ }^{[10-12]}$, em que se consideram, por exemplo, os custos de maquinário, mão-de-obra, etc. 
Para o ALWABP, a literatura é mais escassa. Miralles et al. ${ }^{[4]}$ realizaram o primeiro estudo sobre o ALWABP. Os autores mostram que a divisão do trabalho a ser realizado em tarefas menores é capaz de tornar certas deficiências dos trabalhadores transparentes. É apresentado um modelo para o ALWABP-2, cuja função objetivo minimiza o tempo de ciclo. Os autores apresentam também um estudo de caso em um CTD na Espanha, que obteve bons resultados.

Chaves ${ }^{[13]}$ apresenta uma meta-heurística híbrida denominada busca por agrupamentos (CS, do inglês clustering search). O autor também propõe o uso de CS para diversos problemas, entre eles o ALWABP.

Chaves et al. ${ }^{[14]}$ apresentam uma heurística Clustering Search para resolver o ALWABP. O método é capaz de encontrar uma boa solução em um tempo computacional relativamente baixo. Foi também gerado um conjunto de instâncias para o problema, divididas em 4 famílias de acordo com o número de tarefas, a densidade do grafo de precedências e a variabilidade os tempos de execução do problema.

Os mesmos autores apresentaram uma melhoria do método ${ }^{[15]}$. Neste trabalho a meta-heurística simulated annealing utilizada no trabalho anterior foi substituída por uma busca local iterativa (ILS, do inglês Iterated Local Search) e foi adicionado um método de descida em vizinhança variável (VND, do inglês variable neighborhood descend).

Moreira e Costa ${ }^{[16]}$ apresentam um algoritmo Busca Tabu para resolução do ALWABP. O algoritmo foi desenvolvido de tal forma a ser simples, flexível, rápido e preciso, tornandoo de fácil entendimento e implementação. Os resultados obtidos foram comparados com aqueles obtidos por Chaves ${ }^{[13-15]}$, obtendo melhores resultados para instâncias maiores.

Os mesmos autores ${ }^{[5]}$ desenvolveram uma heurística construtiva para o ALWABP. Esta heurística é uma adaptação daquela desenvolvida por Scholl e Voß ${ }^{[17]}$ para o SALBP2. Detalhes destas heurísticas, bem como uma adaptação das mesmas para o ALWABP com estações em paralelo e para o ALWABP colaborativo, podem ser vistas no capítulo 5.

Costa e Miralles ${ }^{[18]}$ estudam como programar a rotação de tarefas no ALWABP. Foi desenvolvida uma métrica para este problema. É apresentada uma formulação linear inteira mista que se mostra difícil de ser resolvida de forma exata mesmo para poucos períodos. Os autores desenvolveram então um método heurístico de decomposição por períodos, que se mostrou capaz de encontrar boas soluções em um tempo computacional viável. 
Diversos trabalhos tratam do ALBP com máquinas paralelas, tanto de forma exata quanto utilizando heurísticas. Becker e Sholl ${ }^{[19]}$ apresentam um problema denominado problema de balanceamento de linhas de produção com áreas de trabalho variáveis (VWALBP, do inglês assembly line balancing problem with variable workplaces). O problema inclui restrições que fixam certas tarefas em um grupo específico de estações e permite definir incompatibilidades entre tarefas e estágios e entre tarefas e trabalhadores. Apesar das tarefas serem indivisíveis, tarefas muito grandes podem ser executadas em mais de uma estação na mesma área de trabalho. O problema incorpora também o uso de máquinas paralelas. Os autores desenvolveram um algoritmo branch and bound que pode ser utilizado tanto para resolver o problema de forma exata ou como uma heurística.

Boysen e Fliedner ${ }^{[20]}$ apresentam um algoritmo gráfico de duas fases. O algoritmo pode ser adaptado para trabalhar com linhas em U, estações e tarefas paralelas, sinergia de recursos e custos, alternativas de processamento, restrições de zonas e tempos estocásticos.

Bukchin e Rubinovitz ${ }^{[21]}$ apresentam duas formulações para o ALBP com estações paralelas e seleção de equipamentos. Uma das formulações minimiza o número de estações, enquanto que a outra minimiza custo total. Em ambos os modelos, o tempo de ciclo é fixo. Os autores adaptaram um algoritmo branch-and-bound, desenvolvido para o problema de seleção de equipamentos, para resolver o problema com estações paralelas.

Ege et al. ${ }^{[22]}$ estudam o ALBP com máquinas paralelas. O objetivo é encontrar uma configuração da linha de produção que minimize o custo de ativação das estações e dos equipamentos necessários. Os autores propõem dois métodos branch and bound, um exato e um heurístico. A heurística se mostrou capaz de encontrar soluções próximas da solução ótima, especialmente se o custo dos equipamentos são baixos.

Plebani e Chen ${ }^{[23]}$ apresentam um modelo para o ALBP em linhas em U com máquinas paralelas. Os autores utilizam um algoritmo branch and bound para a resolução do problema. Caso a solução ótima não tenha sido encontrada após um tempo definido pelo usuário, o método alterna para uma heurística, aplicada a nós selecionados da árvore do branch and bound.

Süer ${ }^{[24]}$ propõe um método de resolução em três fases. Na primeira fase são geradas configurações para vários números de estações. Na segunda fase, são alocados os trabalhadores disponíveis para cada configuração gerada. Por fim um modelo matemático determina a linha de montagem que minimiza o número de trabalhadores e que atende a demanda desejada. 
Tiacci e Saetta ${ }^{[25]}$ apresentam um simulador orientado a processo para resolução do ALBP capaz de tratar modelos mistos, tempos estocásticos, estações paralelas e diferentes sequências de agendamento (schedulling sequences).

McMullen e Frazier ${ }^{[26]}$ descrevem uma heurística para resolução do ALBP com linhas multi-modelos, tempos de tarefas estocásticos e estações paralelas. A heurística é uma modificação daquela proposta por Gaither ${ }^{[27]}$, com a adição dos tempos estocásticos. A heurística modificada utiliza sete regras alternativas para seleção de tarefas a serem designadas às estações e tempos de tarefas compostos para indicar a produção de modelos mistos.

Simaria e Vilarinho ${ }^{[28]}$ definem um modelo matemático e um Algoritmo Genético iterativo para o MALBP-II (mixed-model assembly line balancing problem). Objetiva maximizar a taxa de produção dado um número de trabalhadores. Define um tempo limite para a ativação da replicação de estações de trabalho.

Bukchin e Rubinovitz ${ }^{[21]}$ apresentam duas formulações para o ALBP com estações paralelas e seleção de equipamentos. Uma das formulações minimiza o número de estações, enquanto que a outra minimiza custo total. Em ambos os modelos, o tempo de ciclo é fixo. Os autores adaptaram um algoritmo branch-and-bound, desenvolvido para o problema de seleção de equipamentos, para resolver o problema com estações paralelas. Estas duas formulações foram de grande importância para este projeto, pois serviram de base para o desenvolvimento da formulação matemática para o ALWABP com estações em paralelo.

O uso de paralelismo para o ALWABP começou a ser estudado recentemente. Araújo et al. ${ }^{[29,30]}$ apresentaram um modelo linear para o ALWABP com estações paralelas. Os autores realizaram testes em instâncias disponíveis na literatura e em instâncias modificadas, geradas pelos próprios autores. Estas instâncias buscam simular situações em que alguns trabalhadores possuem deficiências semelhantes.

Araújo e Costa ${ }^{[31]}$ estenderam o trabalho anterior, gerando novas instâncias, que simulam a existência de um trabalhador que é muito lento em relação aos demais. 


\section{Formulações Matemáticas}

Neste capítulo apresentamos formulações lineares para o SALBP, ALWABP e ALBP com máquinas paralelas. Estas duas formulações são usadas como base para o desenvolvimento de uma formulação linear para o ALWABP com máquinas paralelas, que também é apresentada.

\subsection{Formulação para o SALBP}

A seguir apresentamos uma formulação para o SALBP-2.

Utilizando a notação:

$i, j$ Índices das tarefas

$s \quad$ Índices dos estágios

$N \quad$ Conjunto de tarefas

$S \quad$ Conjunto de estágios

$p_{i} \quad$ Tempo de execução da tarefa $i$

$D_{j}$ Conjunto de tarefas imediatamente predecessoras à tarefa $j$ no grafo de precedência

E as variáveis:

C Tempo de ciclo

$x_{s i} \quad$ Variável binária. Igual a 1 se a tarefa $i$ é executada pelo trabalhador $w$ no estágio $s$, igual a 0 caso contrário

$\operatorname{Min} C$

s.a. 


$$
\sum_{s \in S} s x_{s i} \leq \sum_{s \in S} s x_{s j} \quad \forall j \in N, \forall i \in D_{j}
$$

$$
\sum_{s \in S} x_{s i}=1 \quad \forall i \in N
$$

$$
\sum_{i \in N} p_{i} x_{s i} \leq C \quad \forall s \in S
$$

A função objetivo (4.1) minimiza o tempo de ciclo. As restrições (4.2) estabelecem as relações de precedência entre as tarefas. As restrições (4.3) garantem que todas as tarefas serão executadas. Por fim, as restrições (4.4) determinam que o tempo de ciclo da linha de montagem corresponde ao tempo de execução da estação mais carregada.

\subsection{Formulação para o ALWABP}

A seguir é apresentada a formulação para o ALWABP-2, proposta por Miralles et al.

[4]. A versão apresentada contém pequenas melhorias introduzidas por Moreira e Costa [16].

Utilizando a notação:

$i, j \quad$ Índices das tarefas

$w \quad$ Índices dos trabalhadores

$s \quad$ Índices dos estágios

$N \quad$ Conjunto de tarefas

$W \quad$ Conjunto de trabalhadores

$S \quad$ Conjunto de estágios

$p_{w i} \quad$ Tempo de execução da tarefa $i$ pelo trabalhador $w$

$D_{j} \quad$ Conjunto de tarefas imediatamente predecessoras à tarefa $j$ no grafo de precedência

$I_{w} \quad$ Conjunto de tarefas que o trabalhador $w$ não é capaz de executar

E as variáveis: 
C Tempo de ciclo

$x_{s w i}$ Variável binária. Igual a 1 se a tarefa $i$ é executada pelo trabalhador $w$ no estágio $s$, igual a 0 caso contrário

$y_{s w} \quad$ Variável binária. Igual a 1 se o trabalhador $w$ está no estágio $s$, igual a 0 caso contrário

$$
\text { Min } C
$$

s.a.

$$
\begin{gathered}
\sum_{w \in W} \sum_{s \in S} x_{s w i}=1 \quad \forall i \in N \\
\sum_{s \in S} y_{s w}=1 \quad \forall w \in W \\
\sum_{w \in W} y_{s w}=1 \quad \forall s \in S \\
\sum_{w \in W} \sum_{s \in S} s x_{s w i} \leq \sum_{w \in W} \sum_{s \in S} s x_{s w j} \quad \forall i, j \in N \mid i \in D_{j} \\
\sum_{w \in W} \sum_{i \in N} p_{w i} x_{s w i} \leq C \\
\sum_{i \in N} x_{s w i} \leq|N| y_{s w} \\
\forall w \in S \in W, \forall s \in S \\
\forall w \in S, \forall i \in I_{w}
\end{gathered}
$$

A função objetivo (4.5) minimiza o tempo de ciclo. As restrições (4.6) garantem que 
cada tarefa será executada por um trabalhador em um estágio. As restrições (4.7) e (4.8) estabelecem que uma relação biunívoca entre trabalhadores e estágios. As restrições (4.9) estabelecem as relações de precedência entre as tarefas. As restrições (4.10) definem o tempo de ciclo como o tempo do estágio mais lento. As restrições (4.11) indicam que uma tarefa só pode ser executada por um trabalhador em um estágio se este trabalhador estiver alocado a este estágio. Por fim, as restrições (4.12) tratam das tarefas que determinados trabalhadores não podem executar.

\subsection{Formulação para o ALBP com estações em paralelo}

A seguir é apresentada uma formulação para o ALBP que permite o uso de estações paralelas, adaptada daquela descrita por Bukchin e Rubinovitz ${ }^{[21]}$. Esta formulação minimiza o custo total dos equipamentos a serem adquiridos dada uma taxa de produção a ser atendida.

Com a notação adicional:

$k \quad$ Indices do número de estações em paralelo

$W_{k} \quad$ Custo de utilizar $k$ estações em paralelo

$K_{M a x} \quad$ Número máximo de estações em paralelo

E as variáveis:

$z_{s k} \quad$ Variável binária. Igual a 1 se existem exatamente $k$ estações paralelas no estágio $s$, igual a 0 caso contrário

Pode-se escrever:

$$
\operatorname{Min} \sum_{s \in S} \sum_{k=1}^{K_{\operatorname{Max}}} W_{k} z_{s k}
$$

s.a.

$$
\sum_{s \in S} s x_{s i} \leq \sum_{s \in S} s x_{s j} \quad \forall i, \forall j \in N \mid i \in D_{j}
$$




$$
\begin{gathered}
\sum_{s \in S} x_{s i}=1 \quad \forall i \in N \\
\sum_{k=1}^{K_{M a x}} z_{s k} \leq 1 \quad \forall s \in S \\
\sum_{i \in N} p_{i} x_{s i} \leq \sum_{k=1}^{K_{M a x}} k z_{s k} C \quad \forall s \in S
\end{gathered}
$$

Este modelo introduz a variável $z_{s k}$, que representa o nível de paralelismo no estágio s. A função objetivo (4.13) minimiza o custo $W_{k} z_{s k}$ de $k$ estações paralelas em um dado estágio $s$. As restrições (4.14) estabelecem as relações de precedência. As restrições (4.15) garante a execução das tarefas. A restrição (4.16) define um único nível de paralelismo em cada estágio. Observe que este valor pode ser zero caso todas as variáveis $z_{s k}$ sejam zero, indicando assim um estágio vazio. Por fim, a restrição (4.17) garante que o tempo de execução de cada estágio não exceda o tempo de ciclo.

Seja $k_{s}$ o nível de paralelismo do estágio $s$, isto é, $z_{s k}$ é igual a 1 para $k=k_{s}$ e 0 para os demais valores de $k$. A restrição (4.17) é equivalente a:

$$
\sum_{i \in N} p_{i} x_{s i} \leq k_{s} C \rightarrow \frac{\sum_{i \in N} p_{i} x_{s i}}{k_{s}} \leq C
$$

Desta forma, o termo da esquerda, que corresponde ao tempo de execução do estágio, não deve exceder o tempo de ciclo desejado. Observe que esta formulação é linear para o ALBP-1, porém as restrições (4.17) a tornam não-linear para o ALBP-2.

\subsection{Formulação para o ALWABP com estações em pa- ralelo}

A partir dos modelos apresentados anteriormente, foi possível desenvolver uma formulação para o ALWABP com máquinas paralelas. A ideia foi de se mesclar conceitos encontrados em cada modelo, como a definição de variáveis com 3 índices indicando a 
execução de uma tarefa por um trabalhador em um dado estágio e a definição de variáveis indicando o nível de paralelismo em cada estágio. A variável $z_{s k}$ foi adaptada, permitindo que o valor de $k$ varie de 0 até $K_{M a x}$. Esta modificação será útil para a linearização do modelo.

Com a adição das variáveis:

$t_{i s} \quad$ Variável binária. Igual a 1 se a tarefa $i$ é executada no estágio $s$, igual a 0 caso contrário

Pode-se escrever um modelo para o ALWABP com estações paralelas como:

$\operatorname{Min} C$

s.a.

$$
\begin{gathered}
\sum_{s \in S} s t_{i s} \leq \sum_{s \in S} s t_{j s} \quad \forall i, j \in N \mid i \in D_{j} \\
\sum_{w \in W} x_{s w i} \geq k\left(t_{i s}+z_{s k}-1\right) \quad \forall s \in S, \forall k \in\left[0, K_{\text {Max }}\right], \forall i \in N \\
x_{s w i} \leq t_{i s} \forall s \in S, \forall w \in W, \forall i \in N \\
\sum_{k=0}^{K_{M a x}} z_{s k}=1 \quad \forall s \in S \\
\sum_{w \in W} y_{s w}=\sum_{k=0}^{K_{M a x}} k z_{s k} \quad \forall s \in S
\end{gathered}
$$




$$
\begin{gathered}
\sum_{s \in S} t_{i s}=1 \quad \forall i \in N \\
x_{s w i} \leq y_{s w} \quad \forall s \in S, \forall w \in W, \forall i \in N \\
x_{s w i}=0 \quad \forall w \in W, \forall s \in S, \forall i \in I_{w} \\
\sum_{w \in W \mid y_{s w}=1} \frac{1}{\sum_{i \in N} p_{w i} x_{s w i}} \geq \frac{1}{C} \quad \forall s \in S \mid z_{s 0}=0
\end{gathered}
$$

A função objetivo (4.18) minimiza o tempo de ciclo. As restrições (4.19) definem as relações de precedência entre as tarefas. As restrições (4.20) indicam que em um estágio com $k$ máquinas paralelas cada tarefa atribuída àquele estágio deve ser executada por pelo menos $k$ trabalhadores. As restrições (4.21) indicam que um trabalhador só pode executar uma tarefa em um estágio caso aquela tarefa tenha sido atribuída àquele estágio. As restrições (4.22) indicam que cada estágio possui exatamente um nível de paralelismo. As restrições (4.23) e (4.24) estabelecem que cada estágio possui $k$ trabalhadores e cada trabalhador executa tarefas em apenas um estágio. As restrições (4.25) obrigam cada tarefa a ser executada em exatamente um estágio. As restrições (4.26) indicam que um trabalhador só pode executar tarefas em um estágio ao qual tenha sido alocado. As restrições (4.27) tratam das tarefas que alguns trabalhadores não podem executar. Por fim, as restrições (4.28) definem a taxa de produção como a menor entre as frequências de execução de cada estágio não vazio, em que um estágio vazio possui zero máquinas $\left(z_{s 0}=1\right)$. A frequência de execução de um estágio corresponde à soma das frequências de execução de cada máquina que, por sua vez, equivalem ao inverso da soma dos tempos de execução de suas tarefas. As restrições (4.28) tornam o modelo (4.18)-(4.28) não-linear.

Com o intuito de linearizar (4.18)-(4.28), definimos $F$ como a frequência de produção da linha de montagem. Desejamos então maximizar a frequência de produção, o que é equivalente a minimizar o tempo de ciclo. Seja $f_{s w}$ a frequência de execução do trabalhador $w$ no estágio $s$. Caso o trabalhador $w$ seja designado ao estágio $s$, isto é, $y_{s w}=1$, temos que 
$f_{s w}=\frac{1}{\sum_{i \in N} p_{w i} x_{s w i}}$, o que é equivalente a $\sum_{i \in N} p_{w i} f_{s w} x_{s w i}=1$. Caso contrário, $f_{s w}=0$. Para tornar estas restrições lineares, definimos a variável $v_{s w i}$ igual a $f_{s w}$ se a tarefa $i$ é executada pelo trabalhador $w$ no estágio $s$ ou 0 caso contrário, ou seja, $v_{s w i}=f_{s w} x_{s w i}$. Seja $M$ um limitante superior para a taxa de produção e $M_{w}$ um limitante superior para a frequência de execução do trabalhador $w$. Estes termos podem ser calculados da seguinte forma:

$$
\begin{aligned}
& M=\frac{|W|}{\sum_{i \in N} p_{w i}^{-}} \\
& M_{w}=\frac{1}{\min _{i \in N} p_{w i}}
\end{aligned}
$$

O valor de $M$ corresponde ao inverso de um limitante inferior para o tempo de ciclo. Este tempo de ciclo equivale a alocar $|\mathrm{W}|$ trabalhadores em um único estágio, em que os tempos destes trabalhadores para cada tarefa $i$ correspondem ao menor tempo de execução desta tarefa entre os trabalhadores do problema original $\left(p_{w i}^{-}\right)$. O valor de $M_{w}$ para um dado trabalhador $w$ equivale a alocar a este trabalhador apenas a tarefa que ele executa mais rapidamente.

O modelo pode então ser reescrito da seguinte forma:

$$
\operatorname{Max} \quad F
$$

$$
(4.19)-(4.27)
$$

$$
\begin{gathered}
\sum_{w \in W} f_{s w} \geq F-M z_{s 0} \quad \forall s \in S \\
\sum_{i \in N} p_{w i} v_{s w i}=y_{s w} \quad \forall w \in W, \forall s \in S \\
f_{s w} \leq M_{w} y_{s w} \quad \forall w \in W, \forall s \in S
\end{gathered}
$$




$$
\begin{gathered}
v_{s w i} \geq f_{s w}-M_{w}\left(1-x_{s w i}\right) \quad \forall s \in S, \forall w \in W, \forall i \in N \\
v_{s w i} \leq|N| x_{s w i} \quad \forall s \in S, \forall w \in W, \forall i \in N
\end{gathered}
$$

A função objetivo (4.29) maximiza a frequência de produção. As restrições (4.30) definem a taxa de produção como a frequência de execução do estágio não vazio mais lento. As restrições (4.31) definem as variáveis $v_{s w i}$ como uma ponderação dos tempos de execução de cada tarefa. As restrições (4.32) forçam $f_{s w}=0$ caso o trabalhador $w$ não tenha sido alocado ao estágio $s$. As restrições (4.33) e (4.34) definem os limitantes para as variáveis $v_{s w i}$. As restrições (4.31) e (4.33) forçam $v_{s w i}=f_{s w}$ se $x_{s w i}=1$, enquanto que as restrições (4.34) forçam $v_{s w i}=0$ se $x_{s w i}=0$.

\subsection{Formulação para o ALWABP colaborativo}

A seguir é apresentada a formulação para o ALWABP colaborativo, utilizando a mesma notação do ALWABP serial.

Min $C$

$$
\sum_{w \in W} \sum_{s \in S} x_{s w i}=1 \quad \forall i \in N
$$

$$
\sum_{s \in S} y_{s w}=1 \quad \forall w \in W
$$

$$
\sum_{w \in W} y_{s w} \leq K_{\text {Max }} \quad \forall s \in S
$$




$$
\begin{gathered}
\sum_{w \in W} \sum_{s \in S} s x_{s w i}=\sum_{w \in W} \sum_{s \in S} s x_{s w j} \quad \forall i, j \in N \mid i \in D_{j} \\
\sum_{i \in N} p_{w i} x_{s w i} \leq C \quad \forall s \in S \\
\sum_{i \in N} x_{s w i} \leq|N| y_{s w} \quad \forall w \in W, \forall s \in S \\
x_{s w i}=0 \quad \forall w \in W, \forall s \in S, \forall i \in I_{w}
\end{gathered}
$$

Este modelo corresponde ao modelo para o ALWABP serial substituindo as restrições (4.8) por (4.38). Com isto, o modelo é capaz de suportar mais de um trabalhador em um mesmo estágio. De fato, caso não desejemos limitar o número de trabalhadores por estágio, podemos eliminar as restrições 4.38 . 


\section{Heuristica Construtiva}

Conforme será visto no Capítulo 6, os modelos apresentados no Capítulo 4 são de difícil resolução, não sendo capazes de resolver problemas de grande porte em um tempo computacional viável. Em vista disto, adaptamos a heurística construtiva desenvolvida por Scholl e Voß ${ }^{[17]}$ para o SALBP. Modificações desta heurística já foram usadas por Moreira e Costa ${ }^{[5]}$ para resolver o problema ALWABP e neste trabalho ela é modificada para adicionar suporte para o ALWABP com estações em paralelo e para o ALWABP colaborativo.

Este capítulo está dividido em quatro sessões. As duas primeiras sessões tratam, respectivamente, das heurísticas existentes para o SALBP-2 (sessão 5.1) e para o ALWABP (sessão 5.2). Na sessão 5.3 descrevemos as alterações realizadas para suporte ao paralelismo, enquanto que, na sessão 5.4 são descritas as modificações necessárias para suporte ao ALWABP colaborativo.

\subsection{Heurística para o SALBP-2}

Scholl e Voß ${ }^{[17]}$ descrevem uma heurística construtiva para o SALBP-2. Esta heurística consiste na resolução do SALBP-1 para diversos valores de tempo de ciclo. Seja $\bar{c}$ o tempo de ciclo desejado, $t\left(S_{k}\right)$ o tempo de execução da estação $k$ e $N$ um conjunto de tarefas. O algoritmo 1 constrói uma solução para o SALBP-1.

\footnotetext{
Algoritmo 1 Procedimento de designação orientado a estações para o SALBP-1

Entrada: Tempo de ciclo máximo $\bar{c}$

1: Inicie em uma estação vazia $n=0, t\left(S_{n}\right)=0$. Adicione as tarefas não alocadas a $U=N$.

2: Aloque à estação atual a tarefa $i$ de maior prioridade tal que $t_{i}+t\left(S_{k}\right) \leq \bar{c}$ e faça $U=U \backslash\{i\}$.

3: Se não houverem tarefas disponíveis, retorne $k$. Caso contrário, caso hajam tarefas disponíveis, mas nenhuma possa ser alocada, faça $k=k+1, t\left(S_{k}\right)=0$. Vá para o Passo 2.
} 
A heurística construtiva para o SALBP-2 consiste na execução do algoritmo 1 para vários valores de tempo de ciclo $\bar{c}$, visando encontrar o menor valor viável de $\bar{c}$. Os autores utilizaram diversos métodos para calcular $\bar{c}$. Um destes métodos consiste em iniciar com um limitante inferior para o problema e executar o Algoritmo 1. Este método é descrito no Algoritmo 2

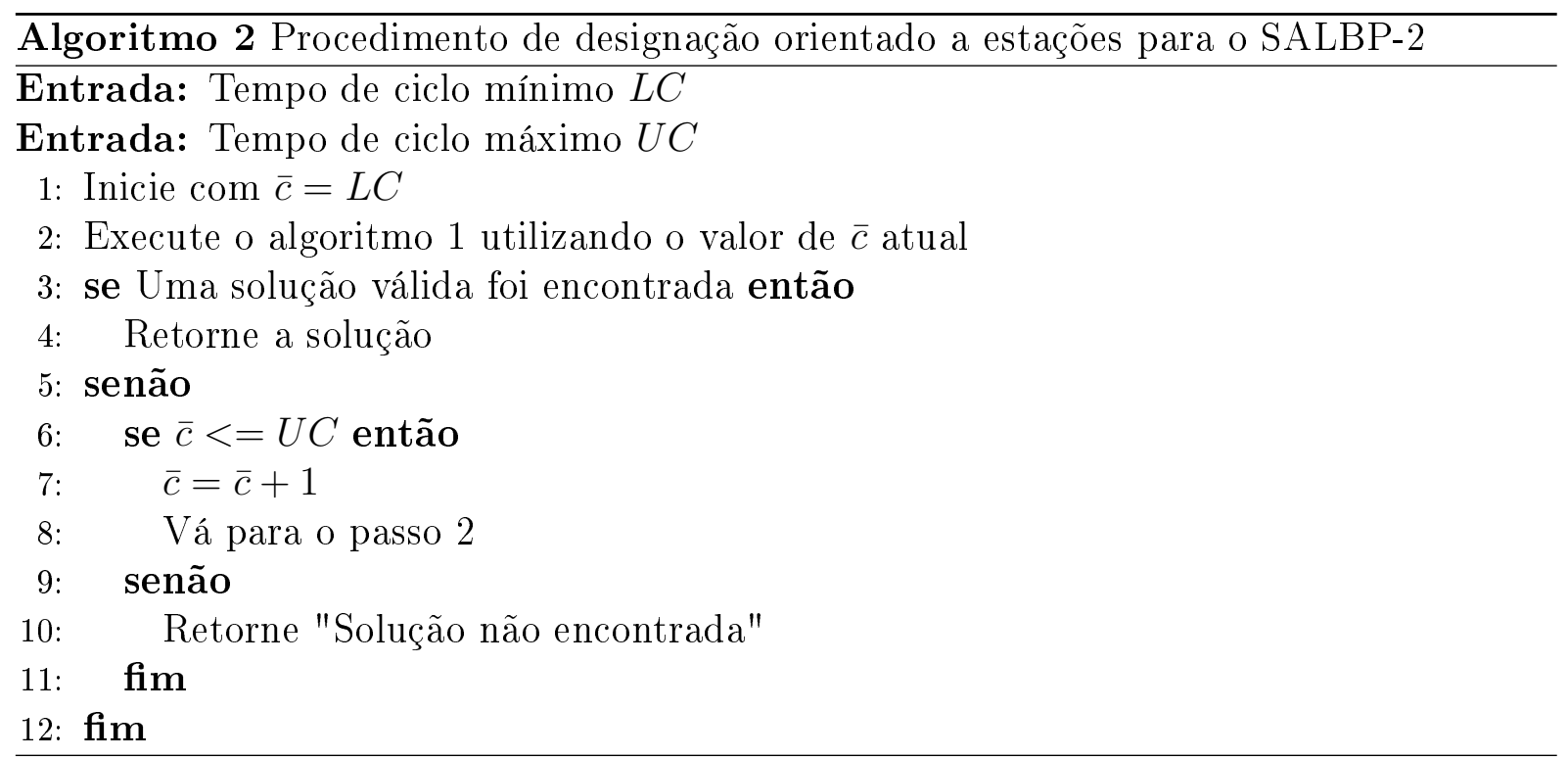

Além disso, os autores propuseram diversas regras de prioridade, de modo a classificar as tarefas disponíveis. As principais regras são descritas a seguir:

1. MaxF: número decrescente de tarefas sucessoras;

2. MaxIF: número decrescente de tarefas sucessoras imediatas;

3. MaxTime: tempos decrescentes das tarefas;

4. MaxPW: positional weights decrescentes;

5. MaxTimeL: razão entre os tempos de execução das tarefas e as respectivas estações "mais tarde" (isto é, a última estação onde esta tarefa pode ser executada para um dado tempo de ciclo respeitando as relações de precedência);

6. MaxTimeSlack: razão entre os tempos de execução das tarefas e a diferença entre a estação "mais tarde" e a estação "mais cedo" (isto é, a primeira estação onde esta tarefa pode ser executada para um dado tempo de ciclo respeitando as relações de precedência)

O positional weight de uma tarefa é dado pela soma do tempo de execução desta tarefa para o trabalhador atual e o somatório dos tempos de execução das tarefas sucessoras. 


\subsection{Heurística para o ALWABP}

Moreira e Costa ${ }^{[5]}$ propuseram uma modificação da heurística proposta por Scholl e Voß ${ }^{[17]}$ para o ALWABP-2. Para isto, os autores precisaram redefinir diversas regras de prioridade, uma vez que a maioria delas se baseia no tempo de execução das tarefas, que é dependente do trabalhador no ALWABP. Além disso, os autores precisaram definir regras de seleção de trabalhadores. O Algoritmo 3 descreve o funcionamento da heurística para o ALWABP.

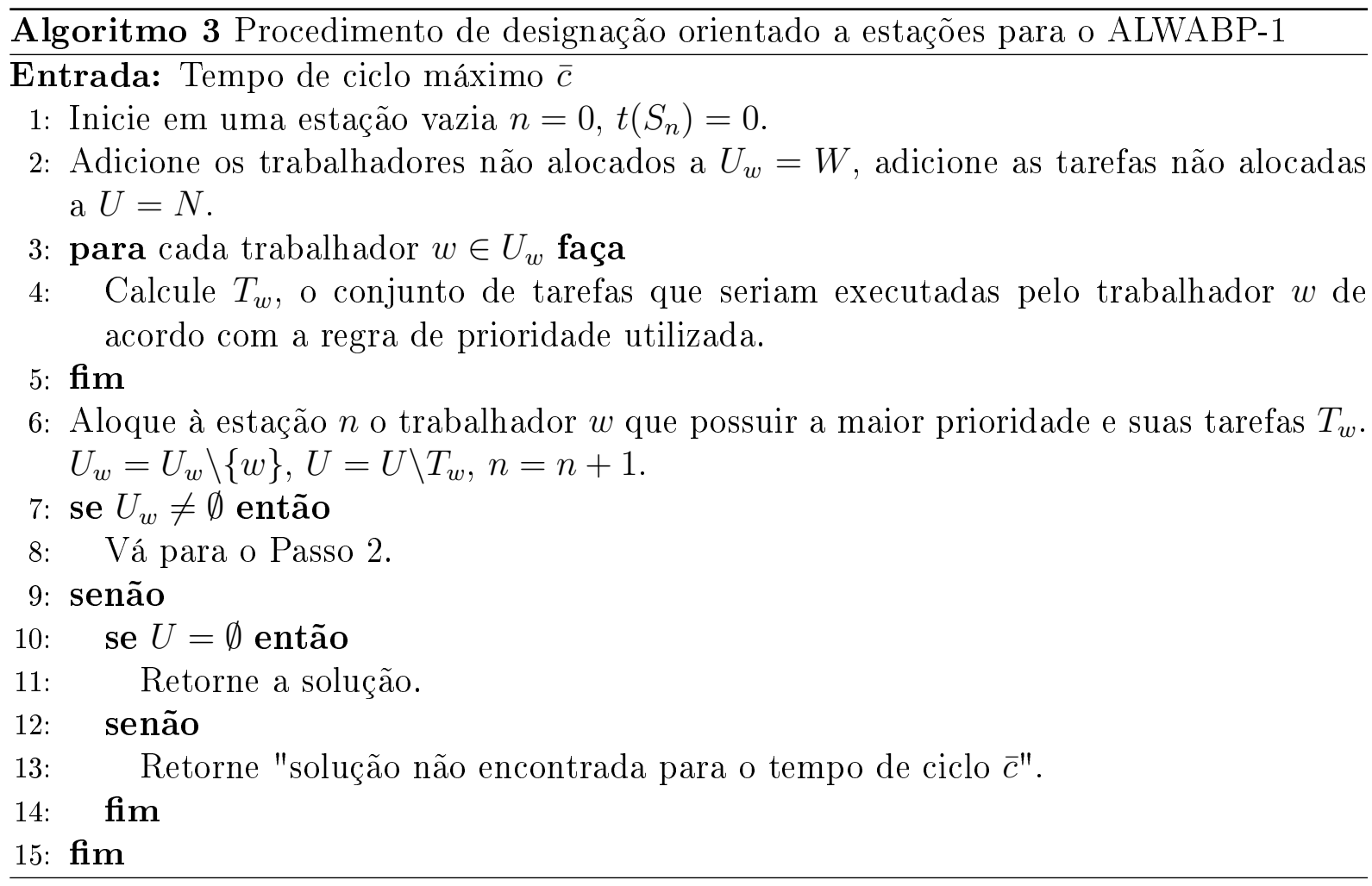

Este algoritmo pode ser executado com o grafo de precedência normal ou reverso. Para este último, as relações de precedência são invertidas, isto é, se a tarefa $i$ precede a tarefa $j$ no grafo normal, a tarefa $j$ passa a preceder a tarefa $i$ no grafo reverso. A solução encontrada pelo algoritmo 3 é então invertida (os trabalhadores e tarefas alocados às primeiras estações são alocados às últimas), resultando em uma solução para o ALWABP.

Para esta heurística, foram utilizadas as seguintes regras de prioridade, adaptadas daquelas utilizadas por Scholl e $\operatorname{Vo}^{[17]}$ :

1. MaxF: número decrescente de seguidores;

2. MaxIF: número decrescente de seguidores imediatos;

3. MaxTime ${ }^{-}$: valores decrescentes dos tempos mínimos das tarefas; 
4. MaxTime ${ }^{+}$: valores decrescentes dos tempos máximos das tarefas;

5. MaxTime: valores decrescentes dos tempos médios das tarefas;

6. MinTime ${ }^{-}$valores crescentes dos tempos mínimos das tarefas;

7. MinTime ${ }^{+}$: valores crescentes dos tempos máximos das tarefas;

8. MinTime: valores crescentes dos tempos médios das tarefas.

9. $\operatorname{Max} P W^{-}$: valores decrescentes dos positional weights mínimos;

10. $\operatorname{Max} P W^{+}$: valores decrescentes dos positional weights máximos;

11. MaxPW: valores decrescentes dos positional weights médios;

12. MinD: valores crescentes da diferença entre o tempo da tarefa para este trabalhador e o menor tempo da tarefa;

13. MinR: valores crescentes da razão entre o tempo da tarefa para este trabalhador e o menor tempo da tarefa;

14. MaxFTime: valores decrescentes da razão entre o número de seguidores e o tempo da tarefa;

15. MaxIFTime: valores decrescentes da razão entre o número de seguidores imediatos e o tempo da tarefa;

16. MinRank: valores crescentes da classificação do tempo de execução da tarefa em relação a outros trabalhadores.

O tempo mínimo de uma tarefa corresponde ao menor tempo de execução desta tarefa entre os trabalhadores disponíveis (isto é, os trabalhadores que ainda não foram alocados), enquanto que os tempos máximo e médio da tarefa correspondem, respectivamente, ao maior tempo de execução e à média dos tempos de execução desta tarefa entre os trabalhadores disponíveis e que são capazes de executá-la. O positional weight de uma tarefa é dado pela soma do tempo de execução desta tarefa para o trabalhador atual e o somatório dos tempos de execução das tarefas sucessoras.

Além destas regras de prioridade, os autores utilizaram regras para seleção de trabalhadores. Entre elas, podemos destacar:

1. MaxTasks: número decrescentes de tarefas alocadas; 
2. MinRLB: valores decrescentes dos limitantes inferiores relaxados

A regra MaxTasks prioriza os trabalhadores que conseguem alocar mais tarefas. Já a regra MinRLB calcula o limitante inferior para o tempo de ciclo das estações restantes. Este limitante corresponde ao somatório dos menores tempos de execução das tarefas restantes dividido pelo número de trabalhadores restantes.

A eficiência do algoritmo 3 depende de bons limitantes inferiores para o problema. Em vista disso, Moreira e Costa ${ }^{[5]}$ adaptaram os limitantes utilizados por Scholl e Becker ${ }^{[32]}$. Entre estes limitantes inferiores, podemos citar o limitante denominado LC1. Seja $m$ o número de trabalhadores e $t_{i}^{-}$o menor tempo de execução da tarefa $i$ entre todos os trabalhadores. O cálculo do limitante LC1 é dado pela seguinte fórmula:

$$
L C 1=\max \left\{\max _{i \in N} t_{i}^{-},\left\lceil\sum_{i \in N} t_{i}^{-} / m\right\rceil\right\}
$$

O termo $\max _{i \in N} t_{i}^{-}$indica que, caso tomemos o menor tempo de cada tarefa entre todos os trabalhadores, o tempo de ciclo é maior ou igual ao maior destes tempos. Já o termo $\left\lceil\sum_{i \in N} t_{i}^{-} / m\right\rceil$ corresponde a uma estimativa do tempo de ciclo, supondo que cada tarefa é executada pelo trabalhador que a executa mais rapidamente.

\subsection{Heurística para o ALWABP com estações em para- lelo}

A heurística descrita na sessão anterior pode ser adaptada para o caso em que há estações em paralelo. Para isto, a principal dificuldade encontrada é a necessidade de redefinir as regras de prioridade para as tarefas. Uma vez que o tempo de execução de uma tarefa não é bem definido para trabalhadores em paralelo, muitas regras de prioridade tiveram que ser alteradas. Além disso, para a regra de seleção de trabalhadores MaxTasks, o uso de paralelismo geralmente implica em um número maior de tarefas alocadas a um estágio. No entanto, isto nem sempre resulta em uma boa solução em termos de tempo de ciclo. Em vista disto, é necessário utilizar técnicas para controlar o uso do paralelismo.

O algoritmo 4 descreve o procedimento para obter uma solução ALWABP-1 com estações em paralelo. este algoritmo requer, além do tempo de ciclo $\bar{c}$, o número máximo de estações em paralelo $K_{M a x}$. 


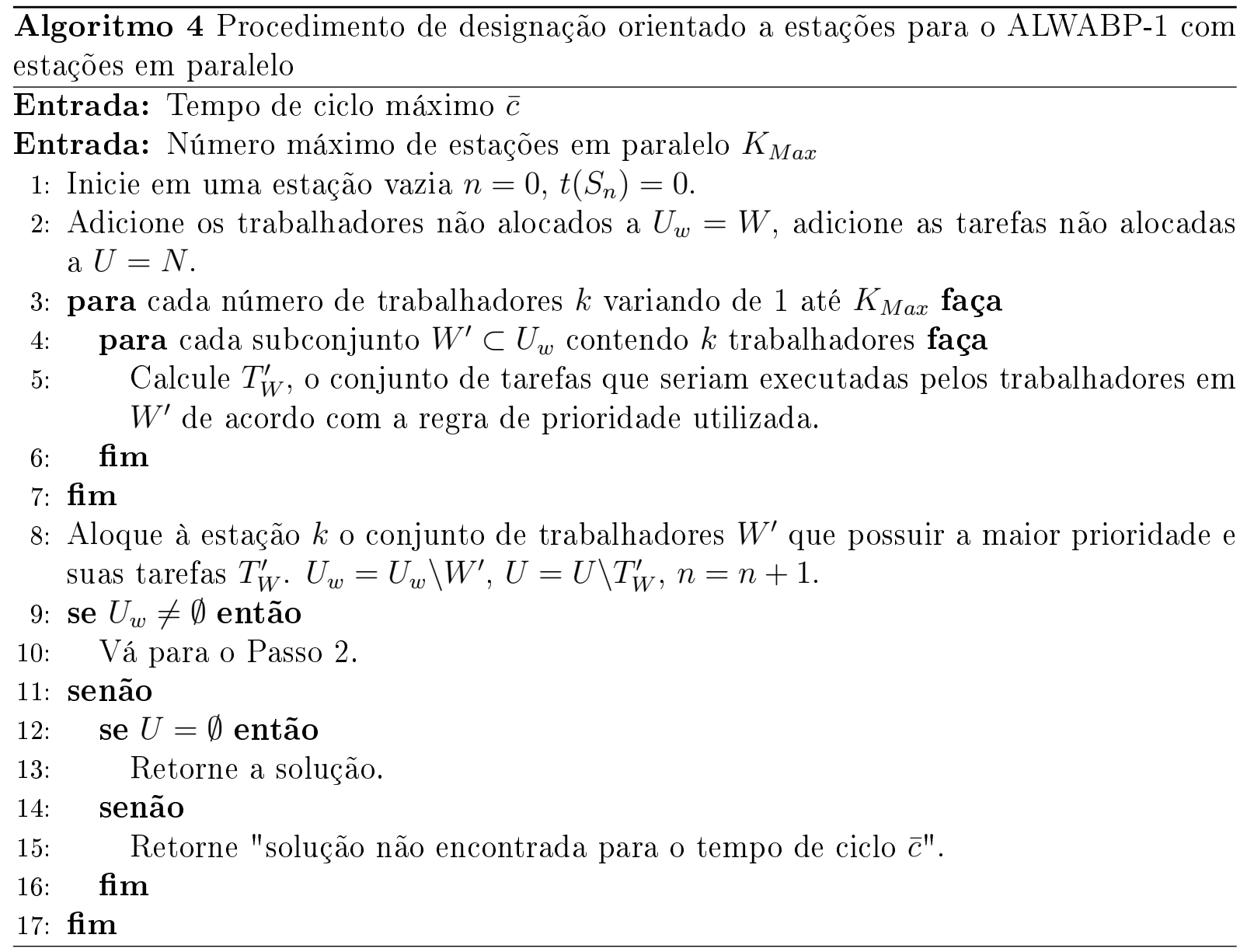




\subsubsection{Adaptação do custo de adição de uma tarefa}

Visando adaptar as regras de prioridade definidas por Moreira e Costa ${ }^{[5]}$, definimos o custo de uma tarefa como o incremento no tempo de execução de um estágio causado pela adição desta tarefa. Observe que, para o caso com apenas um trabalhador em um estágio, este custo é equivalente ao tempo de execução da tarefa. Caso mais de um trabalhador seja alocado, o custo da tarefa é dependente não apenas do tempo de execução desta tarefa pelos trabalhadores considerados, mas também das tarefas que estão alocadas naquele estágio.

Por exemplo, suponhamos que desejemos adicionar a tarefa $i$ a um estágio com dois trabalhadores, A e B. O tempo de execução desta tarefa é de 5 s para o trabalhador A e de 10s para o trabalhador B. Se nenhuma tarefa tiver sido alocada para estes trabalhadores, custo da adição desta tarefa será de $\frac{1}{\frac{1}{5}+\frac{1}{10}}=3,33 \mathrm{~s}$. Suponhamos agora que outras tarefas já foram alocadas a estes trabalhadores e que o tempo total das tarefas alocadas é de 20s para o trabalhador A e 15s para o trabalhador B. O tempo de execução deste estágio sem a tarefa i é de $\frac{1}{\frac{1}{20}+\frac{1}{15}}=8,6 \mathrm{~s}$. Se adicionarmos a tarefa $i$, o tempo de execução será de $\frac{1}{\frac{1}{20+5}+\frac{1}{15+10}}=12,5 \mathrm{~s}$. Logo, o custo da adição da tarefa $i$ neste caso é de 3,9s.

Utilizando este cálculo do custo da tarefa, selecionamos as seguintes regras de prioridade para as tarefas.

1. MinD: valores crescentes da diferença entre o custo da tarefa e o menor tempo da tarefa;

2. MinR: valores crescentes da razão entre o custo da tarefa e o menor tempo da tarefa;

3. MaxFTime: valores decrescentes da razão entre o número de seguidores e o custo da tarefa;

4. MaxIFTime: valores decrescentes da razão entre o número de seguidores imediatos e o custo da tarefa;

5. $M a x P W S^{-}$: valores decrescentes dos positional weights estáticos mínimos;

6. $M a x P W S^{+}$: valores decrescentes dos positional weights estáticos máximos;

7. MaxPW $D^{-}$: valores decrescentes dos positional weights dinâmicos mínimos;

8. MaxPW $D^{+}$: valores decrescentes dos positional weights dinâmicos máximos; 
O positional weight dinâmico corresponde ao positional weight descrito na seção 5.2, substituindo o tempo de execução da tarefa atual pelo custo desta tarefa. O positional weight estático corresponde a uma simplificação do positional weight dinâmico em que os tempos das tarefas sucessoras utilizados não dependem dos trabalhadores alocados, o que torna o custo computacional deste critério menor em relação ao positional weight dinâmico.

Conforme dito anteriormente, o custo da tarefa para um dado conjunto de trabalhadores é dependente das outras tarefas que estes trabalhadores executam. Por isso, nos critérios que utilizam o tempo de execução de outros trabalhadores não são considerados conjuntos de mais de um trabalhador, visando com isto evitar um aumento no custo computacional da heurística.

\subsubsection{Adaptação das regras de seleção de trabalhadores}

Além destas regras de prioridade para as tarefas, utilizamos também duas regras de seleção de trabalhadores: MaxTasks e MinRLB. Para a regra MaxTasks dividimos o número de tarefas por um certo peso caso mais de um trabalhador seja alocado ao estágio, visando controlar melhor o uso do paralelismo. Este controle adicional não foi utilizado no MinRLB, uma vez que o cálculo do tempo de ciclo relaxado depende do número de trabalhadores não alocados. Desta forma, utilizamos as seguintes regras para seleção de trabalhadores.

1. MaxTasks: número decrescentes de tarefas alocadas;

2. MaxTasks1.2: número decrescentes de tarefas alocadas dividido por 1,2;

3. MaxTasks1.4: número decrescentes de tarefas alocadas dividido por 1,4;

4. MaxTasks1.6: número decrescentes de tarefas alocadas dividido por 1,6;

5. MaxTasks1.8: número decrescentes de tarefas alocadas dividido por 1,8;

6. MaxTasks2: número decrescentes de tarefas alocadas dividido por 2;

7. MaxTasks3: número decrescentes de tarefas alocadas dividido por 3;

8. MaxTasksK: número decrescentes de tarefas alocadas dividido pelo número de trabalhadores alocados neste estágio;

9. MinRLB: valores decrescentes dos limitantes inferiores relaxados 
Assim como foi feito para as regras de prioridade para as tarefas, para o calculo dos limitantes inferiores relaxados consideramos apenas os tempos de cada trabalhador individualmente.

Conforme dito no capítulo 2, o uso de estações em paralelo pode resultar em soluções com tempo de ciclo menor. No entanto, visando reduzir o tempo de execução da heurística, foi mantido o limitante LC1 para o tempo de ciclo utilizados na heurística para o ALWABP.

\subsubsection{Modificações na heurística}

Para testar a qualidade das soluções que utilizam paralelismo, foram criadas quatro heurísticas modificadas utilizando como base a heurística para o ALWABP com estações em paralelo. estas heurísticas foram denominadas P1, P2, PS e PW.

Para a heurística P1, modificamos o passo 3 do algoritmo 2. Uma solução para esta heurística é válida se a mesma é uma solução viável para o problema e utiliza paralelismo, isto é, existe pelo menos um estágio com mais de um trabalhador. Caso a solução não utilize paralelismo, ela é descartada e a execução da heurística continua com um tempo de ciclo maior.

A heurística P2 corresponde a uma modificação na heurística P1 de modo a encontrar soluções com paralelismo mais facilmente. Para isto, as regras de seleção de trabalhadores foram ligeiramente modificadas. Em caso de empate para as regras MaxTasks e MinRLB, a heurística P2 prioriza o conjunto com o maior número de trabalhadores. Observe que as heurísticas P1 e P2 não garantem que a solução que está sendo construída utiliza paralelismo.

A heurística PS corresponde a uma forma de se obter soluções forçando o paralelismo em cada estágio. A heurística original tenta construir uma solução para cada valor do tempo de ciclo. Já na heurística PS tentamos construir um conjunto de soluções para cada valor do tempo de ciclo. Em cada uma destas soluções um estágio é selecionado para abrigar dois ou mais trabalhadores em paralelo, enquanto que em cada um dos outros estágios será alocado apenas um trabalhador. Desta forma, esta heurística altera o passo 4 do algoritmo 4 de forma que o paralelismo seja utilizado em exatamente um estágio.

Por fim, a heurística PW modifica a heurística PS forçando a presença de um trabalhador específico em um estágio com paralelismo. Assim como a heurística PS, para 
cada valor do tempo de ciclo esta heurística tenta construir um conjunto de soluções. Porém, diferentemente de PS, nesta heurística, para cada solução que tentamos construir selecionamos um trabalhador. Este trabalhador só poderá ser alocado em paralelo com outros trabalhadores, enquanto que os demais trabalhadores só poderão ser alocados em paralelo com este trabalhador. Da mesma forma que a heurística PS, a heurística PW altera o passo 4 do algoritmo 4. Ao contrário das heurísticas P1 e P2, as heurísticas PS e PW garantem que, se uma solução for encontrada, esta utilizará paralelismo.

\subsection{Heurística para o ALWABP colaborativo}

A heurística desenvolvida para o ALWABP serial pode também ser adaptada para suportar o ALWABP colaborativo. Assim como o ALWABP com estações paralelas, precisamos redefinir o custo das tarefas, bem como controlar a alocação de mais de um trabalhador em um estágio.

Aplicando a mesma ideia utilizada na heurística para o ALWABP com estações em paralelo, definimos o custo de uma tarefa como o aumento no tempo de execução de um estágio gerado pela alocação desta tarefa a este estágio. Para o ALWABP colaborativo, este custo corresponde ao menor tempo de execução desta tarefa entre os trabalhadores alocados a este estágio. Diferentemente do caso do ALWABP com estações em paralelo, este custo não depende das outras tarefas alocadas a este estágio.

As regras de prioridade para as tarefas, bem como as regras de seleção de trabalhadores, são análogas àquelas definidas para o ALWABP com estações paralelas, apenas alterando o cálculo do custo das tarefas. Para esta heurística, utilizamos o limitante LC1, que é um limitante válido para o ALWABP colaborativo.

\subsubsection{Modificações na heurística}

Assim como no caso do ALWABP com estações paralelas, desenvolvemos também um conjunto de heurísticas modificadas de modo a testar a qualidade das soluções em que mais de um trabalhador está alocado a um estágio. Isto resultou no desenvolvimento de quatro heurísticas denominadas C1, C2, CS e CW. Estas heurísticas são análogas às heurísticas P1, P2, PS e PW, respectivamente, apresentadas na sessão 5.3. 


\section{Testes Computacionais}

Os modelos para os problemas ALWABP com estações em paralelo e ALWABP colaborativo foram implementados e utilizados para resolver instâncias de pequeno porte disponíveis na literatura, bem como instâncias modificadas. Os resultados obtidos pelos modelos foram comparados entre si e com as soluções ótimas para o problema ALWABP serial. Os resultados foram obtidos utilizando o pacote comercial IBM ILOG CPLEX 12.1 em um processador Intel Core 2 Duo T5450, 1,66 GHz e 3 GB de RAM.

O modelo para o ALWABP com estações em paralelo se mostrou bastante difícil de resolver. Limitando o tempo de execução em uma hora para cada instância, o modelo conseguiu resolver apenas instâncias muito pequenas, com quatro trabalhadores e algumas instâncias com cinco trabalhadores. Para as instâncias com cinco trabalhadores, o tempo de execução do modelo para o ALWABP com estações em paralelo cresceu muito rapidamente. Em vista disto, limitamos o número máximo de estações em paralelo para estas instâncias em 2 e 3. Os resultados obtidos mostraram que esta modificação resultou em uma redução considerável do tempo de execução, permitindo resolver um maior número de instâncias. O tempo de execução para o ALWABP colaborativo foi consideravelmente menor, não requerendo esta modificação para encontrar soluções em um tempo computacional baixo.

Para as instâncias originais, o modelo para o ALWABP com estações em paralelo conseguiu reduzir o tempo de ciclo das soluções ótimas em duas instâncias das 80, enquanto que o ALWABP colaborativo conseguiu uma redução do tempo de ciclo em quatro instâncias. Entre as soluções que possuem mais de um trabalhador em um estágio, as soluções encontradas pelo ALWABP com estações em paralelo resultaram em uma melhoria de $3,25 \%$ em relação ao modelo serial, contra $43 \%$ para o ALWABP colaborativo em relação ao ALWABP serial.

Foram utilizados também dois conjuntos de instâncias modificadas. O primeiro conjunto simula situações em que dois trabalhadores possuem deficiências semelhantes, en- 
quanto que o segundo conjunto simula a adição de um trabalhador pouco eficiente à linha de produção. O ALWABP com estações em paralelo conseguiu melhorar 43 soluções, contra 13 do ALWABP colaborativo. A maior melhoria obtida pelo ALWABP com estações em paralelo foi de 13,4\%. Já o ALWABP colaborativo encontrou soluções com até 50\% de redução do tempo de ciclo.

Além dos testes com os modelos, foram testadas também cinco heurísticas construtivas para o ALWABP com estações em paralelo e cinco para o ALWABP colaborativo. O tempo de execução destas heurísticas utilizando $K_{\text {Max }}=3$ foi entre duas e cinco vezes maior que o tempo de execução para $K_{M a x}=2$, sendo que este valor de $K_{\text {Max }}$ obteve soluções melhores, em média.

Em relação às regras de seleção de trabalhadores utilizadas, a regra MaxTasks1 encontrou o maior número de soluções com mais de um trabalhador por estágio. No entanto, o tempo de ciclo destas soluções era maior do que os tempos de ciclo das soluções obtidas pelas outras regras utilizadas. A regra MinRLB encontrou as melhores soluções, em média.

As seções 6.1 e 6.2 relatam de forma mais detalhada os resultados obtidos pelos modelos e pelas heurísticas construtivas, respectivamente.

\subsection{Testes com os modelos}

Para testar os modelos, foram utilizadas instâncias definidas por Chaves et al. ${ }^{[14]}$, geradas a partir de problemas disponíveis em http://www.assembly-line-balancing.de/. Os tempos originais das tarefas foram mantidos para o primeiro trabalhador e os demais trabalhadores receberam tempos aleatórios. Foram adicionadas também 10 a $20 \%$ de tarefas incompatíveis para os trabalhadores, exceto o primeiro. Foram selecionados oito grupos de instâncias, cada uma com 4 trabalhadores, sendo que destes 4 são da família de Roszieg, com 25 tarefas a serem executadas, e 4 da família de Heskia, com 28 tarefas.

Utilizamos também dois conjuntos de instâncias modificadas utilizando como base os mesmos 4 grupos de instâncias da família Heskia e 4 da família Roszieg. Para o primeiro conjunto de instâncias, substituímos os tempos de execução das tarefas para o último trabalhador de cada instância pelos tempos correspondentes para o segundo trabalhador. Com isto, pudemos simular casos em que os trabalhadores possuem deficiências semelhantes. As duas novas famílias de instância foram denominadas Heskia mod 1 e Roszieg mod 1. Um segundo grupo de instâncias modificadas foi gerado adicionando um trabalhador 
cujo tempo de execução de cada tarefa corresponde ao triplo do maior tempo de execução desta tarefa entre os trabalhadores da instância original que conseguem executá-la. Este conjunto de instância simula a adição de um trabalhador pouco eficiente em relação aos demais. As duas novas famílias de instâncias foram denominadas Heskia mod 2 e Roszieg $\bmod 2$.

Para as instâncias Roszieg, Roszieg mod 1, Heskia e Heskia mod 1, o nível máximo de paralelismo (parâmetro $K_{\text {Max }}$ ) utilizado corresponde ao número total de trabalhadores. As tabelas 3 e 4 mostram os resultados obtidos para as instâncias originais, enquanto que as tabelas 5 e 6 mostram os resultados obtidos para as famílias Roszieg mod 1 e Heskia mod 1, respectivamente. Os resultados estão divididos por grupo. As colunas Serial, Paralelo e Colaborativo indicam, respectivamente, os resultados obtidos pelo ALWABP serial, ALWABP com estações em paralelo e ALWABP colaborativo. A subcoluna C indica o tempo de ciclo médio da solução obtida entre as instâncias do grupo, enquanto que a subcoluna T Exec. indica o tempo de execução médio do modelo.

Utilizar o número de trabalhadores como limitante para o número máximo de estações em paralelo torna difícil a resolução das instâncias das famílias Heskia mod 2 e Roszieg mod 2. Em vista disto, para estas instâncias utilizamos $K_{\text {Max }}=2$ e $K_{\text {Max }}=3$ para o ALWABP com estações em paralelo. As tabelas 7 e 8 mostram os resultados para as famílias Roszieg mod 2 e Heskia mod 2, respectivamente. O tempo de execução destas duas famílias foi limitado em 3600 segundos. Além das colunas utilizadas nas demais instâncias, adicionamos a coluna Gap, que indica o gap médio caso a otimalidade da solução não tenha sido provada após 3600 segundos de execução.

Os resultados foram obtidos utilizando o pacote comercial IBM ILOG CPLEX 12.1 em um processador Intel Core 2 Duo T5450, 1,66 GHz e 3 GB de RAM.

Tabela 3: Resultados para a família Heskia

\begin{tabular}{|c|c|c|c|c|c|}
\hline & Serial & \multicolumn{2}{|c|}{ Paralelo } & \multicolumn{2}{c|}{ Colaborativo } \\
\hline Grupo & $\mathrm{C}$ & $\mathrm{C}$ & $\mathrm{T}$ & $\mathrm{C}$ & $\mathrm{T}$ \\
\hline 1 & 102,3 & 102,3 & 113,19 & 102,3 & 1,11 \\
2 & 122,6 & 122,6 & 82,65 & 122,6 & 1,25 \\
3 & 172,5 & 172,5 & 204,68 & 172,5 & 1,43 \\
4 & 171,2 & 171,2 & 173,31 & 171,2 & 1,2 \\
\hline
\end{tabular}

O tempo de execução do ALWABP colaborativo foi bastante menor que o tempo de execução para o ALWABP com estações em paralelo para todas as famílias de instâncias. Para a família Roszieg em quatro instâncias a solução ótima utiliza paralelismo, sendo que duas destas apresentaram uma melhora no tempo de ciclo se comparadas com as 
Tabela 4: Resultados para a família Roszieg

\begin{tabular}{|c|c|c|c|c|c|}
\hline & Serial & \multicolumn{2}{|c|}{ Paralelo } & \multicolumn{2}{c|}{ Colaborativo } \\
\hline Grupo & C & C & T & C & T \\
\hline 1 & 20,1 & 20,1 & 52,85 & 20,1 & 7,67 \\
2 & 31,5 & 31,36 & 18,81 & 26,3 & 3,38 \\
3 & 28,1 & 28,1 & 96,17 & 28,1 & 10,94 \\
4 & 28 & 28 & 82,7 & 28 & 5,55 \\
\hline
\end{tabular}

Tabela 5: Resultados para a família Heskia mod 1

\begin{tabular}{|c|c|c|c|c|c|}
\hline & Serial & \multicolumn{2}{|c|}{ Paralelo } & \multicolumn{2}{c|}{ Colaborativo } \\
\hline Grupo & $\mathrm{C}$ & $\mathrm{C}$ & $\mathrm{T}$ & $\mathrm{C}$ & $\mathrm{T}$ \\
\hline 1 & 128,4 & 128,05 & 103,96 & 128,4 & 6,57 \\
2 & 142,5 & 141,8 & 38,53 & 142,5 & 3,37 \\
3 & 206,4 & 206,35 & 144,4 & 206,4 & 6,61 \\
4 & 192,1 & 191,95 & 321,75 & 192,1 & 5,71 \\
\hline
\end{tabular}

Tabela 6: Resultados para a família Roszieg mod 1

\begin{tabular}{|c|c|c|c|c|c|}
\hline & Serial & \multicolumn{2}{|c|}{ Paralelo } & \multicolumn{2}{c|}{ Colaborativo } \\
\hline Grupo & $\mathrm{C}$ & $\mathrm{C}$ & $\mathrm{T}$ & $\mathrm{C}$ & $\mathrm{T}$ \\
\hline 1 & 23,2 & 23,05 & 41,86 & 23,2 & 9,63 \\
2 & 39,1 & 39,1 & 5,74 & 29,3 & 5,19 \\
3 & 30,3 & 30,1 & 45,74 & 30,3 & 9,57 \\
4 & 30,1 & 29,75 & 26,3 & 30,1 & 9,57 \\
\hline
\end{tabular}

Tabela 7: Resultados para a família Roszieg mod 2

\begin{tabular}{|c|c|c|c|c|c|c|c|c|c|}
\hline & Serial & \multicolumn{7}{|c|}{ Paralelo } & \multicolumn{3}{c|}{ Colaborativo } \\
\hline & & \multicolumn{3}{|c|}{$K_{\text {Max }}=2$} & \multicolumn{3}{c|}{$K_{\text {Max }}=3$} & & \\
\hline Grupo & $\mathrm{C}$ & $\mathrm{C}$ & Gap & $\mathrm{T}$ & $\mathrm{C}$ & Gap & $\mathrm{T}$ & $\mathrm{C}$ & $\mathrm{T}$ \\
\hline 1 & 17,7 & 17,63 & $0,00 \%$ & 1646,21 & 17,63 & $0,15 \%$ & 1781,4 & 17,7 & 68,52 \\
2 & 20,9 & 20,59 & $0,00 \%$ & 654,04 & 20,59 & $0,00 \%$ & 716,14 & 20,6 & 54,29 \\
3 & 25,1 & 24,91 & $2,77 \%$ & 2280,54 & 24,91 & $4,55 \%$ & 2394,27 & 25,1 & 67,39 \\
4 & 25,6 & 25,5 & $2,59 \%$ & 2340,28 & 25,5 & $4,39 \%$ & 2460,79 & 25,6 & 68,93 \\
\hline
\end{tabular}

Tabela 8: Resultados para a família Heskia mod 2

\begin{tabular}{|c|c|c|c|c|c|c|c|c|c|}
\hline & Serial & \multicolumn{9}{|c|}{ Paralelo } & \multicolumn{3}{c|}{ Colaborativo } \\
\hline & & \multicolumn{3}{|c|}{$K_{\text {Max }}=2$} & \multicolumn{3}{c|}{$K_{\text {Max }}=3$} & & \\
\hline Grupo & $\mathrm{C}$ & $\mathrm{C}$ & Gap & $\mathrm{T}$ & $\mathrm{C}$ & Gap & $\mathrm{T}$ & $\mathrm{C}$ & $\mathrm{T}$ \\
\hline 1 & 97,9 & 96,54 & $43,04 \%$ & 2769,71 & 96,69 & $469,28 \%$ & 3078,1 & 97,9 & 23,95 \\
2 & 116,3 & 111,68 & $2,83 \%$ & 2030,83 & 112,41 & $43,16 \%$ & 2262,34 & 116,3 & 22,63 \\
3 & 164,8 & 163,98 & $89,23 \%$ & 3617,28 & 163,74 & $149,81 \%$ & 3590,11 & 164,8 & 25,97 \\
4 & 161,4 & 161,79 & $52,08 \%$ & 3161,23 & 163,97 & $1103,45 \%$ & 3377,75 & 161,4 & 26,12 \\
\hline
\end{tabular}

respectivas soluções dos problemas seriais, com uma melhoria média de 3,25\%. Em seis instâncias a solução ótima do colaborativo utilizava mais de um trabalhador em alguma 
estação, sendo que quatro destas apresentaram uma redução média do tempo de ciclo de 24,63\%. Uma das soluções encontradas apresentou uma redução de $43 \%$ no tempo de ciclo em relação ao problema serial.

Para a família Heskia apenas duas instâncias apresentaram uma solução ótima paralela com tempo de ciclo igual à solução ótima serial. Da mesma forma, apenas uma solução ótima do colaborativo alocou mais de um trabalhador em algum estágio. Nenhuma destas soluções apresentou melhoria em relação ao tempo de ciclo da solução ótima do problema serial.

Para a família Roszieg mod 1, 15 instâncias apresentaram solução ótima utilizando paralelismo, com 7 destas apresentando um tempo de ciclo em média 3,44\% melhor. Quatro instâncias apresentaram soluções ótimas utilizando mais de um trabalhador em um mesmo estágio para o ALWABP colaborativo, sendo que duas destas apresentaram melhoria média de $7,03 \%$.

Para a família Heskia mod 1 o modelo obteve 14 soluções ótimas utilizando paralelismo, sendo que 5 destas apresentaram uma melhoria de 1,56\% em média. Os testes também mostraram que os dois trabalhadores idênticos (isto é, o segundo e o último de cada instância) tendiam a ficar no mesmo estágio nas soluções ótimas que utilizavam paralelismo. O ALWABP colaborativo não conseguiu encontrar soluções utilizando mais de um trabalhador em um mesmo estágio para esta família.

As famílias Heskia mod 2 e Roszieg mod 2 mostram a complexidade do ALWABP com estações em paralelo. O tempo médio de execução das instâncias aumentou entre 15 e 30 vezes através da adição de apenas um trabalhador. Para a família Roszieg mod 2, não foi possível provar a otimalidade da solução em 5 instâncias para $K_{\text {Max }}=2$ e 6 para $K_{\text {Max }}=3$. Foi possível encontrar soluções cujos tempos de ciclo são menores que as respectivas soluções ótimas para o ALWABP serial em 11 instâncias. Em 9 instâncias o ALWABP colaborativo conseguiu encontrar soluções utilizando mais de um trabalhador em um mesmo estágio, sendo que 7 destas apresentaram uma redução no tempo de ciclo de 25,53\% em relação à solução ótima do problema serial. Duas das instâncias apresentaram soluções cujos de tempo de ciclo correspondiam à metade do tempo de ciclo das soluções ótimas do problema serial para as respectivas instâncias.

Para a família Heskia mod 2, não foi possível provar a otimalidade da solução de 20 instâncias para $K_{\text {Max }}=2$ e 22 para $K_{\text {Max }}=3$. Mesmo assim, foram encontradas soluções cujos tempos de execução são melhores que os tempos de execução das soluções ótimas para o ALWABP serial em 20 instâncias utilizando $K_{\text {Max }}=2$ e 18 utilizando $K_{\text {Max }}=3$. 
Uma das instâncias desta família apresentou uma melhoria de 13,4\% em relação à solução ótima do ALWABP serial. Para esta família, o ALWABP colaborativo não conseguiu encontrar soluções utilizando mais de um trabalhador em um mesmo estágio.

Para problemas maiores, o tempo de execução cresce muito rápido. Problemas com 6 trabalhadores chegaram a executar por mais de uma hora sem encontrar a solução ótima.

\subsection{Testes com as heurísticas construtivas}

As heurísticas descritas nas sessões 5.3 e 5.4 foram implementadas em $\mathrm{C}++$ utilizando o Visual Studio 2008. Foram implementadas oito regras de prioridade para as tarefas, que foram combinadas com nove regras de seleção de trabalhadores. Foram utilizadas as quatro famílias de instâncias definidas por Chaves et al. ${ }^{[14]}$. As características destas instâncias podem ser vistas na tabela 9. As colunas $|\mathrm{N}|$ e $|\mathrm{W}|$ indicam, respectivamente, o número de tarefas e o número de trabalhadores em cada instância. A coluna Var indica o nível de variabilidade dos tempos de execução em relação ao tempo do primeiro trabalhador, em que L1 corresponde a uma variabilidade baixa (entre 1 e $p_{1 i}$ para cada tarefa $i$ ) e H3 corresponde a uma variabilidade alta (entre 1 e $3 p_{1 i}$ para cada tarefa $i$ ) ${ }^{[14]}$. A coluna Inc indica o percentual de incompatibilidade trabalhador/tarefa, em que I10 corresponde a $10 \%$ e I20 corresponde a 20\%. A coluna Order strength corresponde à fração do número de relações de precedência comparado com o máximo valor possível.

\begin{tabular}{|c|c|c|c|c|c|}
\multicolumn{1}{c|}{ Tabela 9: Características das instâncias } \\
\hline Família & $|\mathbf{N}|$ & $|\mathbf{W}|$ & Var & Inc & Order strength \\
\hline Roszieg & 25 & $4 ; 6$ & L1;H3 & I10;I20 & 71,67 \\
Heskia & 28 & $4 ; 7$ & L1;H3 & I10;I20 & 22,49 \\
Tonge & 70 & $10 ; 17$ & L1;H3 & I10;I20 & 59,42 \\
Wee-mag & 75 & $11 ; 19$ & L1;H3 & I10;I20 & 22,67 \\
\hline
\end{tabular}

Além disso, fizemos testes com as quatro famílias de instâncias modificadas. As sessões a seguir relatam de forma resumida os resultados obtidos por estas heurísticas. Resultados mais detalhados podem ser vistos no Apêndice A.

\subsubsection{Heurística para o ALWABP com estações em paralelo}

As tabelas 10 e 11 apresentam os resultados obtidos pela heurística para o ALWABP com estações em paralelo, utilizando $K_{\text {Max }}=2$ e $K_{\text {Max }}=3$, respectivamente. Os resultados representam uma média entre todas as instâncias testadas. Cada linha representa uma 
regra de seleção de trabalhadores, associada à melhor regra de prioridade para as tarefas. A coluna Gap indica a distância, em média, entre a solução encontrada pela heurística e a melhor solução conhecida para o problema serial. A coluna Soluções paralelas indica o percentual de soluções encontradas que utiliza paralelismo. A coluna Maior melhoria indica a maior melhoria em relação às melhores soluções conhecidas para o problema serial. Por fim, a coluna Tempo indica o tempo médio de execução da heurística, em segundos.

Tabela 10: Resultados dos testes com a heurística para o ALWABP com estações em paralelo utilizando $K_{\text {Max }}=2$

\begin{tabular}{|l|r|r|r|r|}
\hline Regra & Gap & Soluções paralelas & Maior melhoria & Tempo (s) \\
\hline MaxTasks1 + MaxPWD- & $50,85 \%$ & $90,21 \%$ & $8,47 \%$ & 6,78 \\
MaxTasks1.2 + MinD & $38,67 \%$ & $81,88 \%$ & $13,96 \%$ & 0,30 \\
MaxTasks1.4 + MinR & $27,92 \%$ & $70,21 \%$ & $15,08 \%$ & 0,27 \\
MaxTasks1.6 + MaxPWD- & $23,12 \%$ & $59,79 \%$ & $14,29 \%$ & 0,58 \\
MaxTasks1.8 + MinPWD- & $21,10 \%$ & $41,25 \%$ & $14,29 \%$ & 0,57 \\
MaxTasks2 + MaxPWD- & $19,93 \%$ & $18,54 \%$ & $14,29 \%$ & 5,75 \\
MaxTasks3 + MaxPWD- & $19,24 \%$ & $4,79 \%$ & $13,49 \%$ & 5,81 \\
MaxTasksK + MaxPWD- & $19,52 \%$ & $10,00 \%$ & $13,49 \%$ & 5,81 \\
MinRLB + MaxPWD- & $14,92 \%$ & $28,54 \%$ & $14,29 \%$ & 6,37 \\
\hline
\end{tabular}

Tabela 11: Resultados dos testes com a heurística para o ALWABP com estações em paralelo utilizando $K_{\text {Max }}=3$

\begin{tabular}{|l|r|r|r|r|}
\hline Regra & Gap & Soluções paralelas & Maior melhoria & Tempo (s) \\
\hline MaxTasks1 + MaxPWD- & $68,02 \%$ & $90,21 \%$ & $4,76 \%$ & 28,78 \\
MaxTasks1.2 + MinD & $57,59 \%$ & $75,04 \%$ & $10,41 \%$ & 1,51 \\
MaxTasks1.4 + MinD & $41,23 \%$ & $52,96 \%$ & $11,70 \%$ & 1,34 \\
MaxTasks1.6 + MinR & $31,88 \%$ & $39,74 \%$ & $12,05 \%$ & 1,25 \\
MaxTasks1.8 + MinR & $26,83 \%$ & $31,59 \%$ & $12,05 \%$ & 1,19 \\
MaxTasks2 + MaxPWD- & $24,75 \%$ & $29,17 \%$ & $0,00 \%$ & 23,68 \\
MaxTasks3 + MaxPWD- & $20,17 \%$ & $7,29 \%$ & $0,00 \%$ & 22,71 \\
MaxTasksK + MaxPWD- & $21,02 \%$ & $10,21 \%$ & $0,00 \%$ & 22,68 \\
MinRLB + MaxPWD- & $14,91 \%$ & $28,75 \%$ & $2,65 \%$ & 24,60 \\
\hline
\end{tabular}

Regra MaxTasks1 encontrou o maior número de soluções utilizando paralelismo. No entanto, as soluções encontradas foram, em geral, de baixa qualidade. Para a maioria das regras de seleção de trabalhadores, a regra MaxPWD- encontrou as melhores soluções em média. A combinação desta regra com a regra MinRLB encontrou as melhores soluções em média, chegando a um gap médio de $14,92 \%$ para $K_{\text {Max }}=2$ e $14,92 \%$ para $K_{\text {Max }}=3$. O tempo de execução da heurística utilizando as regras MaxPWD- e MaxPWD + foi muito superior às demais, em alguns casos chegando a mais de 20 vezes o tempo de execução da heurística utilizando as demais regras. Em vista disto, optamos por não utilizar estas regras nos testes seguintes. 


\subsubsection{Testes com as heurísticas modificadas}

As tabelas 12 e 13 apresentam os resultados obtidos pelas heurísticas modificadas para o ALWABP com estações em paralelo, utilizando $K_{\text {Max }}=2$ e $K_{\text {Max }}=3$, respectivamente. Os resultados representam uma média entre todas as instâncias testadas. Cada linha representa uma heurística. A coluna Gap indica a distância, em média, entre as melhores soluções encontradas pela heurística (entre todas as combinações de regras) e as melhores soluções conhecidas para o problema serial. A coluna Soluções paralelas indica o percentual de soluções encontradas que utiliza paralelismo. A coluna Maior melhoria indica a maior melhoria em relação às melhores soluções conhecidas para o problema serial. Por fim, a coluna Tempo indica o tempo médio de execução da heurística, em segundos.

Tabela 12: Resultados dos testes com as heurísticas modificadas para o ALWABP com estações em paralelo utilizando $K_{\operatorname{Max}}=2$

\begin{tabular}{|l|r|r|r|r|}
\hline Heurística & Gap & Soluções paralelas & Maior melhoria & Tempo (s) \\
\hline P1 & $34,21 \%$ & $75,73 \%$ & $20,63 \%$ & 0,57 \\
P2 & $21,21 \%$ & $99,30 \%$ & $20,63 \%$ & 0,62 \\
PS & $16,62 \%$ & $100,00 \%$ & $16,73 \%$ & 0,83 \\
PW & $16,27 \%$ & $100,00 \%$ & $20,63 \%$ & 1,50 \\
\hline
\end{tabular}

Tabela 13: Resultados dos testes com as heurísticas modificadas para o ALWABP com estações em paralelo utilizando $K_{\text {Max }}=3$

\begin{tabular}{|l|r|r|r|r|}
\hline Heurística & Gap & Soluções paralelas & Maior melhoria & Tempo (s) \\
\hline P1 & $36,72 \%$ & $76,59 \%$ & $20,63 \%$ & 1,50 \\
P2 & $23,84 \%$ & $99,32 \%$ & $20,63 \%$ & 1,52 \\
PS & $18,04 \%$ & $97,97 \%$ & $20,63 \%$ & 1,87 \\
PW & $17,35 \%$ & $100,00 \%$ & $20,63 \%$ & 3,55 \\
\hline
\end{tabular}

Entre as heurísticas modificadas, a heurística PW obteve as melhores soluções, em média, atingindo um gap médio de $16,27 \%$ para $K_{\text {Max }}=2$ e $17,25 \%$ para $K_{\text {Max }}=3$. Esta heurística foi capaz de resolver todas as instâncias, utilizando todos os critérios. O tempo de execução desta heurística foi superior ao tempo de execução das demais.

\subsubsection{Heurística para o ALWABP colaborativo}

As tabelas 14 e 14 apresentam os resultados obtidos pela heurística para o ALWABP colaborativo, utilizando $K_{M a x}=2$ e $K_{M a x}=3$, respectivamente. Os resultados representam uma média entre todas as instâncias testadas. Cada linha representa uma regra de seleção de trabalhadores, associada à melhor regra de prioridade para as tarefas. A coluna 
Gap indica a distância, em média, entre a solução encontrada pela heurística e a melhor solução conhecida para o problema serial. A coluna Soluções colaborativas indica o percentual de soluções encontradas que utiliza colaboração. A coluna Maior melhoria indica a maior melhoria em relação às melhores soluções conhecidas para o problema serial. Por fim, a coluna Tempo indica o tempo médio de execução da heurística, em segundos.

Tabela 14: Resultados dos testes com a heurística para o ALWABP colaborativo utilizando $K_{\operatorname{Max}}=2$

\begin{tabular}{|l|r|r|r|r|}
\hline Regra & Gap & Soluções colaborativas & Maior melhoria & Tempo (s) \\
\hline MaxTasks1 + MinD & $53,80 \%$ & $96,04 \%$ & $46,77 \%$ & 0,29 \\
MaxTasks1.2 + MinD & $41,84 \%$ & $81,88 \%$ & $50,00 \%$ & 0,27 \\
MaxTasks1.4 + MinD & $29,79 \%$ & $63,54 \%$ & $46,77 \%$ & 0,25 \\
MaxTasks1.6 + MinR & $23,18 \%$ & $47,92 \%$ & $50,00 \%$ & 0,25 \\
MaxTasks1.8 + MinR & $21,31 \%$ & $36,88 \%$ & $50,00 \%$ & 0,25 \\
MaxTasks2 + MinR & $19,96 \%$ & $23,13 \%$ & $50,00 \%$ & 0,25 \\
MaxTasks3 + MinR & $20,78 \%$ & $7,29 \%$ & $50,00 \%$ & 0,26 \\
MaxTasksK + MinR & $19,83 \%$ & $16,04 \%$ & $50,00 \%$ & 0,25 \\
MinRLB + MinR & $16,79 \%$ & $39,79 \%$ & $46,77 \%$ & 0,40 \\
\hline
\end{tabular}

Tabela 15: Resultados dos testes com a heurística para o ALWABP colaborativo utilizando $K_{\text {Max }}=3$

\begin{tabular}{|l|r|r|r|r|}
\hline Regra & Gap & Soluções colaborativas & Maior melhoria & Tempo (s) \\
\hline MaxTasks1 + MinD & $74,12 \%$ & $97,71 \%$ & $46,77 \%$ & 1,42 \\
MaxTasks1.2 + MinD & $64,81 \%$ & $87,29 \%$ & $50,00 \%$ & 1,39 \\
MaxTasks1.4 + MinD & $49,36 \%$ & $68,33 \%$ & $46,77 \%$ & 1,27 \\
MaxTasks1.6 + MinD & $40,19 \%$ & $55,83 \%$ & $45,45 \%$ & 1,24 \\
MaxTasks1.8 + MinR & $32,81 \%$ & $47,08 \%$ & $45,45 \%$ & 1,20 \\
MaxTasks2 + MinR & $26,09 \%$ & $32,29 \%$ & $50,00 \%$ & 1,16 \\
MaxTasks3 + MinR & $21,62 \%$ & $9,79 \%$ & $50,00 \%$ & 1,18 \\
MaxTasksK + MinR & $19,87 \%$ & $16,04 \%$ & $50,00 \%$ & 1,13 \\
MinRLB + MinR & $16,68 \%$ & $39,79 \%$ & $46,77 \%$ & 1,81 \\
\hline
\end{tabular}

A regra MinRLB encontrou as melhores soluções, em média, para ambos os valores de $K_{\text {Max }}$. O gap médio obtido por essa regra, quando combinada com a regra MinR, foi de $16,79 \%$ para $K_{M a x}=2$ e de $16,68 \%$ para $K_{M a x}=3$. A heurística conseguiu encontrar soluções com melhorias de até $50 \%$ em um tempo computacional baixo (cerca de $1 \mathrm{~s}$ ).

\subsubsection{Testes com as heurísticas modificadas}

As tabelas 16 e 17 apresentam os resultados obtidos pelas heurísticas modificadas para o ALWABP colaborativo, utilizando $K_{\text {Max }}=2$ e $K_{\text {Max }}=3$, respectivamente. Os resultados representam uma média entre todas as instâncias testadas. Cada linha representa uma heurística. A coluna Gap indica a distância, em média, entre as melhores soluções encontradas pela heurística (entre todas as combinações de regras) e as melhores soluções 
conhecidas para o problema serial. A coluna Soluções colaborativas indica o percentual de soluções encontradas que utiliza colaboração. A coluna Maior melhoria indica a maior melhoria em relação às melhores soluções conhecidas para o problema serial. Por fim, a coluna Tempo indica o tempo médio de execução da heurística, em segundos.

Tabela 16: Resultados dos testes com as heurísticas modificadas para o ALWABP colaborativo utilizando $K_{\operatorname{Max}}=2$

\begin{tabular}{|l|r|r|r|r|}
\hline Heurística & Gap & Soluções colaborativas & Maior melhoria & Tempo (s) \\
\hline C1 & $21,57 \%$ & $85,83 \%$ & $50,00 \%$ & 0,34 \\
C2 & $19,72 \%$ & $99,63 \%$ & $50,00 \%$ & 0,33 \\
CS & $16,28 \%$ & $100,00 \%$ & $50,00 \%$ & 0,69 \\
CW & $11,25 \%$ & $77,47 \%$ & $50,00 \%$ & 0,95 \\
\hline
\end{tabular}

Tabela 17: Resultados dos testes com as heurísticas modificadas para o ALWABP colaborativo utilizando $K_{\operatorname{Max}}=3$

\begin{tabular}{|l|r|r|r|r|}
\hline Heurística & Gap & Soluções colaborativas & Maior melhoria & Tempo (s) \\
\hline C1 & $22,70 \%$ & $81,28 \%$ & $50,00 \%$ & 1,48 \\
C2 & $20,36 \%$ & $99,61 \%$ & $50,00 \%$ & 1,47 \\
CS & $17,22 \%$ & $100,00 \%$ & $47,73 \%$ & 1,64 \\
CW & $11,84 \%$ & $78,73 \%$ & $50,00 \%$ & 3,25 \\
\hline
\end{tabular}

A heurística CW encontrou as melhores soluções, em média, com gap de 11,25\% para $K_{\text {Max }}=2$ e $11,84 \%$ para $K_{\text {Max }}=3$. No entanto, esta heurística não foi capaz de resolver todas as instâncias utilizando todas as combinações de regras. A heurística CS foi capaz de resolver todas as instâncias utilizando todas as combinações de critérios, porém a qualidade média das melhores soluções obtidas por esta heurística foi menor.

\subsubsection{Comentários gerais sobre os resultados}

Entre as combinações de regras utilizadas, a combinação das regras MinRLB e MinR encontrou as melhores soluções, em média, para a maioria das famílias testadas. As regras MaxPWD + e MaxPWD- inicialmente encontraram boas soluções, porém o seu tempo de execução elevado as torna seu uso inviável em métodos mais sofisticados.

Para as instâncias de pequeno porte, as heurísticas básicas para o ALWABP com estações em paralelo e para o ALWABP colaborativo conseguiram encontrar soluções muito próximas às soluções ótimas para o ALWABP serial, sendo que em alguns casos foram encontradas soluções com tempo de ciclo menor do que as soluções ótimas para o problema serial. Para instâncias de médio e grande porte, a heurística conseguiu encontrar boas soluções, que podem ser utilizadas em uma futura meta-heurística. 
Os testes forçando o paralelismo mostraram que modificações nas heurísticas podem levar a novas soluções melhores do que aquelas encontradas pelas heurísticas básicas. Em especial, para instâncias de médio e grande porte, a heurística PS conseguiu encontrar soluções melhores do que aquelas encontradas pela heurística básica para o ALWABP com estações em paralelo. 


\section{Conclusões e Passos futuros}

Neste trabalho, apresentamos duas extensões para o problema ALWABP. A primeira permite o uso de estações paralelas, enquanto que a segunda permite que dois ou mais trabalhadores executem tarefas sobre um mesmo produto, suprindo as dificuldades um do outro. Para cada extensão um modelo linear foi desenvolvido e testado em instâncias de pequeno porte. Os resultados indicaram que a introdução de trabalhadores em paralelo, bem como o a introdução de mais de um trabalhador por estação de trabalho, pode ser benéfica, mesmo em situações onde os trabalhadores são completamente distintos uns dos outros, como no caso estudado.

Uma análise dos resultados obtidos pelas instâncias modificadas mostrou que o uso paralelismo permite obter soluções melhores, em especial em casos em que alguns trabalhadores possuem deficiências semelhantes e em casos em que alguns trabalhadores são pouco eficientes. Já o uso de colaboração conseguiu obter melhores soluções em casos em que os tempos de execução dos trabalhadores são bastante distintos.

Para cada uma das extensões foram desenvolvidas heurísticas construtivas. As heurísticas encontraram soluções muito próximas das soluções ótimas para instâncias de pequeno porte. Para instâncias de médio e grande porte, as soluções encontradas pelas heurísticas tem grande potencial para serem utilizadas em futuras meta-heurísticas.

Estes resultados são particularmente interessantes em CTD's, pois permitem o emprego de trabalhadores relativamente bem mais lentos sem penalizar de maneira excessiva a taxa de produção da linha (como seria o caso em configurações seriais). Tais resultados incentivam a continuação desta linha de pesquisa, focando-se possivelmente em métodos heurísticos que permitam a resolução de instâncias maiores, uma vez que é justamente nestas instâncias onde espera-se obter os maiores ganhos devido a flexibilização de layout proposta.

De fato, acreditamos que a grande contribuição desta dissertação é mostrar que layouts alternativos podem ser de grande valia no contexto de balanceamento de linhas de produ- 
ção com trabalhadores deficientes. Em alguns casos testados, a possibilidade de se usar o ALWABP paralelo ou o ALWABP colaborativo permitiu-se atingir acréscimos de até $20 \%$ e $50 \%$ de eficiência, respectivamente. Estes resultados abrem portas para novos estudos, envolvendo desenvolvimentos teóricos e também de ordem prática, como os listados na seção seguinte.

\subsection{Trabalhos futuros}

A formulação para o ALWABP com estações em paralelo mostrou-se pouco eficiente, sendo capaz de resolver de forma exata apenas instâncias muito pequenas. Uma inspeção durante a resolução das instâncias revelou que a solução inicial obtida pelo modelo está muito distante da solução real do problema. Isto mostra que o modelo desenvolvido está muito distante da envoltória convexa do problema. Uma formulação mais forte se faz necessária para resolver instâncias maiores de forma exata. Um passo inicial seria desenvolver limitantes para o nível máximo de paralelismo (parâmetro $K_{\text {Max }}$ ). Testes iniciais mostraram que valores menores de $K_{M a x}$ podem reduzir o tempo de execução em até $50 \%$.

Em relação às heurísticas desenvolvidas, um fato interessante é que elas podem ser utilizadas para gerar soluções para meta-heurísticas. O aumento na qualidade das soluções observado em instâncias de médio e grande porte, com algumas das heurísticas modificadas é um indício que uma meta-heurística GRASP pode ser bastante viável para ambos os problemas.

A flexibilidade obtida com as duas extensões pode também ser útil para o problema de rotação de tarefas ${ }^{[18]}$. Conforme dito na seção 2.3 , o uso de paralelismo permite que os trabalhadores executem conjuntos de tarefas com tempo total maior que o tempo de ciclo, o que de outro modo poderia reduzir consideravelmente a eficiência da linha de produção. Isto permite que o trabalhador execute tarefas que de outro modo não executaria, por ser pouco eficiente para estas tarefas ou por existir outro trabalhador capaz de executá-las mais rapidamente. Por outro lado, o ALWABP colaborativo permite que um trabalhador execute uma maior variedade de combinações de tarefas, uma vez que as tarefas que ele não consegue executar podem ser realizadas por outros trabalhadores. Os testes mostraram que as tarefas que um trabalhador executa nas soluções para ambas as extensões costumam ser bem diferentes daquelas que ele executa na solução serial. Com isto, temos uma maior variedade de tarefas executadas pelo trabalhador, com pouca 
ou nenhuma perda de desempenho da linha de produção, o que é de extrema importância para o problema de rotação de tarefas. 


\section{Referências Bibliográficas}

1 Retratos da deficiência no brasil, 2003. Disponível em: http://www.fgv.br/cps/deficiencia_br/PDF/PPD_Sumario_Executivo.pdf, acesso em 26 de janeiro de 2010.

2 SimOnelli, A. P.; DA SIlva RODRIGUES, D.; SOARES, L. Caracterização do perfil de trabalhadores afastados e de pessoas com deficiência no mercado de trabalho do municipio de são carlos. In: . c2006.

3 SIMONELLI, A. P. Contribuições da análise da atividade e do modelo social para a inclusão no trabalho de pessoas com deficiência. 2009. Tese de Doutorado - Universidade Federal de São Carlos, 2009.

4 MiRAlleS, C.; GARCIA-SABATER, J. P.; ANDRéS, C.; CARDOS, M. Advantages of assembly lines in sheltered work centres for disabled. International Journal of Production Economics, v. 110, p. 187-197, 2007.

5 MOREIRA, M. C. O.; COSTA, A. M. Simple heuristics for the assembly line and worker assignment balancing problem. Working Paper, 2009.

6 BECKER, C.; SCHOLL, A. A survey on methods in generalized assembly line balancing. European Journal of Operational Research, v. 168, p. 694-715, 2006.

7 BAYBARS, I. A survey of exact algorithms for the simple assembly line balancing problem. Management Science, v. 32, p. 909-932, 1986.

8 BOYSEN, N.; FLIEDNER, M.; SCHOLL, A. A classification of assembly line balancing problem. European Journal of Operational Research, v. 183, p. 674-693, 2007.

9 BOYSEN, N.; FLIEDNER, M.; SCHOLL, A. Assembly line balancing: Which model to use and when? International Journal of Production Economics, v. 111, p. 509-528, 2008.

10 AMEN, M. Heuristic methods for cost-oriented assembly line balancing: A survey. International Journal of Production Economics, v. 68, p. 1-14, 2000.

11 AMEN, M. Heuristic methods for cost-oriented assembly line balancing: A comparison on solution quality and computing time. International Journal of Production Economics, v. 69, p. 255-264, 2001.

12 AMEN, M. Cost-oriented assembly line balancing: Model formulations, solution difficulty, upper and lower bounds. European Journal of Operational Research, v. 168, p. $747-770,2006$. 
13 CHAVES, A. A. Uma metaheurística híbrida de busca por agrupamentos aplicada a problemas de otimização combinatória. 2009. Tese de Doutorado - Instituto Nacional de Pesquisas Espaciais, 2009.

14 CHAVES, A. A.; MiRAlleS, C.; LORENA, L. A. N. Clustering search approach for the assembly line worker assignment and balancing problem. International Conference on Computers and Industrial Engineering, v. 37, p. 10, 2007.

15 ChaveS, A. A.; LORENA, L. A. N.; MIRAllES, C. Hybrid metaheuristic for the assembly line worker assignment and balancing problem. Lecture Notes on Computer Science, v. 5818, p. 1-14, 2008.

16 MOREIRA, M. C. O.; COSTA, A. M. A minimalist yet efficient tabu search algorithm for balancing assembly lines wirh disabled workers, 2009.

17 SCHOLL, A.; VOSS, S. Simple assembly line balancing - heuristic approaches. Journal of Heuristics, v. 2, p. 217-244, 1996.

18 COSTA, A. M.; MIRALlES, C. Job rotation in assembly lines employing disabled workers. International Journal of Production Economics, v. 120, p. 625-632, 2009.

19 BECKER, C.; SCHOLL, A. Balancing assembly lines with variable parallel workplaces: Problem definition and effective solution procedure. European Journal of Operational Research, v. 199, p. 359-374, 2009.

20 BOYSEN, N.; FLIEDNER, M. A versatile algorithm for assembly line balancing. European Journal of Operational Research, v. 184, p. 39-56, 2006.

21 BUKCHIN, J.; RUBINOVITZ, J. A weightened approach for assembly line design with station paralleling and equipment selection. IIE Transactions, v. 35, p. 73-85, 2003.

22 EGE, Y.; AZIZOGLU, M.; OZDEMIREL, N. E. Assembly line balancing with station paralleling. Computers \& Industrial Engineering, v. 57, p. 1218-1225, 2009.

23 PLEBANI, L. J.; CHEN, S. Balancing u-shaped assembly lines with parallel stations. Technical report, Lehigh University, 2006.

24 SüER, G. A. Designing parallel assembly lines. Computers $\&$ industrial engineering, v. 35, p. $467-470,1998$.

25 TIACCI, L.; SAETTA, S. Process-oriented simulation for mixed-model assembly lines, 2007.

26 MCMUllen, P. R.; FRAZIER, G. V. A heuristic for solving mixed-model line balancing problems with stochastic task durations and parallel stations. International Journal of Production Economics, v. 51, p. 177-190, 1997.

27 GAITHER, N. Production and operations management. 7. ed. Duxbury Press, 1996.

28 SIMARIA, A. S.; VILARINHO, P. M. A genetic algorithm based approach to the mixed-model assembly line balancing problem of type ii. Computers $\mathscr{G}$ Industrial Engineering, v. 47, p. 391-407, 2004. 
29 ARAúJO, F. F. B.; COSTA, A. M.; MIRAlleS, C. Balanceando linhas de produção com trabalhadores deficientes e estações paralelas, 2010.

30 ARAÚJO, F. F. B.; COSTA, A. M.; MIRALlES, C. Extensão do problema alwabp: melhorando a flexibilidade através de estações paralelas, 2010.

31 ARAÚJO, F. F. B.; COSTA, A. M. A linear model for the assembly line and worker assignment balancing problem with parallel workstations, 2010.

32 SCHOLL, A.; BECKER, C. State-of-the-art exact and heuristic solution procedures for simple assembly line balancing. European Journal of Operational Research, v. 168, p. 666-693, 2006. 


\section{APÊNDICE A - Resultados detalhados dos testes computacionais}

As tabelas a seguir apresentam, de forma detalhada, os resultados obtidos pelas heurísticas nas sessões 5.3 e 5.4 .

\section{A.1 Heurística para o ALWABP com estações em pa- ralelo}

As tabelas a seguir apresentam de forma resumida os resultados obtidos pela heurística para o ALWABP com estações em paralelo. Cada linha representa uma regra de prioridade para as tarefas, enquanto que cada coluna representa uma regra de seleção de trabalhadores. Cada coluna está dividida em duas colunas menores. A coluna C\% indica a distância, em média, entre a solução encontrada pela heurística e a melhor solução conhecida na literatura para o ALWABP serial. Já a coluna T indica o tempo médio de execução da heurística, em milisegundos.

As tabelas 18, 19, 20 e 21 apresentam, respectivamente, os resultados obtidos para as famílias Roszieg, Heskia, Tonge e Wee-mag. Além disso, as tabelas 22, 23, 24 e 25 apresentam os resultados obtidos para as famílias Roszieg mod 1, Roszieg mod 2, Heskia mod 1 e Heskia mod 2, respectivamente. A combinação de critérios que obteve os melhores resultados é destacada em negrito para cada família de instâncias.

Para a família Roszieg, o critério MinR combinado com os critérios MaxTasks2, MaxTasks3 e MaxTasksK encontrou os melhores resultados, em relação ao tempo de ciclo, para $K_{M a x}=2$. Para $K_{\text {Max }}=3$ o critério MinR também encontrou bons resultados quando combinado com MaxTasksK e MaxTasks3. Para $K_{M a x}=2$, as melhores soluções encontradas entre todas as combinações de critérios estavam, em média, a 2,73\% da melhor solução conhecida para o ALWABP serial, sendo que em uma das instâncias conseguimos encontrar uma solução 1,62\% melhor do que a melhor solução para o ALWABP serial. 


\begin{tabular}{|c|c|c|c|c|c|c|c|c|c|c|c|c|c|c|c|}
\hline 焉 & 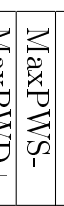 & 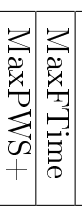 & & & & & 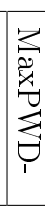 & 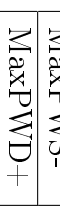 & & & & & & & \\
\hline $\begin{array}{lll}0 \\
0 \\
0\end{array}$ & & & {$\left[\begin{array}{l}\infty \\
\infty \\
d\end{array}\right.$} & & & & $\mid \begin{array}{l}\tilde{0} \\
0 \\
0 \\
\partial \\
0\end{array}$ & 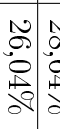 & $\begin{array}{ll}0 \\
0 \\
0\end{array}$ & & & & & & \\
\hline & & 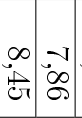 & $\mid$ & & & & 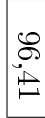 & 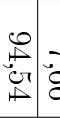 & 5 & & & & & & \\
\hline & & 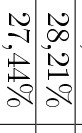 & $\begin{array}{l}1 \\
\infty \\
0 \\
0 \\
0 \\
\partial \\
\partial\end{array}$ & & & & $\begin{array}{l}1 \\
\text { No } \\
\mathbb{D} \\
0 \\
0 \\
0\end{array}$ & 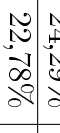 & \begin{tabular}{c|c}
0 \\
0 \\
0 \\
0
\end{tabular} & & & di & & & \\
\hline & & & 。 & & & & $\begin{array}{l}0 \\
0 \\
1 \\
ث \\
\bullet\end{array}$ & 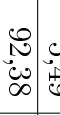 & $\overrightarrow{0}$ & & & î & $\overrightarrow{.}$ & & \\
\hline $\begin{array}{ll}1 \\
7\end{array}$ & 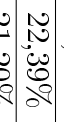 & 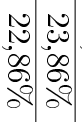 & 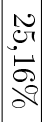 & & & & $\begin{array}{l}\vec{a} \\
\vec{\infty} \\
\dot{\alpha} \\
\partial 8\end{array}$ & 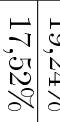 & $\begin{array}{ll}\vec{b} \\
0 \\
0\end{array}$ & & & & & & \\
\hline & 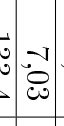 & & $\begin{array}{l}0 \\
\ddot{\theta} \\
\bullet\end{array}$ & & & & $\begin{array}{l}\infty \\
\infty \\
0 \\
0 \\
-0 \\
\end{array}$ & نْ & 9 & อै & & 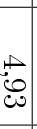 & $\frac{\pi}{5}$ & & \\
\hline & & 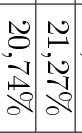 & \begin{tabular}{|c|}
0 \\
0 \\
0 \\
0 \\
0 \\
$\partial$ \\
$\partial$
\end{tabular} & 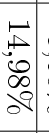 & & & 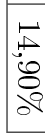 & 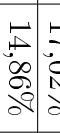 & $\begin{array}{lll}4 & = \\
b & =\end{array}$ & & 5 & 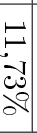 & $\begin{array}{l}0 \\
0 \\
\text { s. } \\
\text { s. }\end{array}$ & & \\
\hline قد & & & $\infty$ & : & & & $\begin{array}{l}\mathscr{8} \\
\infty \\
\infty \\
\infty\end{array}$ & 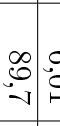 & 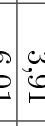 & 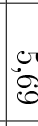 & & $\stackrel{8}{8}$ & s. & & \\
\hline & 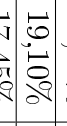 & 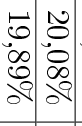 & $\mid$\begin{tabular}{|c}
$\overrightarrow{0}$ \\
0 \\
0 \\
0 \\
$\partial$ \\
$\partial$
\end{tabular} & 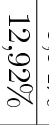 & & & 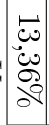 & 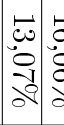 & $\begin{array}{ll}a \\
0 \\
0\end{array}$ & • & $\overrightarrow{e r}$ & $\partial^{\infty}$ & 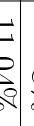 & & \\
\hline 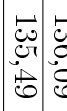 & & 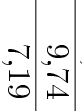 & $\mid$ & & & & 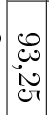 & 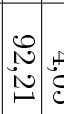 & 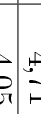 & 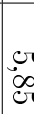 & & هِنْ & 省 & & \\
\hline 8 & 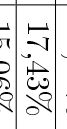 & 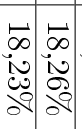 & 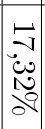 & & & & 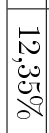 & 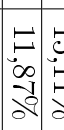 & 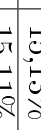 & 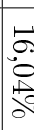 & - & do & 5 & & \\
\hline 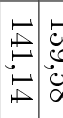 & & & $\begin{array}{l}0 \\
0 \\
0 \\
0 \\
0\end{array}$ & & & & 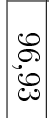 & 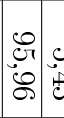 & $\vec{c}$ & $\vec{\perp}$ & $\overrightarrow{6}$ & 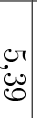 & ه.: & & \\
\hline 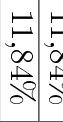 & 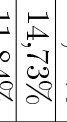 & 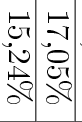 & 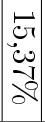 & 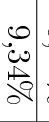 & & & 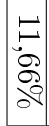 & 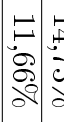 & & & - &. & & & \\
\hline$\because \check{a}$ & & & {$\left[\begin{array}{l}\infty \\
0 \\
0\end{array}\right]$} & 0 & & & 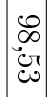 & \begin{tabular}{c|c}
0 \\
0 \\
\hdashline & 0 \\
$\infty$ & 0 \\
0
\end{tabular} & 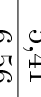 & ठ̊. & $\infty$ & cr & & 3 & \\
\hline 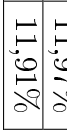 & 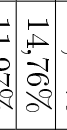 & 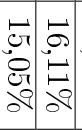 & 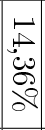 & & & & 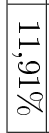 & 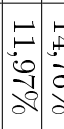 & âd & 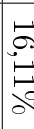 & & 0 & & & \\
\hline 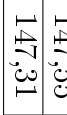 & & & 苑 & 0 & & & $\mid \begin{array}{l}0 \\
0 \\
0 \\
0 \\
0 \\
\end{array}$ & 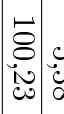 & & & & & & & \\
\hline da & $\begin{array}{ll}0 \\
0 \\
\vdots \\
8\end{array}$ & 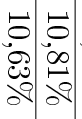 & & & & & 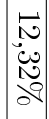 & 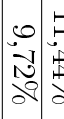 & & & & & & & \\
\hline 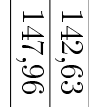 & 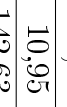 & & & & & & $\mid \begin{array}{l}8 \\
: \\
0 \\
0\end{array}$ & & & & & & & & \\
\hline
\end{tabular}




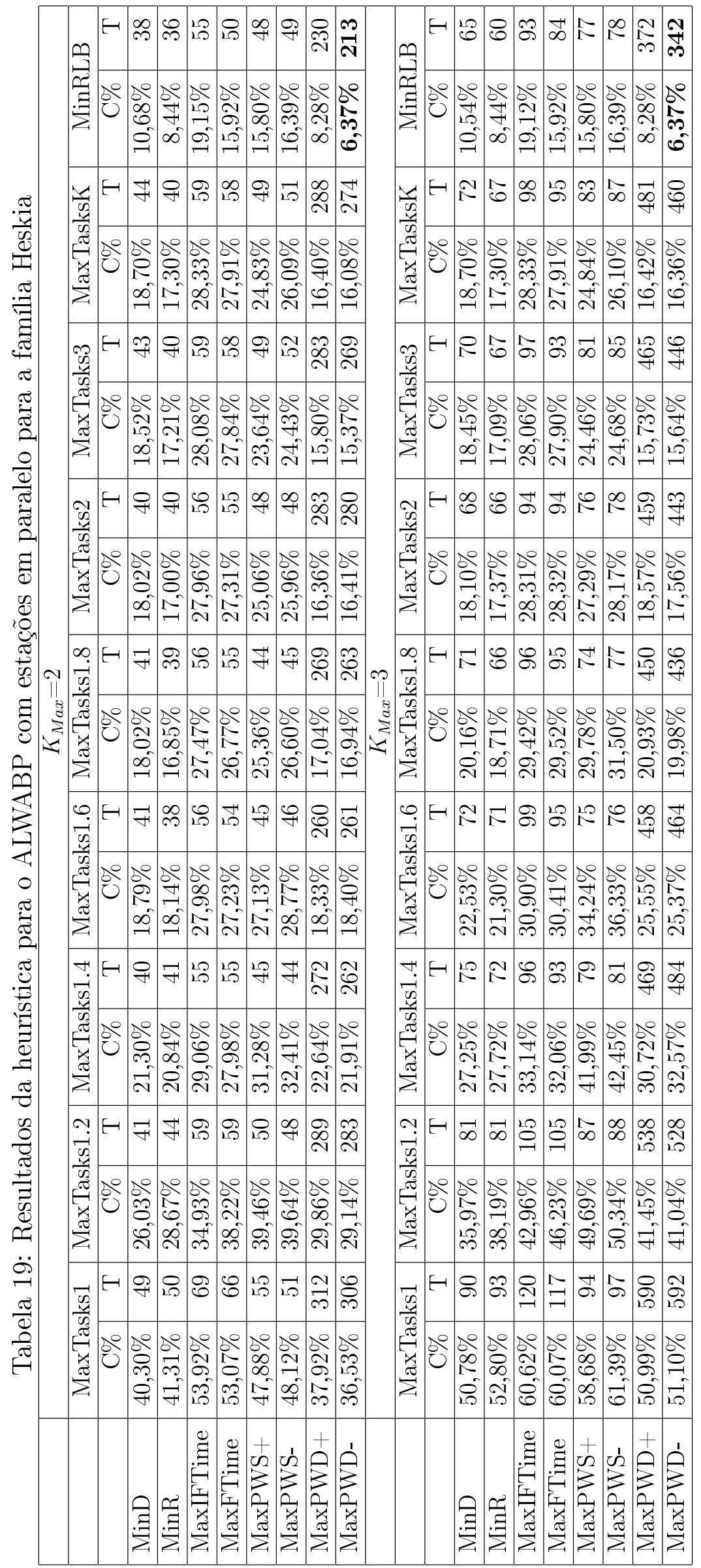




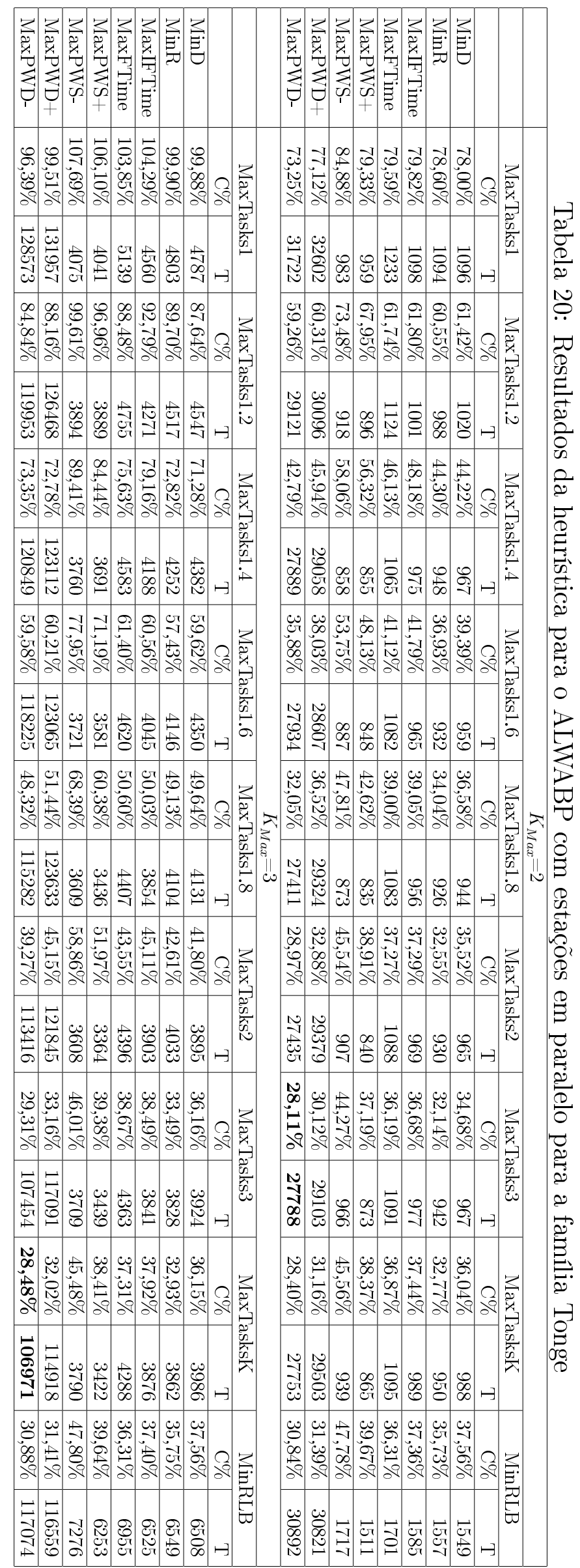




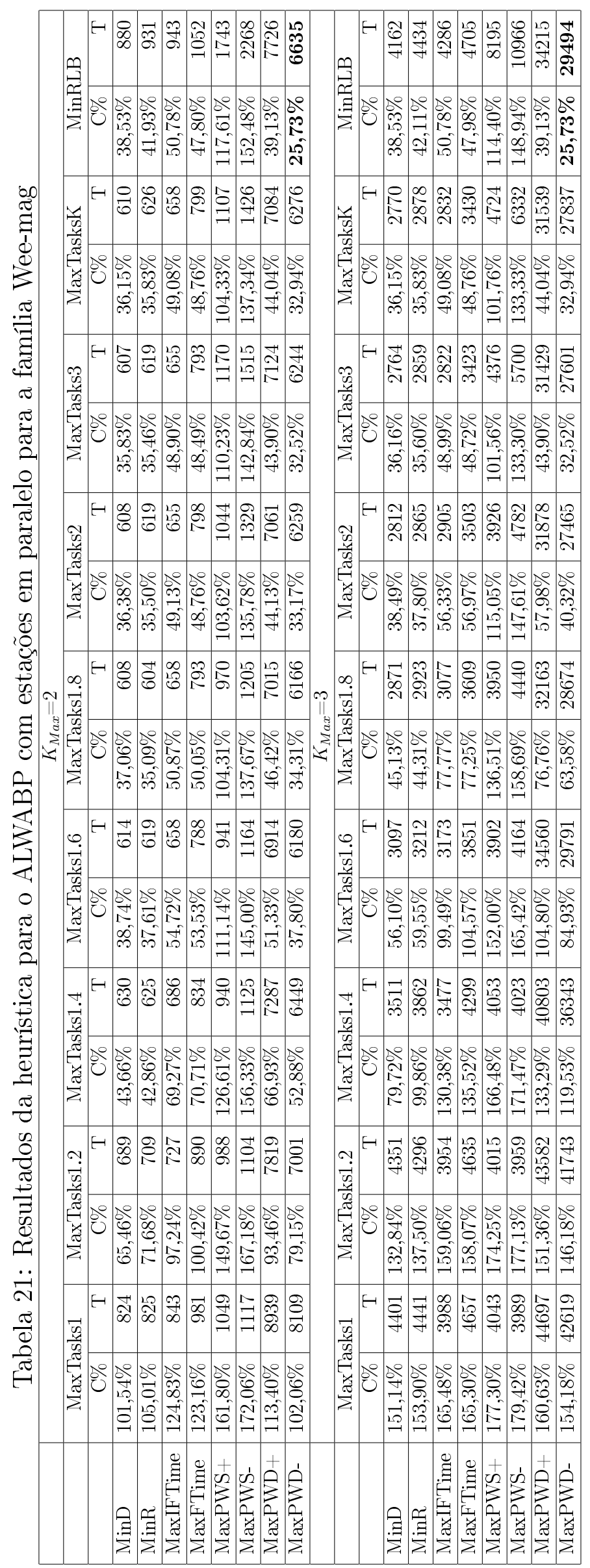




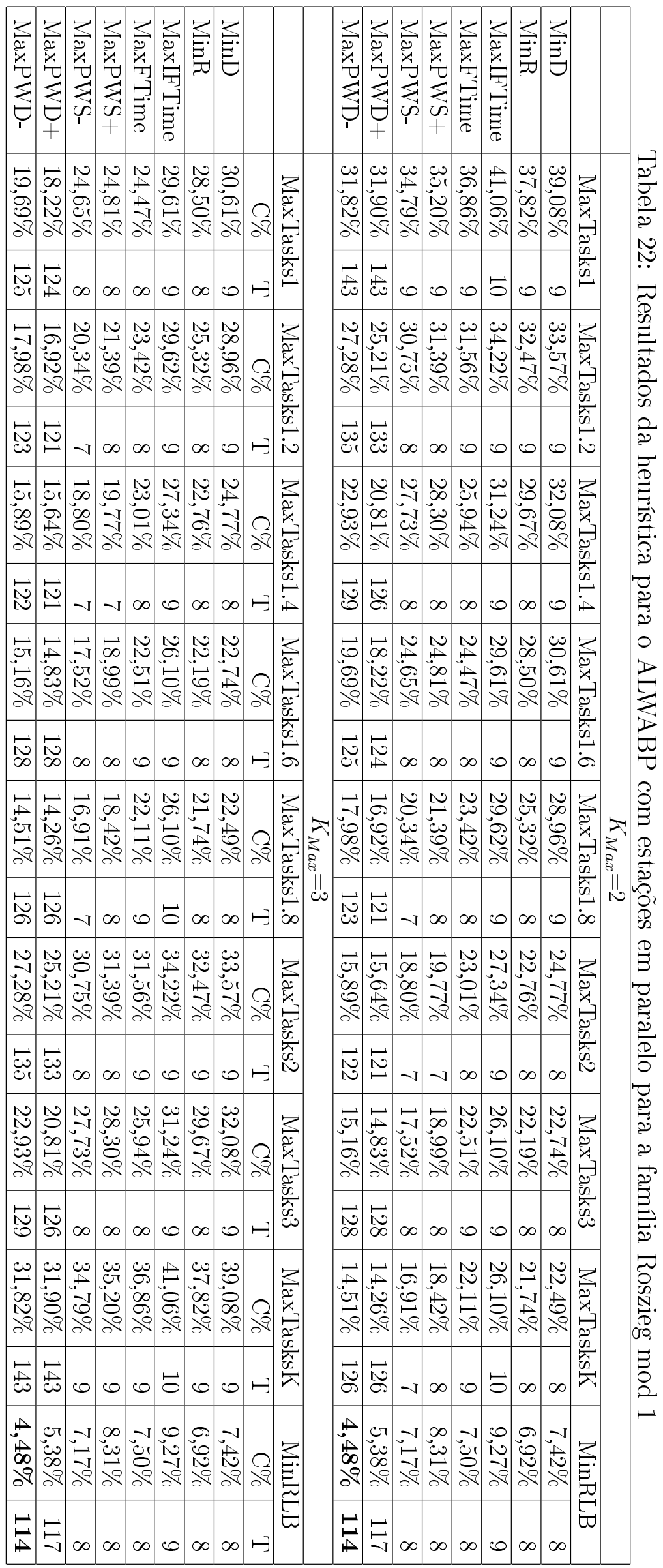




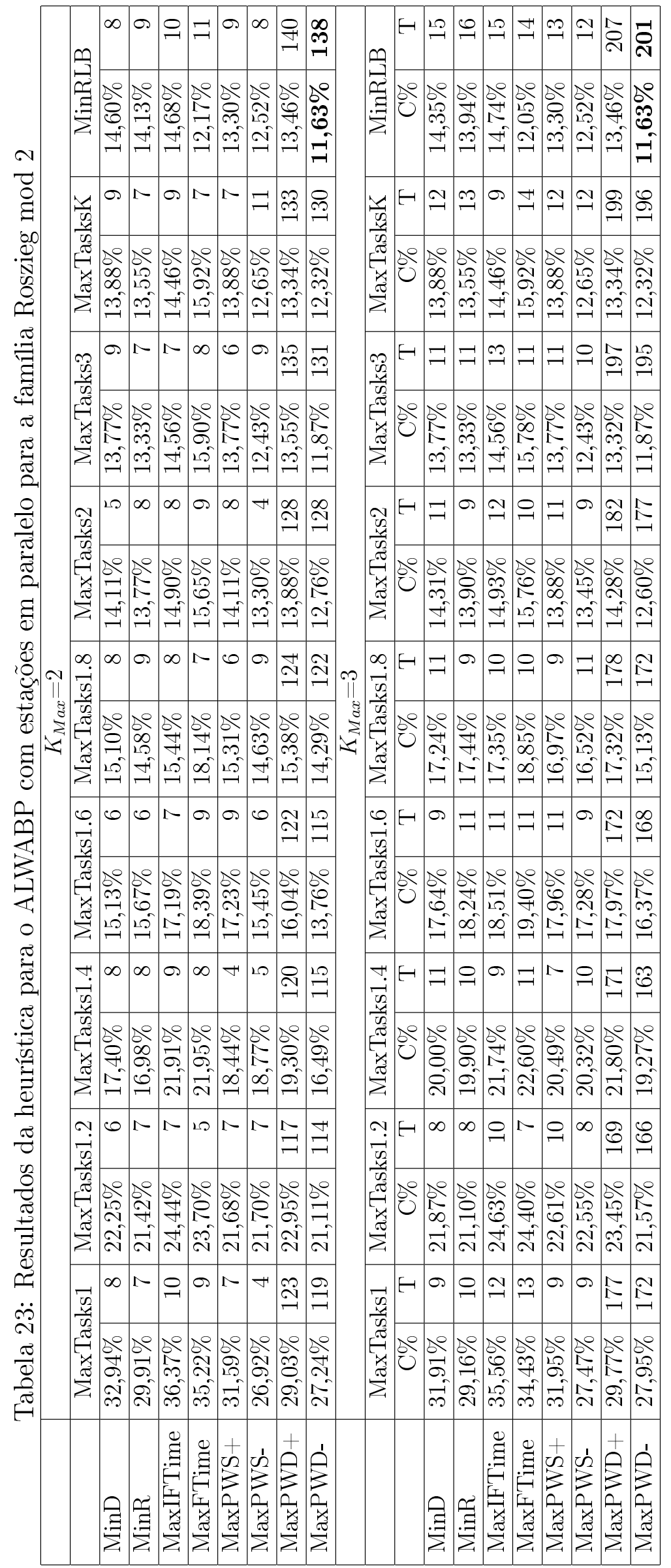




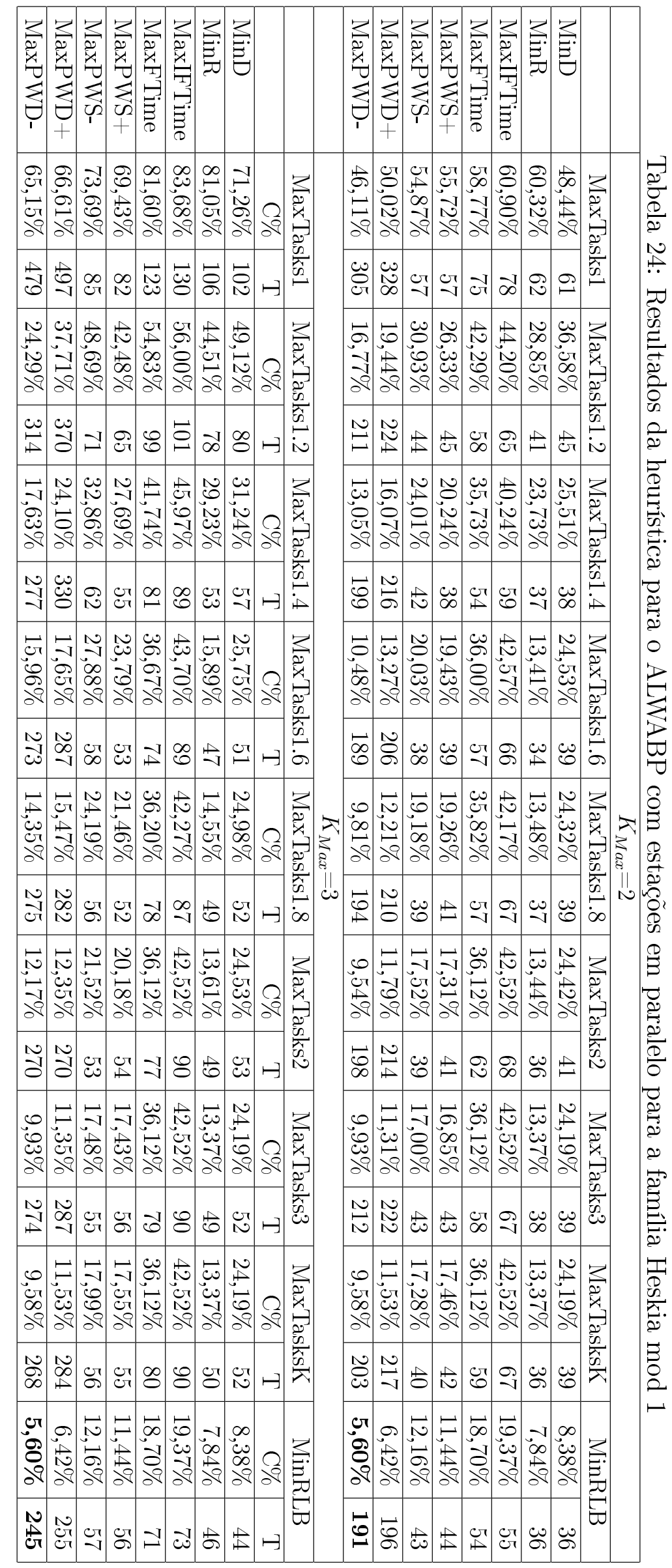




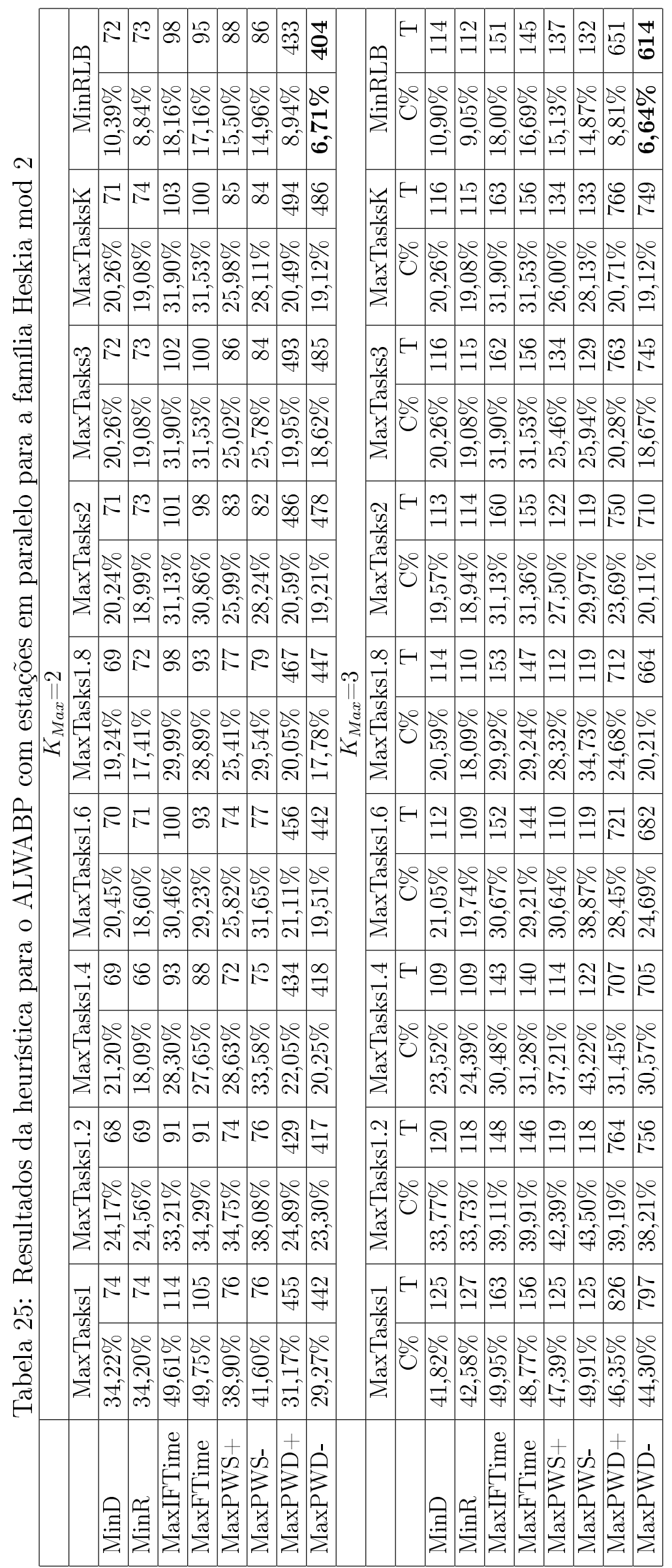


Uma solução é considerada melhor que outra caso seu tempo de ciclo seja menor. Já para $K_{\text {Max }}=3$ as melhores soluções estão, em média, a 2,84\% da melhor solução conhecida para o ALWABP serial.

Para a família Heskia, o critério MinRLB combinado com os critérios MinR, MaxPWD+ e MaxPWD- encontrou as melhores soluções em termos de tempo de ciclo, tanto para $K_{\text {Max }}=2$ quanto para $K_{\text {Max }}=3$. As melhores soluções encontradas entre todas as combinações de critérios estavam, em média a 4,04\% das melhores soluções conhecidas para $K_{\text {Max }}=2$ e a $2,89 \%$ para $K_{\text {Max }}=3$. Para $K_{\text {Max }}=2$ a heurística conseguiu encontrar soluções para 5 instâncias que são melhores que as respectivas melhores soluções conhecidas para o ALWABP serial. Já para $K_{M a x}=3$, em 9 instâncias, as melhores soluções encontradas são melhores do que as melhores soluções conhecidas para o ALWABP serial.

A regra MaxPWD-, quando combinada com as regras MaxTasks2, MaxTasks3 e MaxTasksK, encontrou as soluções com menor tempo de ciclo, em média, para $K_{\text {Max }}=2$. Já para $K_{M a x}=3$, as soluções de menor tempo de ciclo foram encontradas pela regra MaxPWD + combinado com MaxTasks3, MaxTasksK e MinRLB. No entanto, a regra MaxPWD+, assim como MaxPWD-, apresentaram alto custo computacional. Estas regras demoraram entre 30 e 40 vezes o tempo necessário para a execução da heurística com as outras regras. As melhores soluções encontradas estavam, em média, a 19,5\% da melhor solução conhecida para o ALWABP serial, para $K_{\text {Max }}=2$, e a $19,9 \%$ para $K_{\text {Max }}=3$. Para $K_{M a x}=2$ encontramos também uma solução cujo tempo de execução é $3 \%$ menor que a melhor solução conhecida para o ALWABP serial.

Para a família Wee-mag, a regra MaxPWD+ quando combinada com a regra MinRLB encontrou as soluções com os menores tempos de ciclo em média. As melhores soluções encontradas estavam em média a $21,78 \%$ da melhor solução conhecida, tanto para $K_{\text {Max }}=$ 2 quanto para $K_{M a x}=3$. Assim como ocorreu na família Tonge, o tempo de execução da heurística utilizando as regras MaxPWD+e MaxPWD- foi superior ao tempo de execução utilizando as demais regras.

Os tempos de execução das melhores soluções encontradas para a família Roszieg mod 1 estavam, em média, a 1\% das respectivas melhores soluções conhecida para o ALWABP serial, tanto para $K_{\text {Max }}=2$ quanto para $K_{\text {Max }}=3$. A heurística conseguiu encontrar uma instância cujo tempo de ciclo é 2,94\% menor que o tempo de ciclo da melhor solução para o ALWABP serial. Os melhores valores de tempo de ciclo em média foram encontrados pela combinação das regras MaxPWD+ e MinRLB.

Para a família Roszieg mod 2, as melhores soluções encontradas estavam, em média, 
a $3,32 \%$ das melhores soluções para o ALWABP serial para $K_{\text {Max }}=2$ e a $3,2 \%$ para $K_{\text {Max }}=3$. Uma das soluções encontradas representou uma melhoria de 4,76\% sobre o tempo de ciclo da solução ótima da mesma instância para o ALWABP serial. Para esta família, a regra MaxPWD+, quando combinada com a regra MinRLB, apresentou as melhores soluções em média.

Para a família Heskia mod 1, as soluções encontradas estavam, em média, a 2,2\% das melhores soluções para o ALWABP serial tanto para $K_{\text {Max }}=2$ quanto para $K_{\text {Max }}=3$. A heurística foi capaz de encontrar soluções para duas instâncias cujos tempos de ciclo são menores que as das respectivas soluções ótimas para o ALWABP serial. A combinação das regras MinRLB e MaxPWD+ encontrou as melhores soluções, em média.

Por fim, para a família Heskia mod 2, as melhores soluções encontradas estavam, em média, a 3,08\% da solução ótima para o ALWABP serial para $K_{M a x}=2$, e a 3,12\% para $K_{\text {Max }}=3$. A heurística foi capaz de encontrar seis soluções melhores que as respectivas soluções para o ALWABP serial. As soluções com menores tempos de ciclo em média foram encontradas pela combinação das regras MinRLB e MaxPWD+.

Apesar de terem encontrado boas soluções, as regras MaxPWD+ e MaxPWD- apresentaram um custo computacional elevado em relação às demais regras. Em vista disso, decidimos não utilizar estas regras para os testes seguintes.

\section{A.1.1 Testes com as heurísticas modificadas}

A seguir, apresentamos os resultados obtidos pelas heurísticas P1, P2, PS e PW para as famílias Roszieg, Heskia, Tonge, Wee-mag, Roszieg e Heskia mod 1 e 2. Foram utilizadas as mesmas regras utilizadas na heurística para o ALWABP com estações em paralelo, com exceção das regras MaxPWD+ e MaxPWD-.

As tabelas 26, 27, 28 e 29 apresentam os resultados obtidos, respectivamente, pelas heurísticas P1, P2, PS e PW para a família Roszieg.

Entre as quatro heurísticas, a heurística P1 teve os piores resultados para a família Roszieg. A heurística não foi capaz de encontrar uma solução utilizando paralelismo em 11 das 80 instâncias desta família. Considerando apenas as soluções viáveis, para $K_{\text {Max }}=2$, as melhores soluções retornadas estavam, em média, a 11,77\% das melhores soluções conhecidas para o ALWABP serial e a $13,05 \%$ para $K_{\text {Max }}=3$. Observe que, a regra MaxTasks3, quando combinada com a regra MinD, obteve soluções a 10,49\% das melhores soluções conhecidas para $K_{M a x}=2$. No entanto, esta regra foi capaz de resolver 


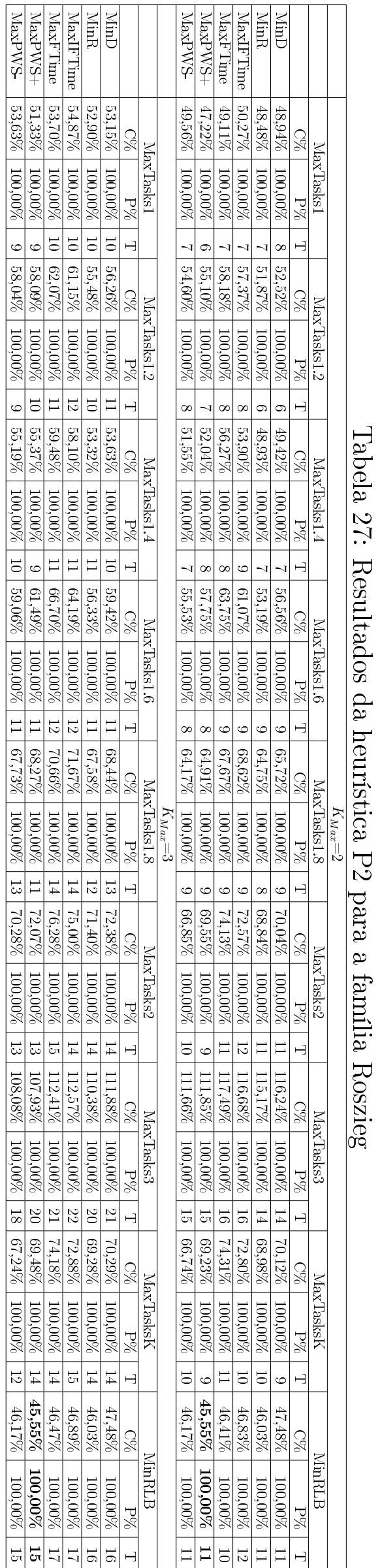

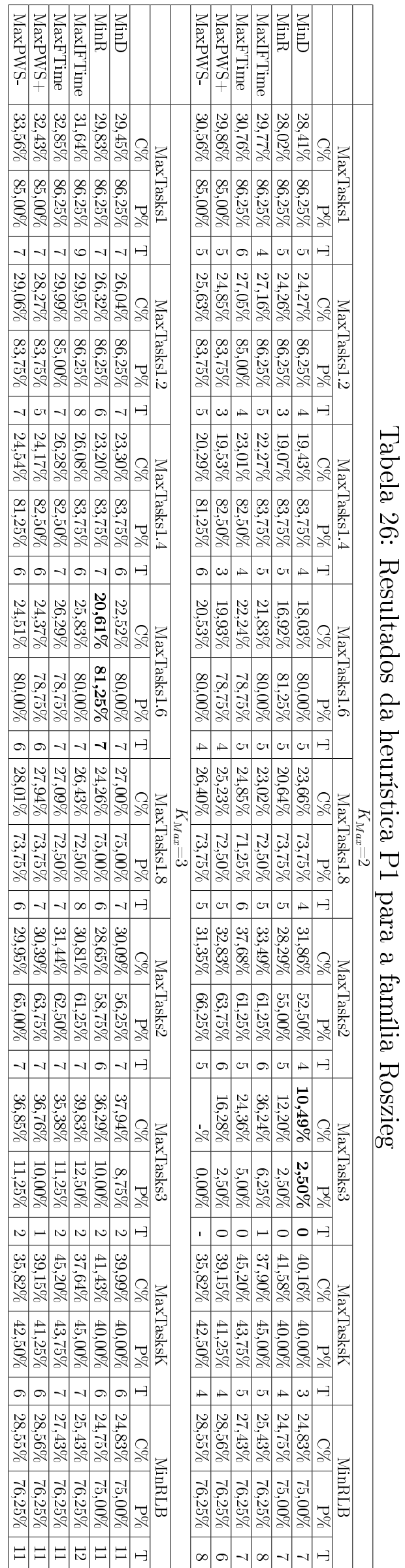



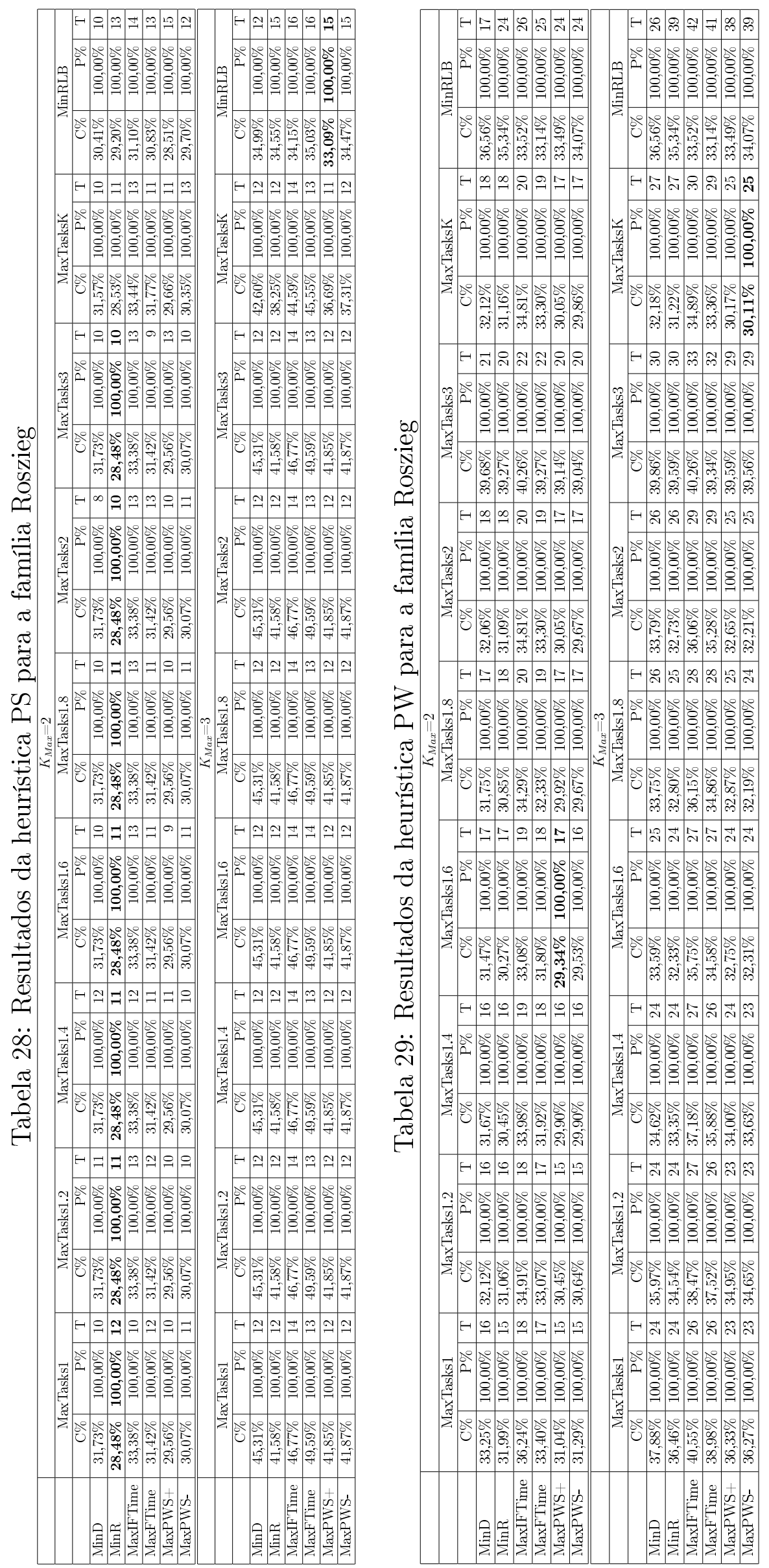
apenas duas instâncias, tendo pouco impacto para os resultados médios da heurística P1.

A heurística P2, conseguiu encontrar soluções para todas as instâncias. No entanto, muitas soluções encontradas apresentaram tempo de ciclo muito superior ao da melhor solução conhecida para a instância. Para $K_{\text {Max }}=2$, as soluções viáveis encontradas por esta heurística estavam, em média, a 24,14\% das melhores soluções conhecidas para o ALWABP serial. Já para $K_{M a x}=3$, estas soluções estavam a 24,39\% das melhores soluções conhecidas. Tanto a heurística P1 quanto a heurística P2 conseguiram encontrar uma solução com tempo de ciclo menor que a melhor solução conhecida para o problema.

A heurística PS conseguiu encontrar duas soluções melhores que as melhores soluções conhecidas para as respectivas instâncias. Observe que, devido à forma como esta heurística força o paralelismo, as regras derivadas de MaxTasks, com exceção de MaxTasksK, obtiveram os mesmos resultados em termos de tempo de ciclo. A regra MaxTasksK obteve resultados diferentes porque a penalidade aplicada ao número de tarefas para esta regra (isto é, o número de trabalhadores alocados) é um número inteiro, enquanto que para as demais regras a penalidade é um número real. Para esta heurística, a regra MinR, quando combinada com as regras MaxTasks, obtiveram os melhores resultados para $K_{\text {Max }}=2$, enquanto que a regra MinRLB combinada com a regra MaxPWS- obteve os melhores resultados em média para $K_{M a x}=3$. Em média, as melhores soluções encontradas por esta heurística estavam a 19,73\% das melhores soluções conhecidas para $K_{\text {Max }}=2$ e a $22,55 \%$ para $K_{\text {Max }}=3$.

Por fim, para $K_{\text {Max }}=2$, o critério MaxTasks1.6 combinado com o critério MaxPWS+ encontrou os melhores resultados em média para a heurística PW. Para $K_{M a x}=3$, os melhores resultados foram encontrados pela combinação dos critérios MaxTasksK e MaxPWS + . Os melhores resultados obtidos estavam, em média, a 19,41\% da melhor solução conhecida para o ALWABP serial, para $K_{\text {Max }}=2$ e a $20,09 \%$ para $K_{\text {Max }}=3$. Desta forma, para a família Roszieg, a heurística PW obteve soluções com os menores tempos de ciclo, em média.

As tabelas 30, 31, 32 e 33 apresentam os resultados para a família Heskia obtidos, respectivamente, pelas heurísticas $\mathrm{P} 1, \mathrm{P} 2$, PS e PW.

Para a família Heskia, a Heurística P1 conseguiu encontrar soluções utilizando paralelismo para todas as instâncias. A heurística obteve os melhores resultados em média utilizando uma combinação dos critérios MinRLB e MinR. A heurística P1 foi também capaz de encontrar soluções melhores do que as melhores soluções para o ALWABP serial em 8 das 80 instâncias. Uma destas soluções representou em um tempo de ciclo 

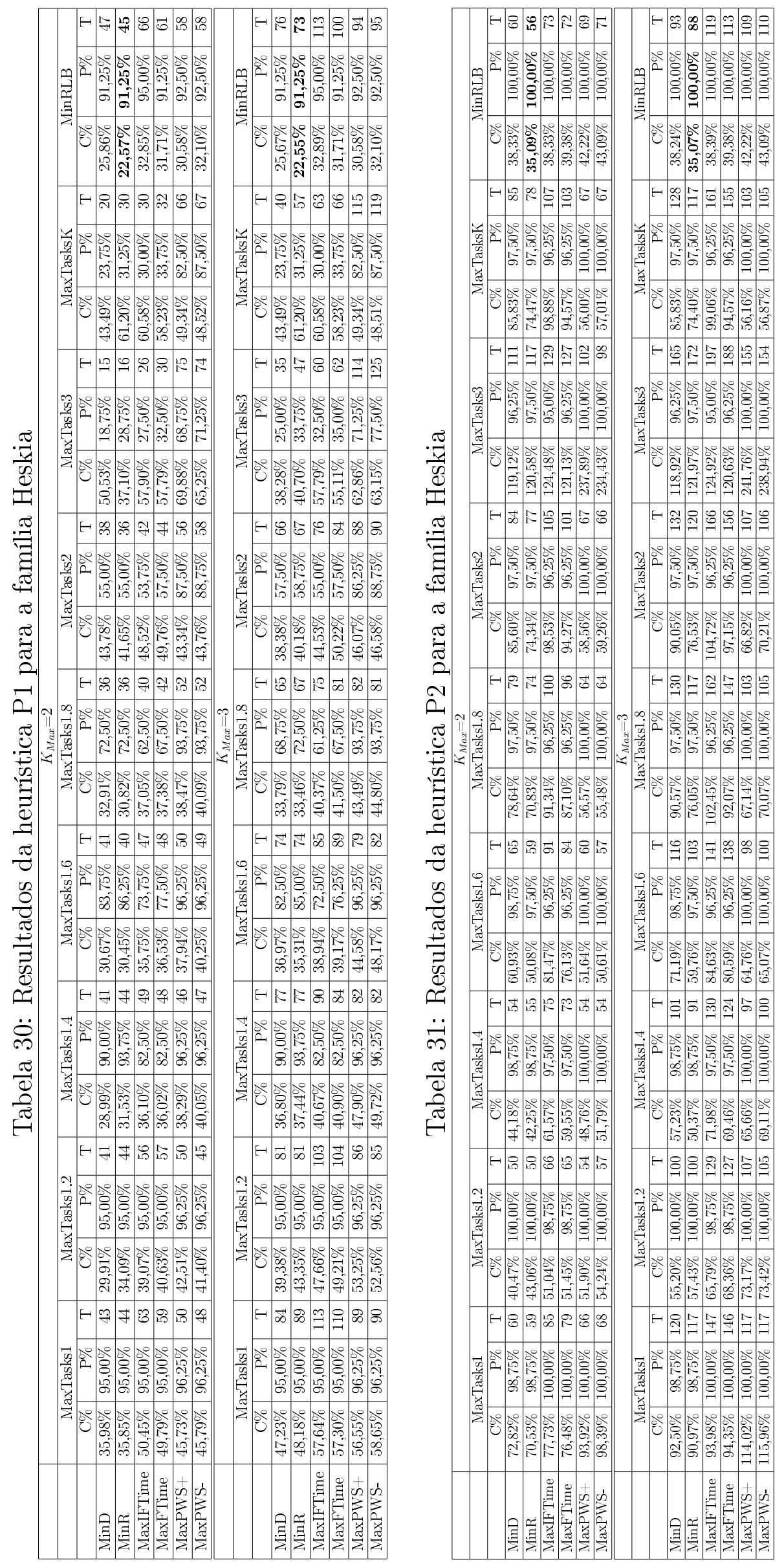


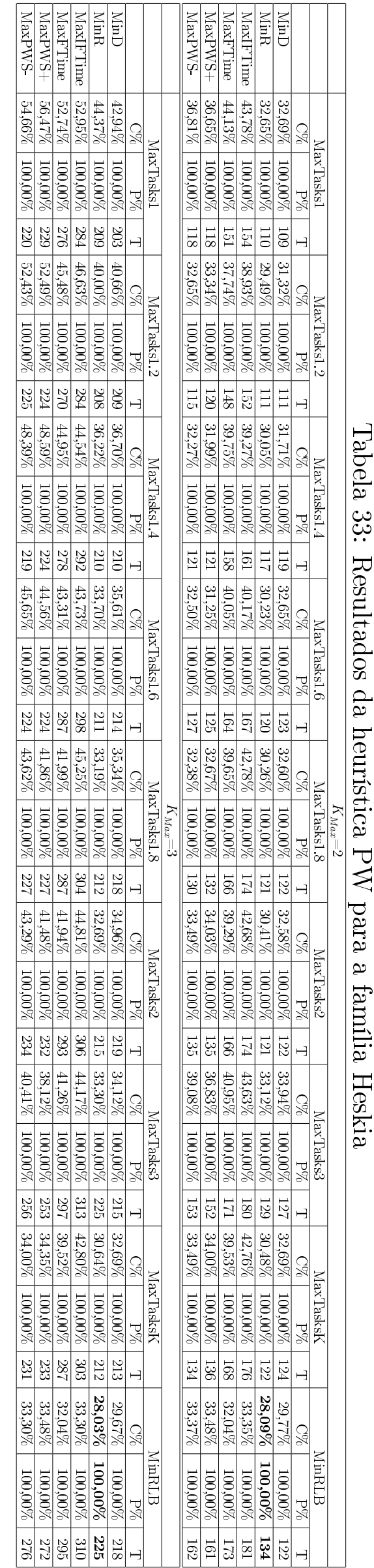

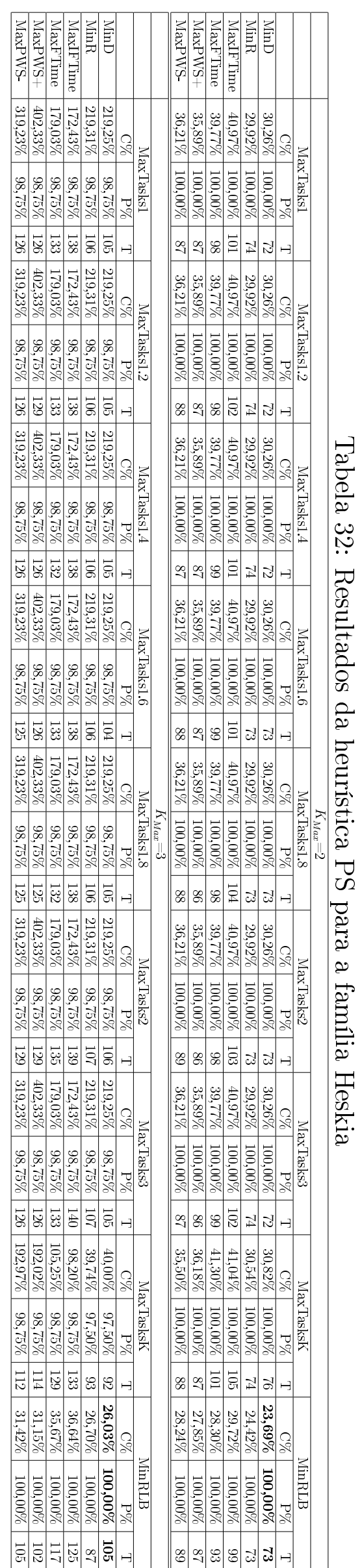


20,63\% menor em relação à melhor solução conhecida para a instância. Em média, para $K_{\text {Max }}=2$, as soluções encontradas estavam em média a 18,83\% das melhores soluções conhecidas para o ALWABP serial e a $18,88 \%$ para $K_{\text {Max }}=3$.

A heurística P2 conseguiu também encontrar 8 soluções cujos tempos de ciclo são menores que as melhores soluções conhecidas para os respectivos problemas. A regra MinRLB combinada com a regra MinR apresentou também os melhores resultados em média para a heurística P2. Os melhores resultados obtidos para esta heurística, quando comparados com os melhores resultados conhecidos para as respectivas instâncias, eram $16,13 \%$ maiores para $K_{M a x}=2$ e $17,32 \%$ maiores para $K_{M a x}=3$.

Para a heurística PS, conseguimos novamente encontrar 8 soluções melhores que as melhores soluções conhecidas para as respectivas instâncias. No entanto, a maior melhoria foi de 16,73\%. A regra MinRLB apresentou os melhores resultados em termos de tempo de ciclo, especialmente quando combinada com a regra MinD. Para $K_{\text {Max }}=2$, os melhores resultados obtidos estavam, em média, a 13,42\% das melhores soluções conhecidas para as respectivas instâncias. Já para $K_{M a x}=3$, este valor é de $15,51 \%$.

Já a heurística PW conseguiu encontrar 9 soluções cujos tempos de ciclo são menores que as melhores soluções conhecidas para as respectivas instâncias. A maior melhoria no tempo de ciclo obtida por esta heurística foi de 20,63\%. Para esta heurística, a regra MinRLB, quando combinada com a regra MinR, retornou as soluções com menores tempos de ciclo em média. As melhores soluções obtidas pela heurística PW estavam, em média, a $13,08 \%$ das respectivas melhores soluções conhecidas para $K_{\text {Max }}=2$ e a $13,38 \%$, para $K_{M a x}=3$. A heurística PW obteve, em média, as melhores soluções em termos de tempo de ciclo para a família Heskia entre as quatro heurísticas que forçam o paralelismo.

Os resultados encontrados pelas heurísticas P1, P2, PS e PW para a família Tonge são apresentados, de forma resumida, nas tabelas 34, 35, 36 e 37, respectivamente.

A heurística P1 conseguiu encontrar soluções utilizando paralelismo para todas as instâncias da família Tonge. Entre os critérios utilizados, apenas os critérios MaxTasks2, MaxTasks3 e MaxTasksK não conseguiram encontrar soluções viáveis para todas as instâncias. Para $K_{M a x}=2$, a regra MaxTasks1.8, quando combinada com a regra MinR, encontrou as melhores soluções, em média. Já para $K_{M a x}=3$, a regra MinRLB retornou as melhores soluções, especialmente quando combinada com a regra MaxIFTime. A heurística P1 foi capaz de encontrar uma solução que é 3,09\% melhor que a melhor solução conhecida para a instância a qual refere. Em média, as melhores soluções encontradas estão a $28,41 \%$ das melhores soluções conhecidas para $K_{M a x}=2$ e a $37,75 \%$ para 


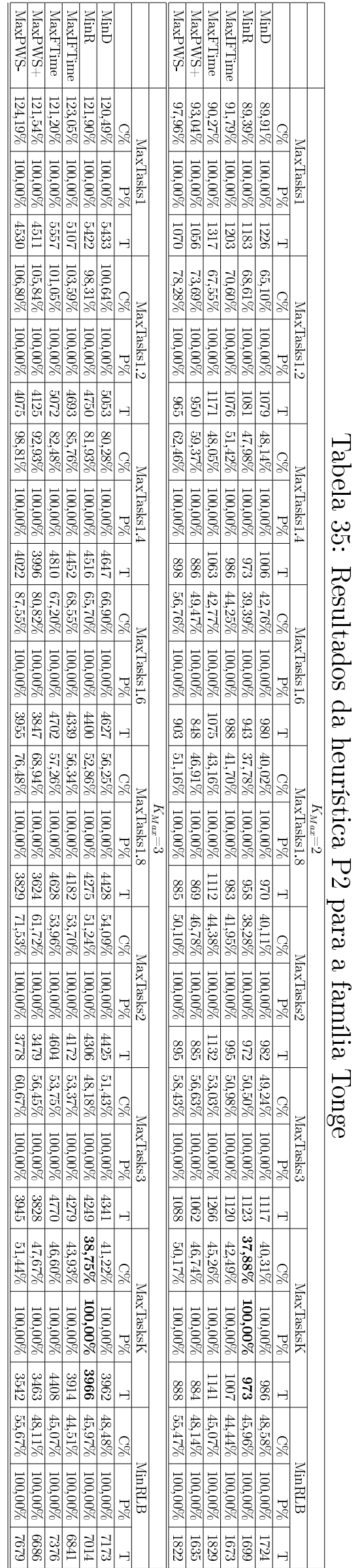

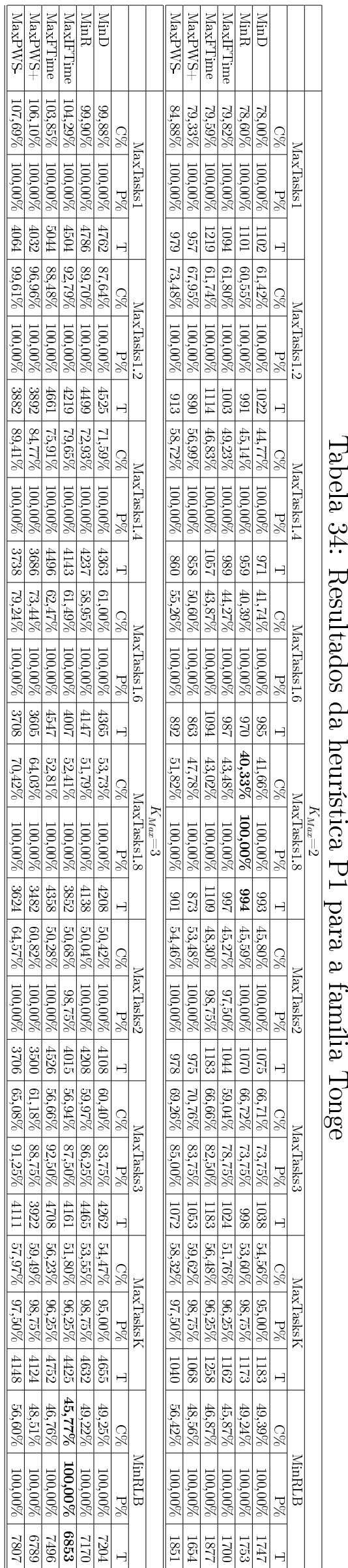



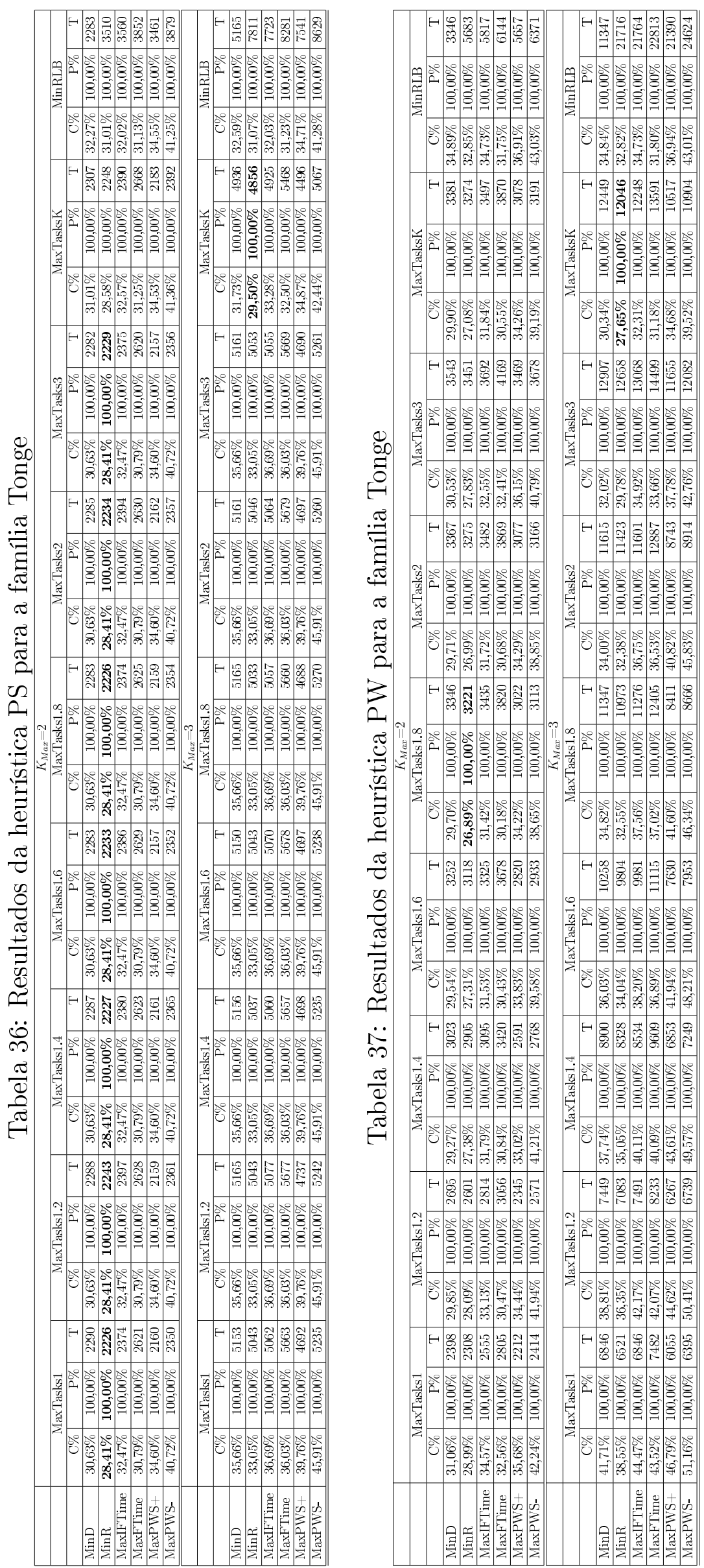
$K_{\text {Max }}=3$.

A heurística P2 conseguiu encontrar soluções utilizando paralelismo em todas as instâncias da família Tonge, utilizando todas as combinações de critérios. Para esta heurística, a combinação dos critérios MaxTasksK e MinR encontrou as melhores soluções, em média, tanto para $K_{M a x}=2$ quanto para $K_{\text {Max }}=3$. As melhores soluções encontradas por esta heurística estão, em média, a 27,72\% das melhores soluções conhecidas para $K_{\text {Max }}=2$ e a $37,75 \%$ para $K_{\text {Max }}=3$.

Para a heurística PS, a regra MinR encontrou os melhores resultados em termos de tempo de ciclo para $K_{M a x}=2$ quando combinada com as regras MaxTasks. Para $K_{M a x}=3$, a combinação das regras MinR e MaxTasksK apresentou as melhores soluções em média. As soluções de menor tempo de ciclo obtidas estavam, em média, a 21,94\% das melhores soluções para $K_{\text {Max }}=2$ e a $22,81 \%$ para $K_{\text {Max }}=3$.

A regra MinR obteve os melhores resultados, em média, para a heurística PW. Para $K_{\operatorname{Max}}=2$, esta regra obteve os melhores resultados quando combinada com a regra MaxTasks2, enquanto que, para $K_{\text {Max }}=3$, a regra MaxTasksK apresentou os melhores resultados quando combinada com a regra MinR. As melhores soluções encontradas estavam, em média, a 19,80\% das melhores soluções conhecidas para $K_{\text {Max }}=2$ e a $20,99 \%$ para $K_{M a x}=3$. Desta forma, a heurística PW, assim como a regra MinR, foi a que apresentou os melhores resultados para a família Tonge.

As tabelas 38, 39, 40 e 41 apresentam, respectivamente, os resultados obtidos pelas heurísticas P1, P2, PS e PW para a família Wee-mag.

Para a família Wee-mag, a heurística P1 não foi capaz de resolver algumas instâncias utilizando as regras MaxTasks1.8, MaxTasks2, MaxTasks3 e MaxTasksK. Para $K_{\text {Max }}=2$ as soluções com menores tempos de ciclo em média foram encontradas pela combinação das regras MaxTasks1.6 e MinR. Já para $K_{\text {Max }}=3$, a combinação das regras MinRLB e MinD obteve as melhores soluções. As melhores soluções encontradas pela heurística estavam, em média, a 31,51\% das melhores soluções conhecidas (para $K_{\text {Max }}=2$ ) e a $35,01 \%\left(K_{\operatorname{Max}}=3\right)$.

Para a heurística P2, a regra MinR encontrou as melhores soluções, em média, quando combinada com as regras MaxTasks1.6 (para $K_{\text {Max }}=2$ ) e MaxTasksK (para $K_{\text {Max }}=3$ ). Para $K_{\text {Max }}=2$, as soluções de menor tempo de ciclo encontradas pela heurística estavam, em média, a $27,72 \%$ dos melhores valores conhecidos. Para $K_{M a x}=3$, estas soluções estavam a $37,75 \%$ dos melhores valores conhecidos. 

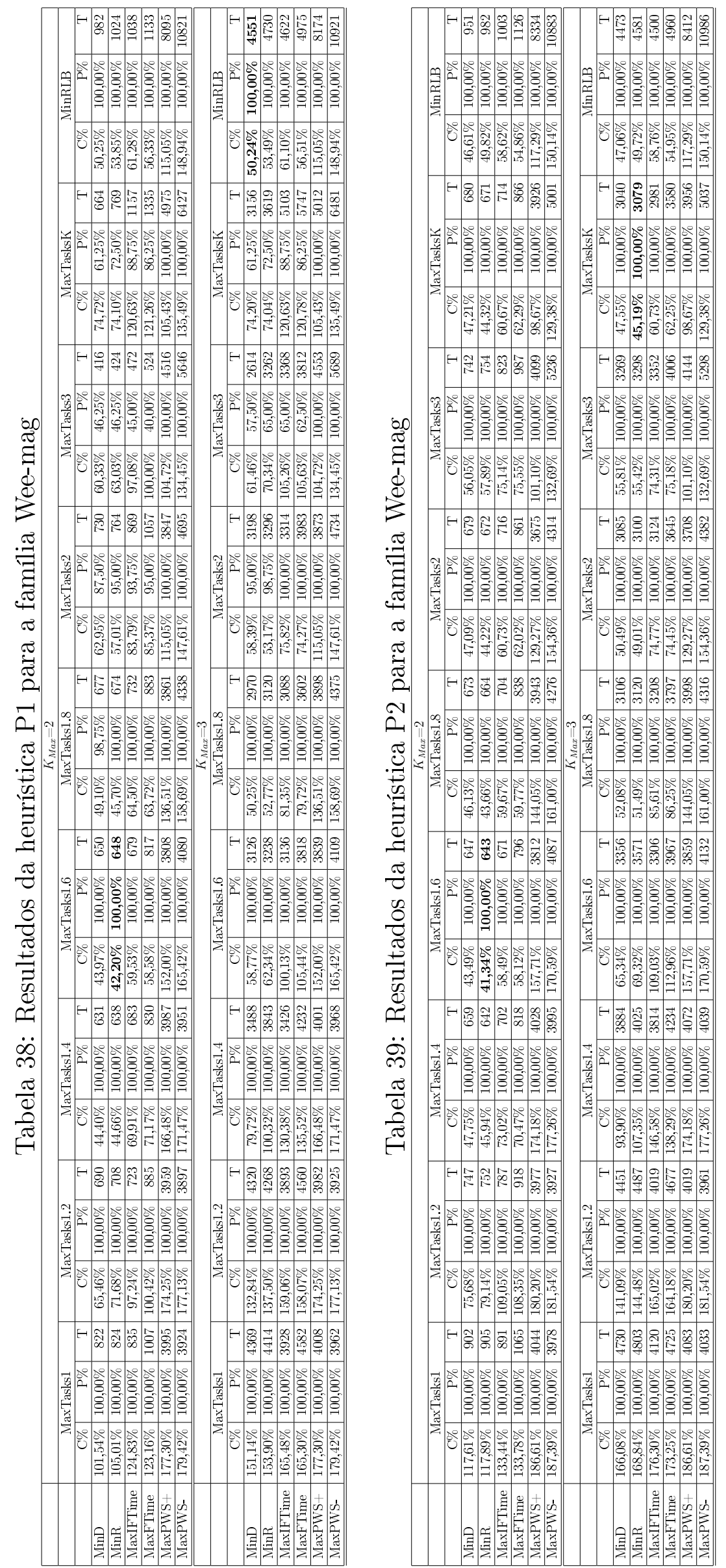


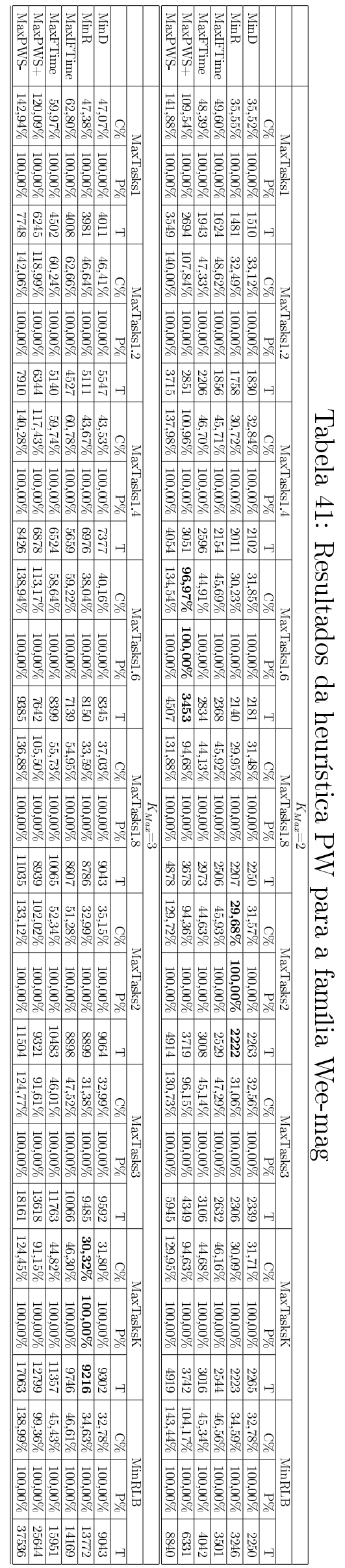

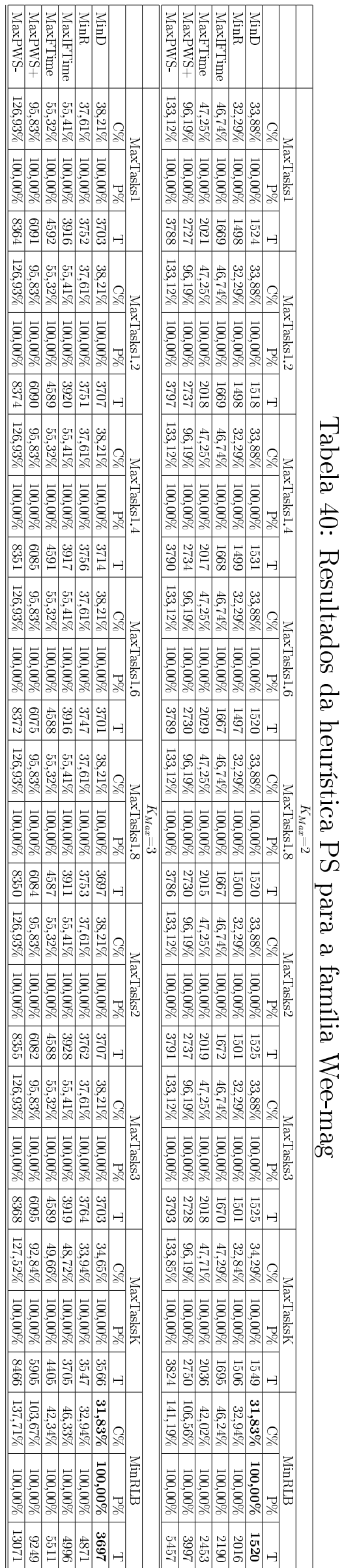


A combinação das regras MinRLB e MinD obteve as melhores soluções para a heurística PS, tanto para $K_{M a x}=2$ quanto para $K_{M a x}=3$. As melhores soluções encontradas estavam, em média, a 23,64\% das melhores soluções conhecidas para $K_{M a x}=2$ e a 24,21\%, para $K_{\text {Max }}=3$.

Por fim, para a heurística PW, a regra MinR encontrou as soluções de menor tempo de ciclo quando combinada com as regras MaxTasks2 (para $K_{M a x}=2$ ) e MaxTasksK (para $\left.K_{M a x}=3\right)$. Em média, as melhores soluções encontradas para esta heurística estavam a $22,38 \%$ das melhores soluções conhecidas, para $K_{\text {Max }}=2$, e a $23,23 \%$, para $K_{\text {Max }}=3$. Assim, a heurística PW obteve as soluções de menor tempo de ciclo, em média, para a família Wee-mag.

As tabelas 42, 43, 44 e 45 apresentam os resultados obtidos pelas heurísticas P1, P2, PS e PW, respectivamente, para a família Roszieg mod 1.

A heurística P1 não conseguiu resolver 10 instâncias da família Roszieg mod 1. entre as soluções viáveis utilizando paralelismo, as melhores soluções encontradas estavam, em média a $17,54 \%$ das respectivas soluções ótimas para o ALWABP serial, para $K_{\text {Max }}=2$, e a $18,14 \%$ para $K_{M a x}=3$. A maioria das combinações de regras conseguiu resolver menos da metade das instâncias.

A heurística P2 conseguiu encontrar soluções para todas as instâncias utilizando todas as regras. O fato de estarmos forçando o paralelismo juntamente com o pequeno número de trabalhadores resultou em uma perda da qualidade da solução em relação à heurística original. Mesmo assim, a heurística P2 conseguiu encontrar soluções em 3 instâncias cujos tempos de execução são menores do que as respectivas soluções para o ALWABP serial. As melhores soluções encontradas estão, em média, a 24,39\% da solução ótima para o ALWABP serial, para $K_{\text {Max }}=2$ e a $25,82 \%$, para $K_{\text {Max }}=3$. A combinação das regras MinRLB e MaxPWS+ encontrou as melhores soluções em média para esta heurística.

Para a heurística PS, as melhores soluções encontradas estavam a $21 \%$ das melhores soluções para o problema serial, para $K_{\text {Max }}=2$ e a $22,61 \%$ para $K_{\text {Max }}=3$. A heurística encontrou também 3 soluções melhores que as melhores soluções para o ALWABP. A combinação das regras MinRLB e MaxPWS- retornou as melhores soluções em média.

Utilizando a heurística PW, as melhores soluções estavam a 22,5\% das melhores soluções para o problema serial, para $K_{\text {Max }}=2$, e a $24,7 \%$, para $K_{\text {Max }}=3$. As melhores soluções, em média, foram encontradas pela combinação das regras MinRLB e MaxPWS+.

As tabelas 46, 47, 48 e 49 apresentam os resultados para a família Roszieg mod 2 


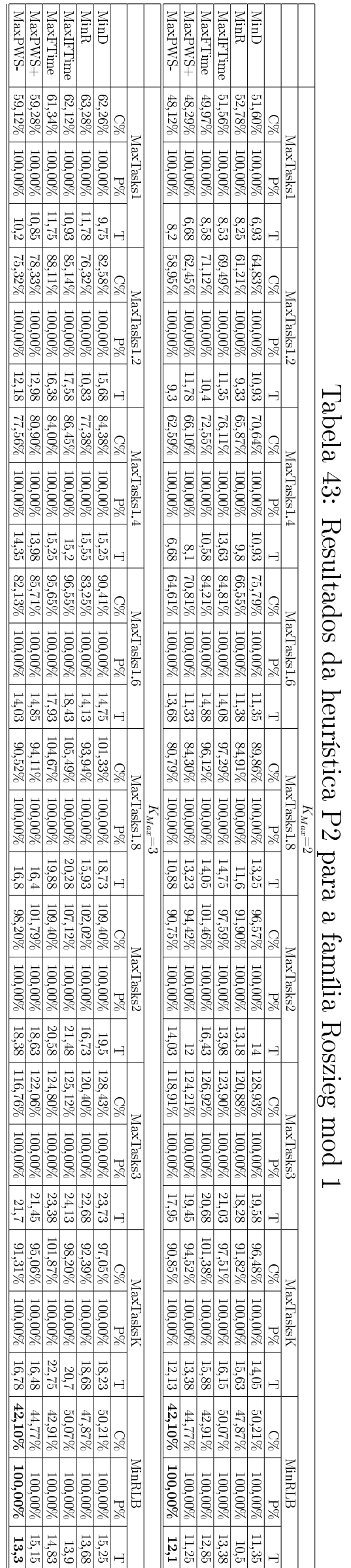

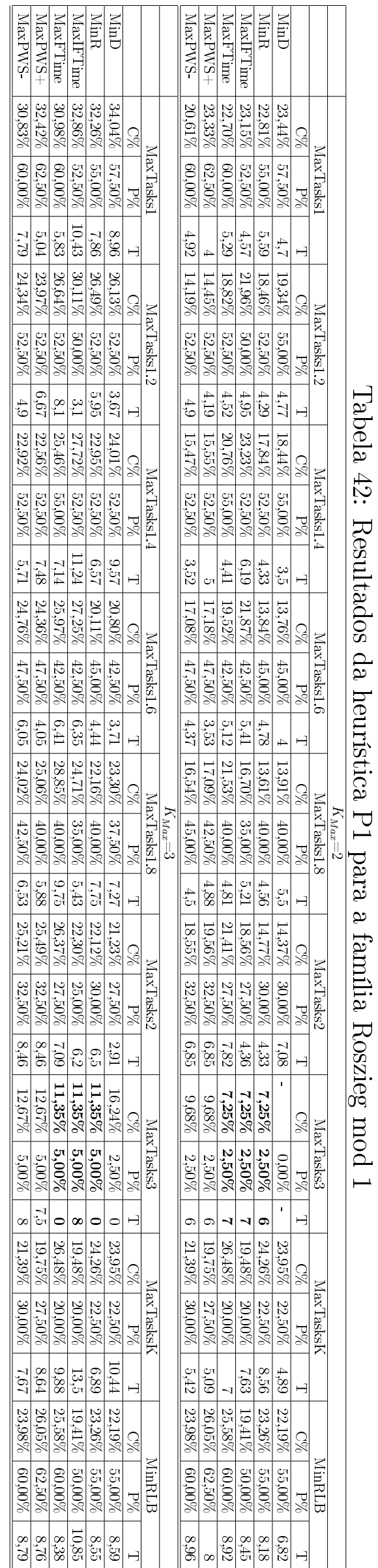



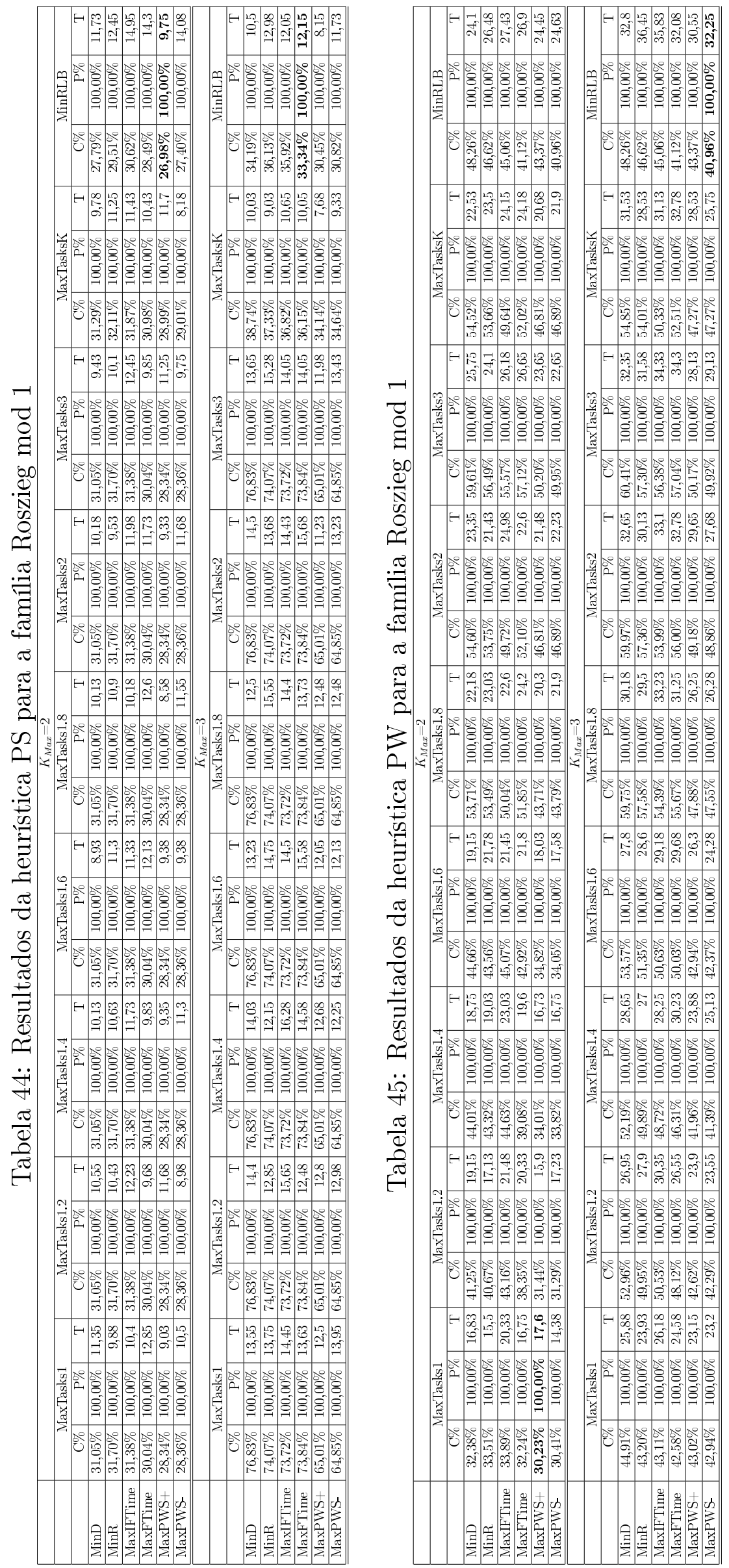
obtidos pelas heurísticas P1, P2, PS e PW, respectivamente.

Para a família Roszieg mod 2, a heurística P1 conseguiu encontrar soluções utilizando paralelismo em todas as instâncias, apesar de que algumas combinações de regras não conseguiram resolver muitas instâncias. As melhores soluções encontradas para $K_{\text {Max }}=2$ estavam, em média, a 12,67\% das soluções ótimas para o ALWABP serial. A regra MinR, quando combinada com a regra MaxTasks1.8, retornou as melhores soluções em média para $K_{\text {Max }}=2$. Para $K_{\text {Max }}=3$, a combinação das regras MaxTasks3 e MaxIFTime encontrou as melhores soluções em média, porém esta combinação conseguiu resolver poucas instâncias.

As melhores soluções encontradas pela heurística P2 estavam, em média, a 10,42\% das melhores soluções para o ALWABP serial para $K_{\text {Max }}=2$ e a $10,65 \%$ para $K_{\text {Max }}=3$. A regra MinRLB, quando combinada com a regra MaxPWS+, retornou as melhores soluções em média.

Para a heurística PS, as melhores soluções encontradas estavam, em média, a 7,97\% das respectivas soluções ótimas do problema serial para $K_{\text {Max }}=2$ e a 8,89\% para $K_{\text {Max }}=$ 3. Esta heurística foi capaz de encontrar quatro soluções cujos tempos de execução são melhores que os tempos de execução das soluções ótimas das respectivas instâncias para o ALWABP serial. A regra MinRLB encontrou as melhores soluções, em média, quando combinada com as regras MaxPWS- para $K_{\text {Max }}=2$ e MaxPWS + para $K_{\text {Max }}=3$.

As melhores soluções encontradas pela heurística PW estavam, em média, a 7,16\% das soluções ótimas das respectivas instâncias para o ALWABP serial utilizando $K_{\text {Max }}=$ 2 e a $8,11 \%$ utilizando $K_{M a x}=3$. Para $K_{M a x}=2$, em três instâncias a heurística conseguiu encontrar soluções melhores do que aquelas encontradas pelo ALWABP serial. As melhores soluções, em média, para esta heurística foram encontradas pela combinação das regras MinR e MaxTasks3.

Os resultados das heurísticas P1, P2, PS e PW para a família Heskia mod 1 podem ser vistos nas tabelas 50, 51, 52 e 53, respectivamente.

As melhores soluções obtidas pela heurística P1 estavam, em média, a 24,8\% das soluções ótimas para o ALWABP serial, utilizando $K_{\text {Max }}=2$, e a $25,86 \%$, utilizando $K_{\text {Max }}=3$. Para duas instâncias, foi possível encontrar soluções cujos tempos de ciclo eram menores que as soluções para o ALWABP serial. A combinação das regras MinRLB e MinR obteve as soluções com menor tempo de ciclo em média.

Para a heurística P2, as melhores soluções estavam, em média, a 15,11\% das melhores 

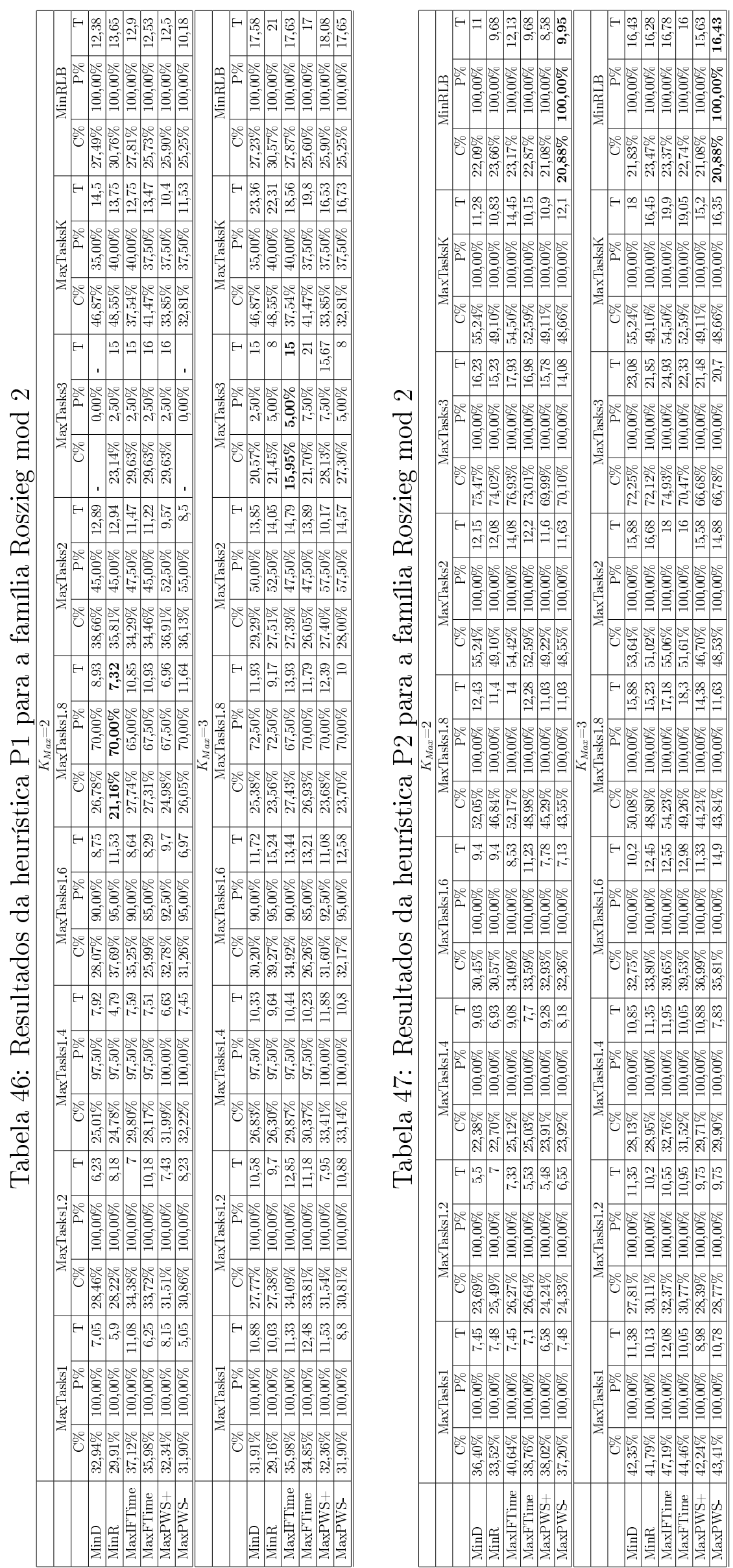


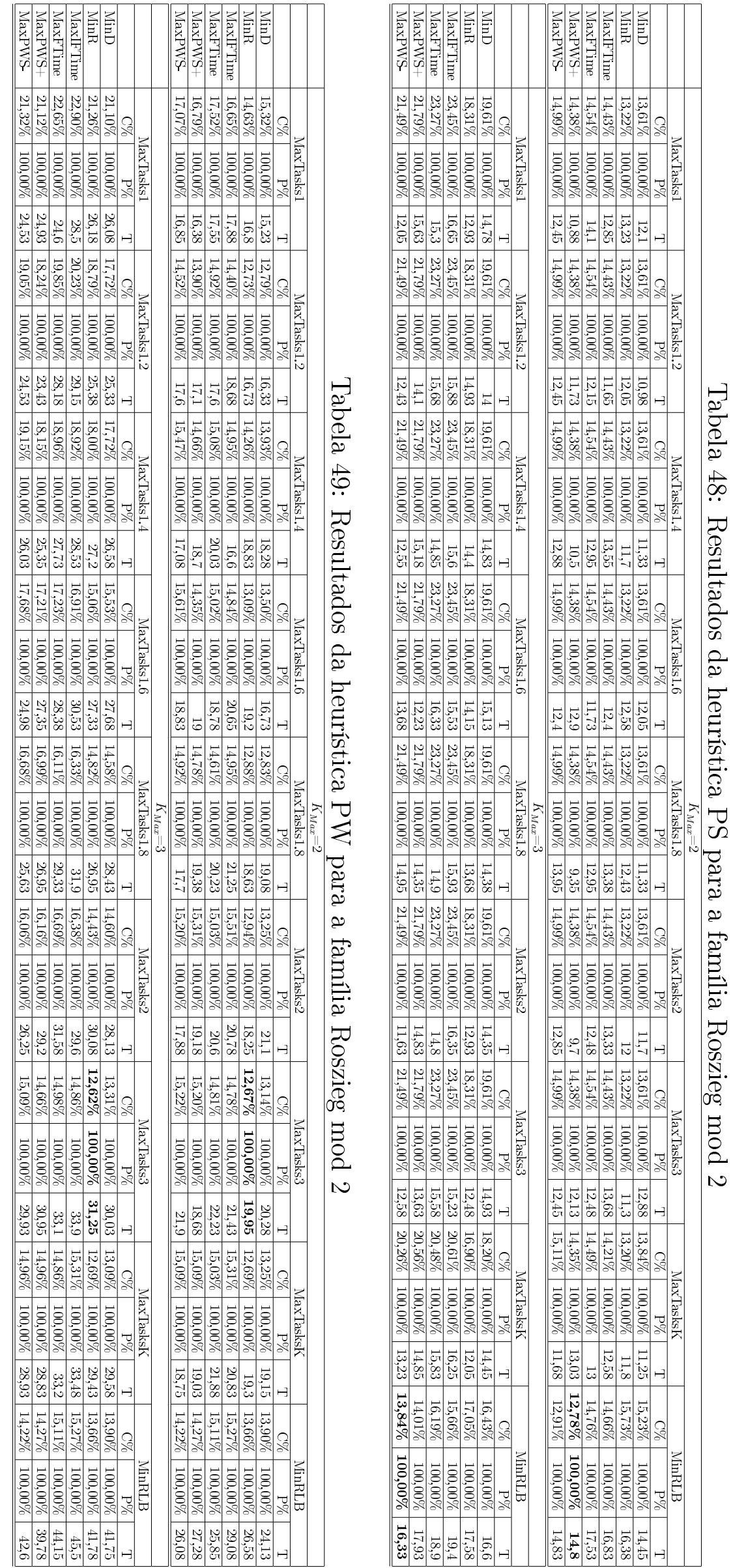



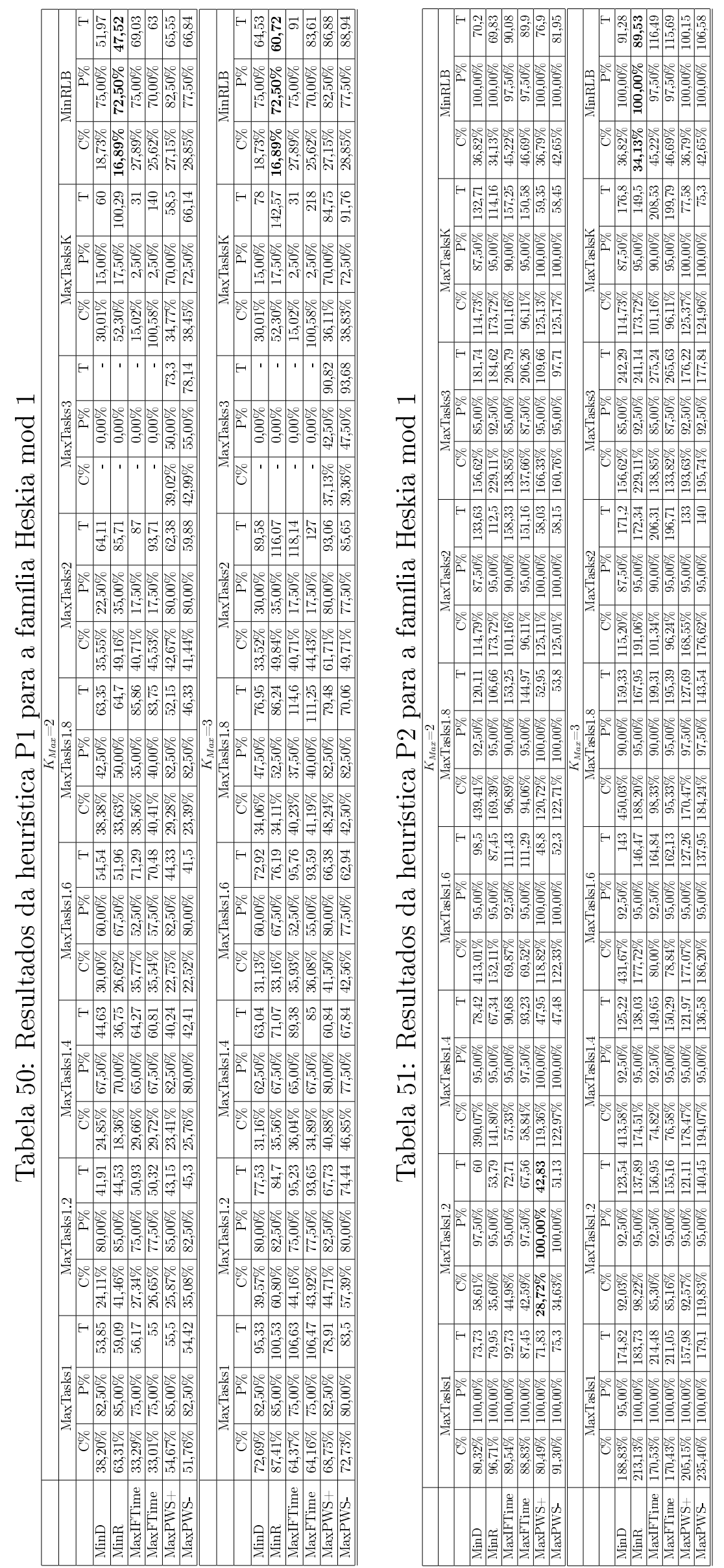

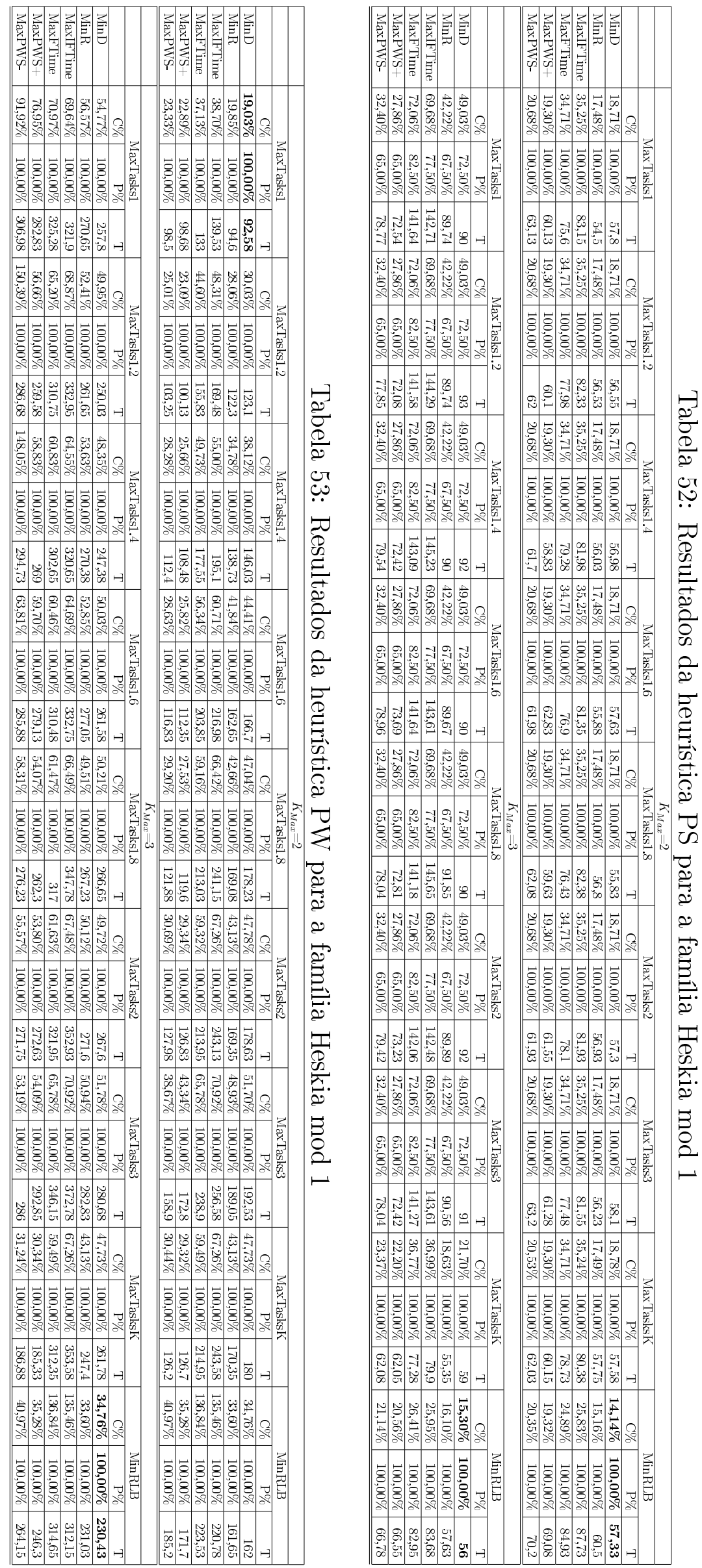
soluções para o problema serial para $K_{\text {Max }}=2$ e a $18,53 \%$ para $K_{\text {Max }}=3$. Esta heurística também encontrou duas soluções cujos tempos de execução são melhores que as soluções ótimas das respectivas instâncias para o problema serial. Para $K_{\text {Max }}=2$, as regras MaxTasks1.2 e MaxPWS- encontrou as melhores soluções em média. Já para $K_{M a x}=3$, as melhores soluções foram encontradas pelas regras MinRLB e MinR.

As melhores soluções encontradas pela heurística PS utilizando $K_{M a x}=2$ estavam a $10,23 \%$ das melhores soluções para o problema serial, enquanto que para $K_{M a x}=3$ estas soluções estavam a 11,05\%. A família Heskia mod 1 foi a única em que a heurística PS não conseguiu achar soluções utilizando todas as combinações de regras. A combinação das regras MinRLB e MinD encontrou as melhores soluções em média.

Para a heurística PW, utilizando $K_{\text {Max }}=2$, as melhores soluções encontradas estavam a 12,31\% das soluções ótimas para o problema serial, enquanto que para $K_{\text {Max }}=2$ estas soluções estavam a 16,66\%. Duas instâncias apresentaram melhoria em relação à solução ótima do problema serial. A regra MinD encontrou as melhores soluções, em média, especialmente quando combinada com as regras MaxTasks1 para $K_{\text {Max }}=2$ e MinRLB para $K_{M a x}=3$.

As tabelas 54, 55, 56 e 57 apresentam os resultados obtidos pelas heurísticas P1, P2, PS e PW, respectivamente, para a família Heskia mod 2.

Utilizando a heurística P1, as melhores soluções encontradas para a família Heskia mod 2 estavam, em média, a 7,16\% das soluções ótimas para o problema serial para $K_{\text {Max }}=2$ e a $8 \%$ para $K_{\text {Max }}=3$. A combinação das regras MaxTasks3 e MinR obteve as melhores soluções em média, porém conseguiu resolver poucas instâncias.

Para a heurística P2, as melhores soluções encontradas para $K_{\text {Max }}=2$ estavam, em média, a 5,94\% das soluções ótimas para o ALWABP serial e a $6,64 \%$ para $K_{\text {Max }}=3$. Esta heurística encontrou soluções melhores que as soluções ótimas para o problema serial em quatro instâncias. A combinação das regras MinRLB e MinR encontrou as melhores soluções, em média.

As melhores soluções encontradas pela heurística PS estavam, em média, a 2,77\% das soluções ótimas para o problema serial, usando $K_{\text {Max }}=2$, e a $3,76 \%$, usando $K_{\text {Max }}=3$. Em seis instâncias esta heurística conseguiu encontrar soluções melhores que as respectivas soluções ótimas para o ALWABP serial. A regra MinRLB, quando combinada com a regra MinR, encontrou as melhores soluções em média.

Por fim, para a heurística PW, as melhores soluções encontradas para $K_{\text {Max }}=2$ 

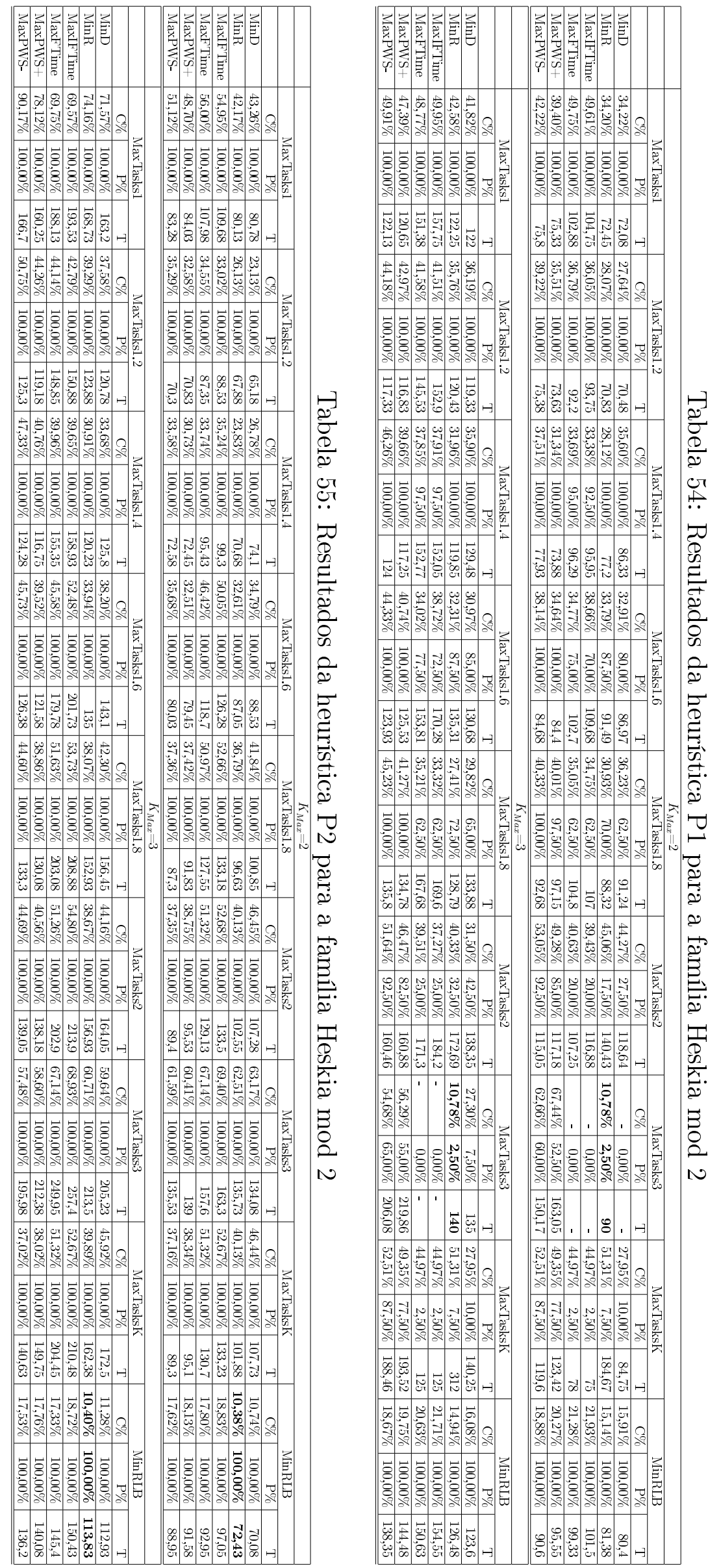

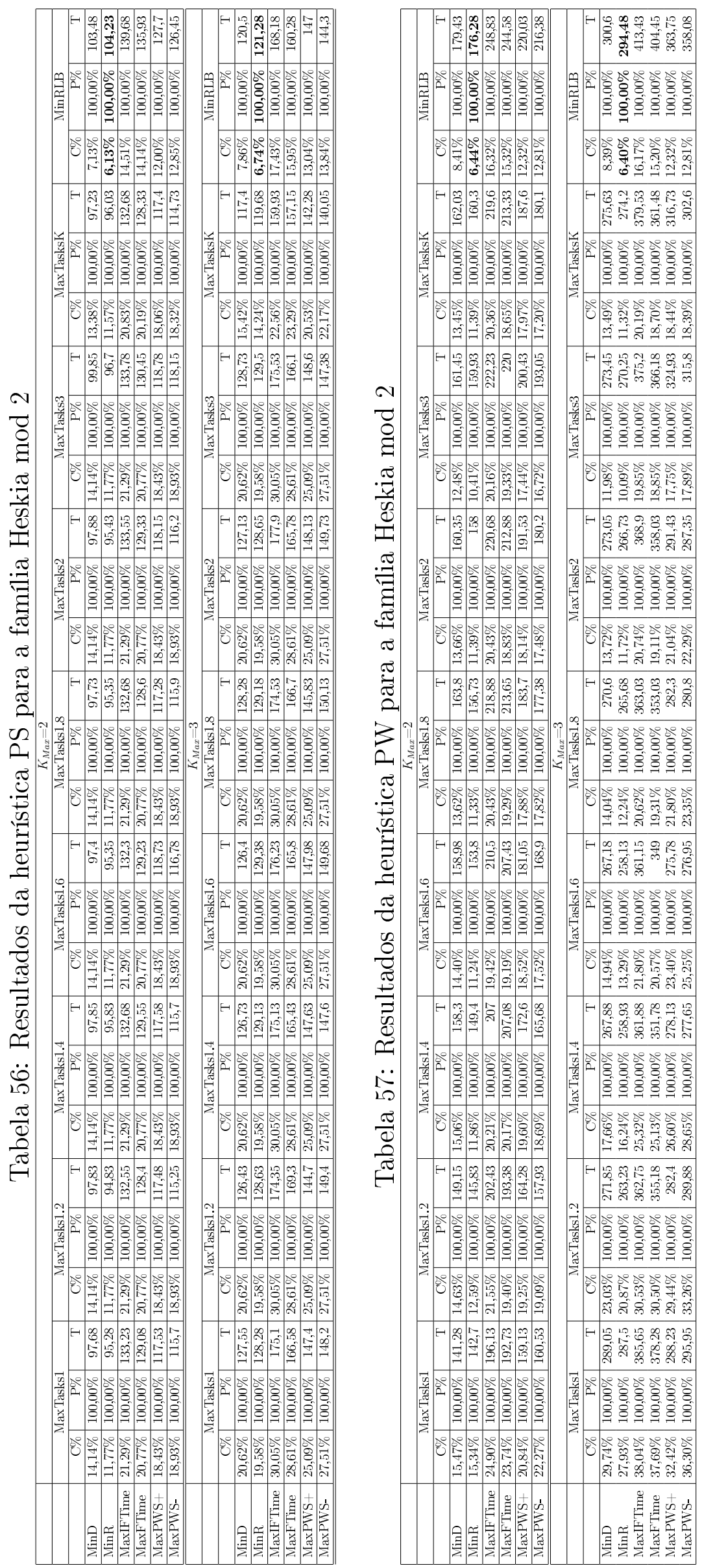
estavam, em média, a 4,05\% das soluções ótimas para o problema serial e, para $K_{\text {Max }}=3$, a 4,29\%. Esta heurística foi capaz de encontrar, em sete instâncias, soluções cujos tempos de execução são menores do que as soluções ótimas das respectivas instâncias para o ALWABP serial. A combinação das regras MinRLB e MinR apresentou as melhores soluções, em média.

Desta forma, a heurística PW foi capaz de encontrar as melhores soluções, em média, para as quatro famílias de instâncias originais. De fato, para a família Tonge, esta heurística encontrou soluções melhores que aquelas encontradas pela heurística para o ALWABP com estações em paralelo. Entre as regras de prioridade utilizadas, a regra MinR obteve as melhores soluções, em média, nas quatro famílias. Para as famílias Heskia e Roszieg, a regra MinRLB obteve as melhores soluções em média, enquanto que para as famílias Tonge e Wee-mag, as melhores soluções foram encontradas pelas regras MinRLB, MaxTasksK e MaxTasks2.

Para as instâncias modificadas, a regra MinRLB também obteve as melhores soluções em média, especialmente quando combinada com as regras MaxPWS- e MaxPWS + , para as famílias Roszieg mod 1 e 2, e com a regra MinR, para as famílias Heskia mod 1 e 2. A heurística PW apresentou os melhores resultados. A heurística P1 foi incapaz de resolver diversas instâncias da maioria das famílias. Os testes mostraram também que as heurísticas encontram dificuldades para encontrar soluções com o aumento do valor

de $K_{\text {Max }}$. Na maioria dos casos, as soluções encontradas utilizando $K_{\text {Max }}=3$ possuem tempo de ciclo maior ou igual àquelas encontradas utilizando $K_{\operatorname{Max}}=2$.

\section{A.2 Heurística para o ALWABP colaborativo}

As tabelas 58, 59, 60 e 61 apresentam, respectivamente, os resultados obtidos pela heurística para as famílias Roszieg, Heskia, Tonge e Wee-mag. Além disso, as tabelas 62, 63, 64 e 65 apresentam os resultados obtidos para as famílias Roszieg mod 1, Roszieg mod 2, Heskia mod 1 e Heskia mod 2, respectivamente. Em cada tabela, apresentamos os resultados obtidos por cada regra de prioridade para as tarefas (em cada linha) quando combinadas com as regras de seleção de trabalhador (em cada coluna). Para cada combinação de regras, apresentamos a distância média entre as soluções encontradas pela heurística e as melhores soluções conhecidas para o ALWABP serial (coluna $C \%$ ), bem como o tempo médio de execução da heurística em milisegundos (coluna $T$ ).

Para a família Roszieg, as melhores soluções encontradas estavam, em média, a 2,17\% 


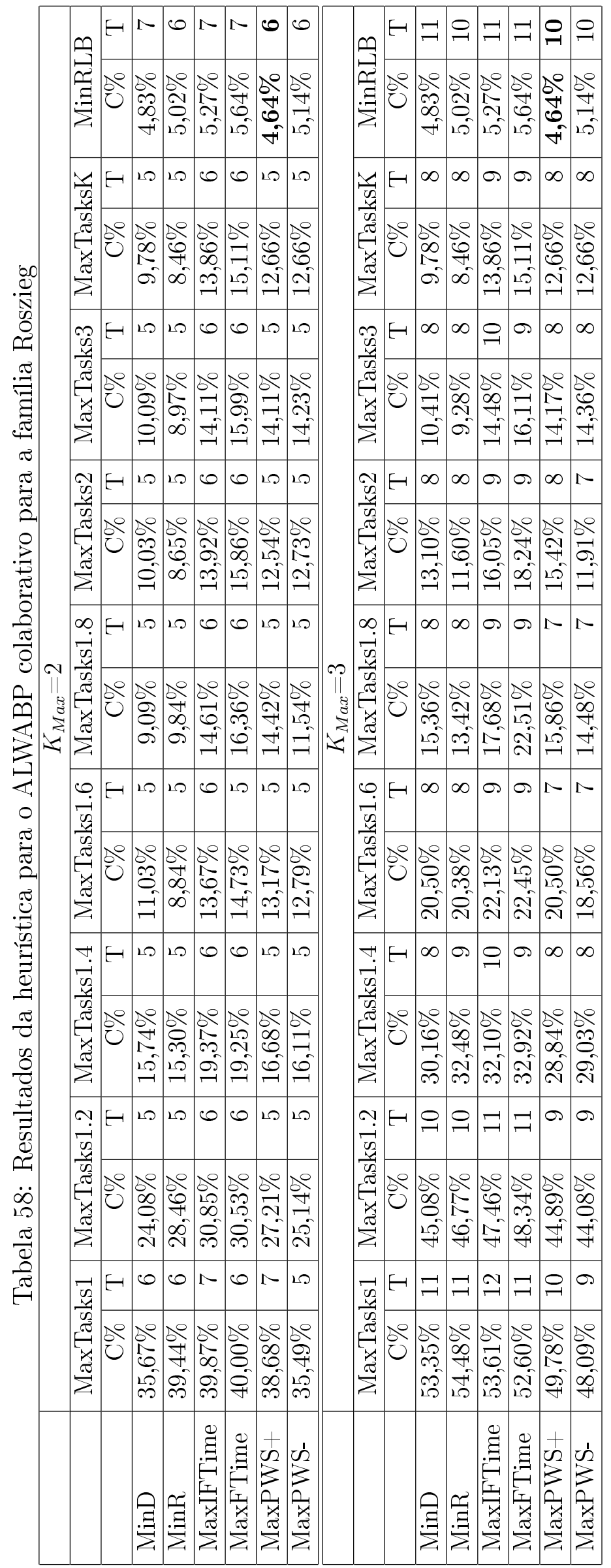




\begin{tabular}{|c|c|c|c|c|c|c|c|c|c|c|c|c|c|c|c|}
\hline 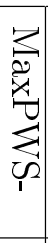 & 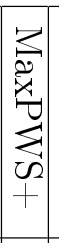 & 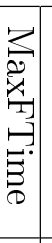 & 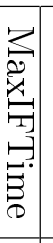 & & & & & & 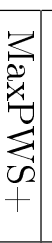 & & & & & & \\
\hline ¿ֶ & $\mid \begin{array}{l}0 \\
0 \\
0 \\
0 \\
0 \\
\partial\end{array}$ & 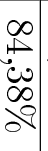 & 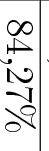 & 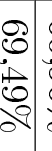 & 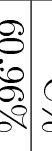 & 8 & 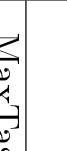 & 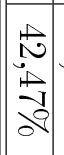 & 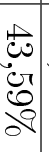 & 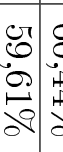 & $\begin{array}{c}8 \\
\\
\\
\end{array}$ & $\begin{array}{l}t \\
b \\
b \\
b\end{array}$ & 5 & \multirow{2}{*}{\multicolumn{2}{|c|}{ 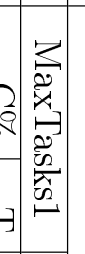 }} \\
\hline 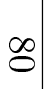 & $\begin{array}{l}\infty \\
1 \\
1\end{array}$ & $\overrightarrow{ \pm}$ & $\vec{\jmath}$ & $\vec{\infty}$ & $\infty$ & $\exists$ & 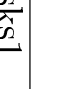 & 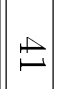 & 는 & 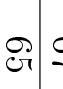 & $g$ & $\stackrel{\Delta}{*}$ & & & \\
\hline 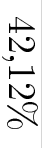 & 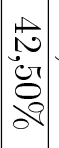 & 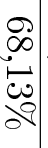 & 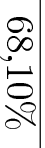 & 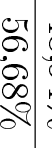 & 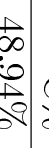 & & 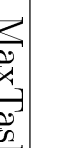 & 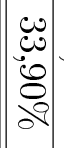 & |c. & 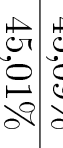 & $\begin{array}{l}\vec{c} \\
6 \\
0 \\
0 \\
0\end{array}$ & 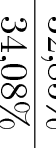 & $\mid$ & & \\
\hline$\vec{c}$ & $\stackrel{D}{D}$ & 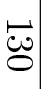 & 峁 & $\underline{v}$ & $\begin{array}{c}\infty \\
\infty\end{array}$ & $\exists$ & in & $\mid \begin{array}{cc}ن v \\
v\end{array}$ & $\begin{array}{c}0 \\
\infty\end{array}$ & ك & $\mathrm{c}$ & . & viv & $\dashv$ & ○ \\
\hline 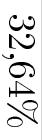 & 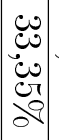 & 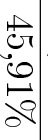 & 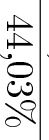 & s) & \begin{tabular}{l|}
0 \\
0 \\
0 \\
0 \\
$\vdots$ \\
0
\end{tabular} & & 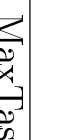 & $\left|\begin{array}{c}0 \\
-1 \\
ن \\
0 \\
\partial \\
\partial \\
\partial\end{array}\right|$ & $\begin{array}{l}0 \\
-1 \\
0 \\
-1 \\
\text { d } \\
\text { and }\end{array}$ & 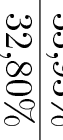 & 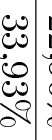 & 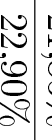 & 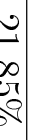 & $\frac{2}{8}$ & 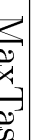 \\
\hline \& & $\stackrel{g}{v}$ & $\overrightarrow{\vec{c}}$ & $\stackrel{\infty}{\infty}$ & $\mathrm{v}$ & . & $\rightarrow$ & $\phi$ & آن & $\stackrel{\varpi}{\varpi}$ & gr & త్ & $\tilde{\sigma}$ & آنَّ & -1 & 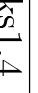 \\
\hline $\begin{array}{l}0 \\
0 \\
\text { N } \\
1 \\
d\end{array}$ & 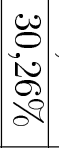 & | & 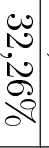 & 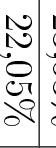 & | & & ن. & 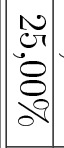 & 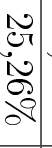 & 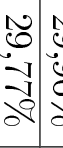 & $\begin{array}{l}0 \\
0 \\
0 \\
0 \\
0 \\
0 \\
0\end{array}$ & $\begin{array}{l}\vec{\infty} \\
\vec{c} \\
d \\
d\end{array}$ & $\begin{array}{l}\frac{0}{2} \\
\frac{1}{8}\end{array}$ & 8 & 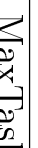 \\
\hline ק & $\mathscr{\delta}$ & ن. & ְi & \&. & $g$ & $\rightarrow$ & 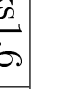 & 莕 & 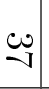 & $\underset{\infty}{\infty}$ & ת] & ن & تَن: & $\dashv$ & $\frac{6}{6}$ \\
\hline 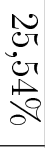 & 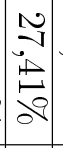 & $\begin{array}{l}0 \\
0 \\
0 \\
0 \\
0 \\
0\end{array}$ & $\begin{array}{c}0 \\
0 \\
0 \\
0 \\
0 \\
0 \\
0\end{array}$ & $\begin{array}{l}\overrightarrow{0} \\
\overrightarrow{0} \\
\vec{b} \\
\overrightarrow{8}\end{array}$ & 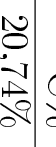 & 3 & 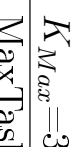 & 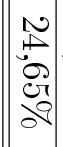 & $\begin{array}{l}1 \\
0 \\
\text { ind } \\
0 \\
\text { d }\end{array}$ & 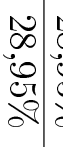 & $\begin{array}{l}0 \\
\infty \\
0 \\
0 \\
0 \\
0 \\
0\end{array}$ & $\begin{array}{l}\vec{\infty} \\
0 \\
0 \\
\vec{c} \\
d\end{array}$ & $\begin{array}{l}0 \\
0 \\
0 \\
0 \\
\end{array}$ & 8 & 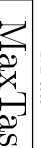 \\
\hline తిنْ & 8 & 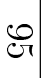 & 8 & $\mathscr{\perp}$ & હ્ञ & $\rightarrow$ & $\frac{\infty}{\infty}$ & $\stackrel{c o s}{\sigma}$ & $\stackrel{.0}{\circ}$ & g్ & g్ & و نِّن & $\dot{t}$ & -1 & $\frac{5}{\infty}$ \\
\hline 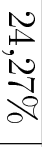 & $\begin{array}{c}0 \\
+ \\
\infty \\
0 \\
\partial \\
\partial \\
0\end{array}$ & 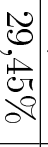 & 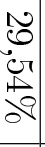 & $\begin{array}{l}\vec{v} \\
\vec{v} \\
\vec{a} \\
\partial\end{array}$ & $\begin{array}{c}\vec{\infty} \\
\vec{c} \\
\vec{c} \\
\vec{\partial}\end{array}$ & مी & | & 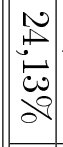 & 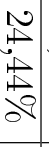 & $\begin{array}{ll}0 & 1 \\
\infty & \\
0 & 0 \\
0 & \\
0 & 8\end{array}$ & $\begin{array}{c}0 \\
\infty \\
\vec{c} \\
\overrightarrow{2}\end{array}$ & $\begin{array}{l}\overrightarrow{0} \\
0 \\
0 \\
0 \\
\partial\end{array}$ & $\begin{array}{l}\infty \\
0 \\
0 \\
0 \\
0\end{array}$ & 8 & 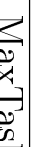 \\
\hline $\mathscr{\perp}$ & 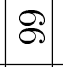 & $\mathscr{8}$ & $\stackrel{0}{v}$ & 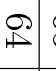 & હ्ञ & $\rightarrow$ & S. & . & | & $g$ & cr. & is & ن & $\rightarrow$ & Ŝ. \\
\hline 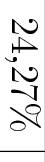 & 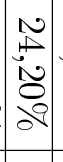 & $\begin{array}{c}0 \\
\infty \\
\infty \\
0 \\
0 \\
0 \\
0\end{array}$ & 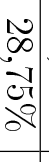 & $\begin{array}{l}\vec{y} \\
\overrightarrow{0} \\
0 \\
0 \\
\partial \\
\partial\end{array}$ & $\begin{array}{c}\vec{\infty} \\
0 \\
0 \\
0 \\
0\end{array}$ & 82 & نَ. & 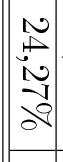 & 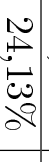 & 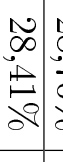 & $\begin{array}{c}0 \\
0 \\
0 \\
0 \\
0 \\
0\end{array}$ & $\begin{array}{l}\overrightarrow{1} \\
\vec{v} \\
0 \\
0 \\
\partial \\
\partial\end{array}$ & 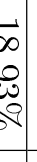 & 8 & خي \\
\hline$\stackrel{\infty}{ }$ & 8 & $\stackrel{\bullet}{\perp}$ & 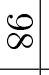 & $\stackrel{8}{\perp}$ & S. & $\rightarrow$ & ن. & $\begin{array}{l}\dot{x}_{\infty} \\
\mid\end{array}$ & $\stackrel{0}{v}$ & $g$ & I & $\stackrel{\sim}{\triangleright}$ & 芒 & - & Liv \\
\hline 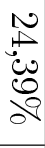 & 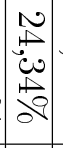 & 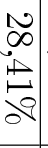 & $\begin{array}{l}0 \\
\infty \\
\infty \\
0 \\
0 \\
\partial\end{array}$ & $\begin{array}{l}\overrightarrow{0} \\
\infty \\
\infty \\
\overrightarrow{0} \\
0\end{array}$ & $\begin{array}{l}\overrightarrow{0} \\
\dot{0} \\
0 \\
0\end{array}$ & की & | & & 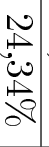 & 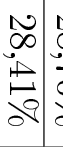 & $\begin{array}{c}0 \\
\infty \\
- \\
0 \\
\partial \\
\partial\end{array}$ & $\begin{array}{l}\vec{\sigma} \\
\infty \\
\mathbb{N} \\
\overrightarrow{8}\end{array}$ & $\overrightarrow{0}$ & 8 & $\frac{1}{0.0}$ \\
\hline$\infty$ & 8 & $\stackrel{\wp}{\ddagger}$ & 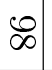 & $\mathcal{\Theta}$ & $\mathscr{\rho}$ & -1 & $n^{n}$ & $\begin{array}{l}\infty_{\infty} \\
\mid\end{array}$ & 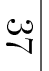 & $g$ & $\mathrm{~N}$ & $\stackrel{ن}{ \pm}$ & $\partial$ & -1 & $\lambda$ \\
\hline $\begin{array}{l}\vec{\sigma} \\
\vec{N} \\
\vec{d}\end{array}$ & $\begin{array}{c}\vec{a} \\
0 \\
0 \\
0 \\
0\end{array}$ & $\begin{array}{l}\vec{v} \\
\vec{v} \\
\text { 心 } \\
\text { di }\end{array}$ & 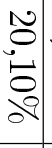 & 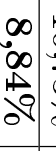 & 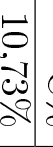 & & & & $\begin{array}{l}\vec{a} \\
0 \\
\overrightarrow{0} \\
\vec{\partial} \\
\partial\end{array}$ & 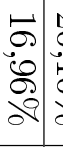 & $\begin{array}{c}0 \\
0 \\
0 \\
0 \\
0 \\
0\end{array}$ & $\begin{array}{l}\infty \\
\infty \\
\infty \\
\overrightarrow{0} \\
\end{array}$ & & & 6 \\
\hline$\vartheta$ & \& & c) & 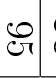 & 今) & S & & & & : & 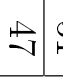 & $\stackrel{\Xi}{\Xi}$ & 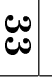 & & & \\
\hline
\end{tabular}




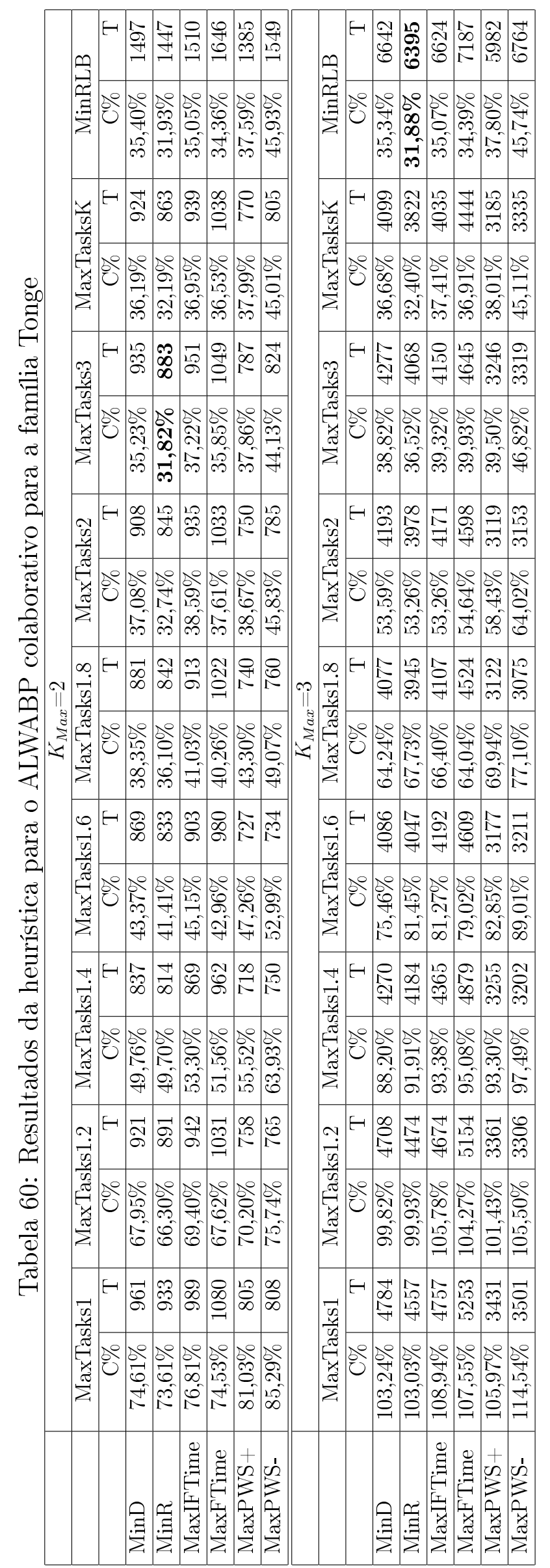




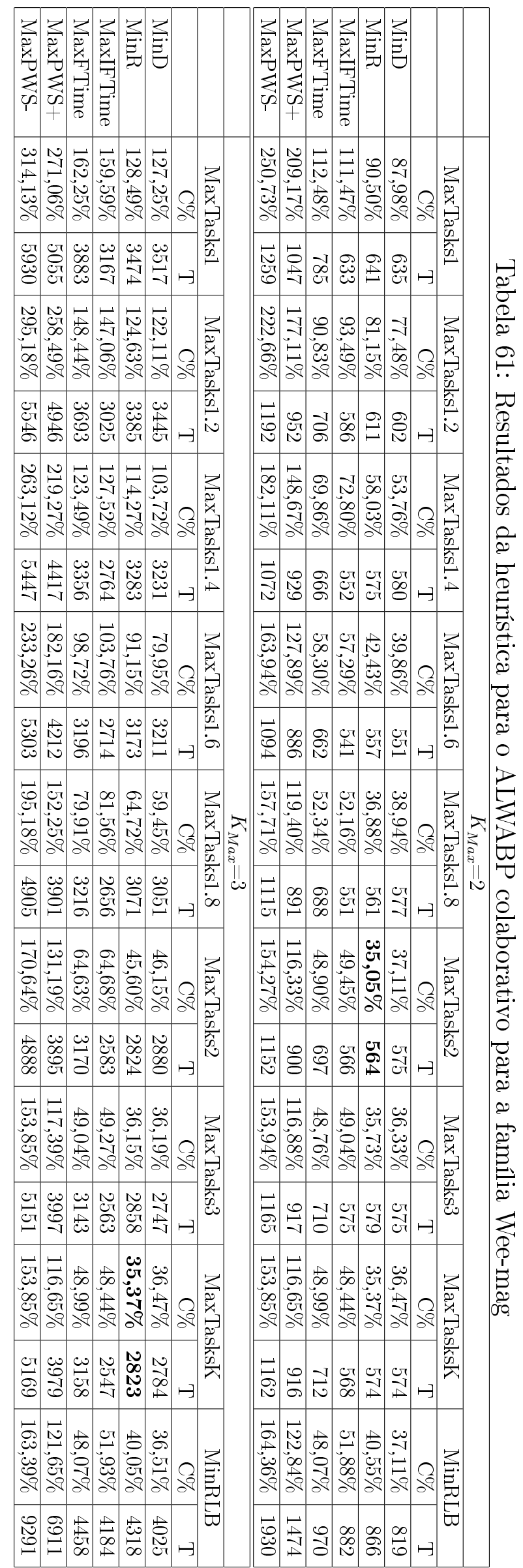




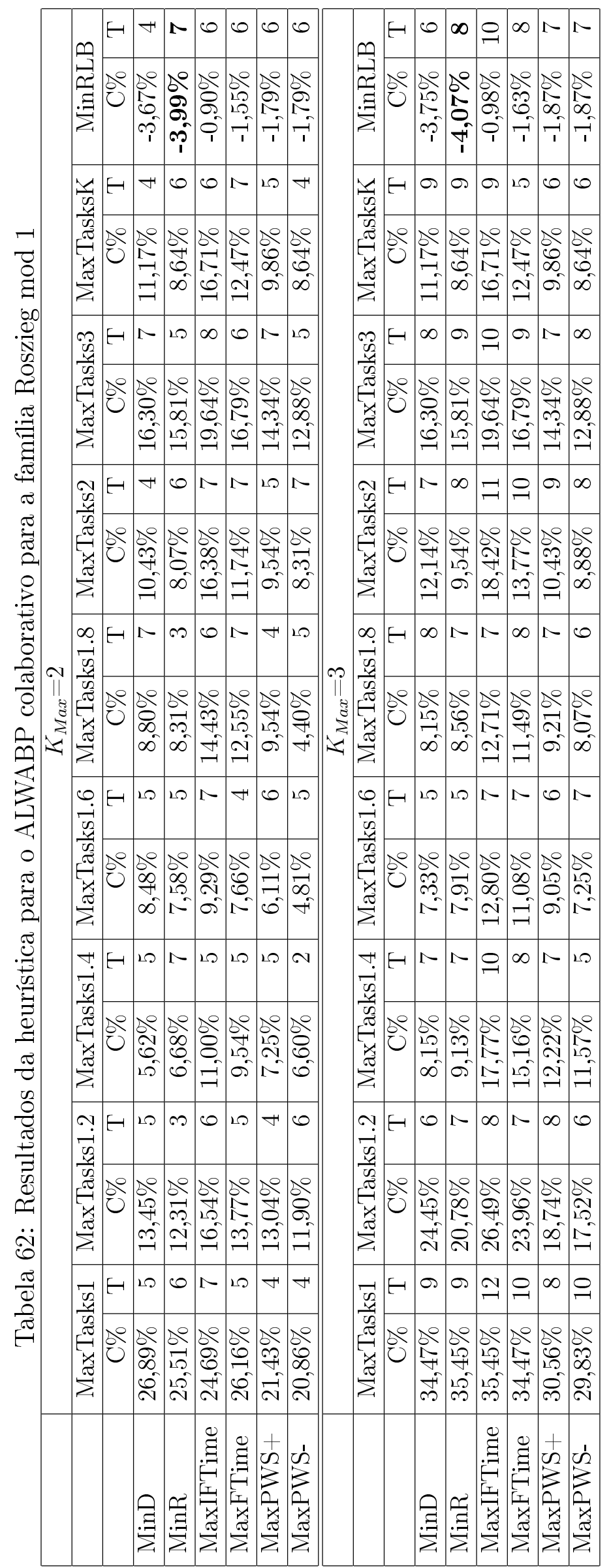




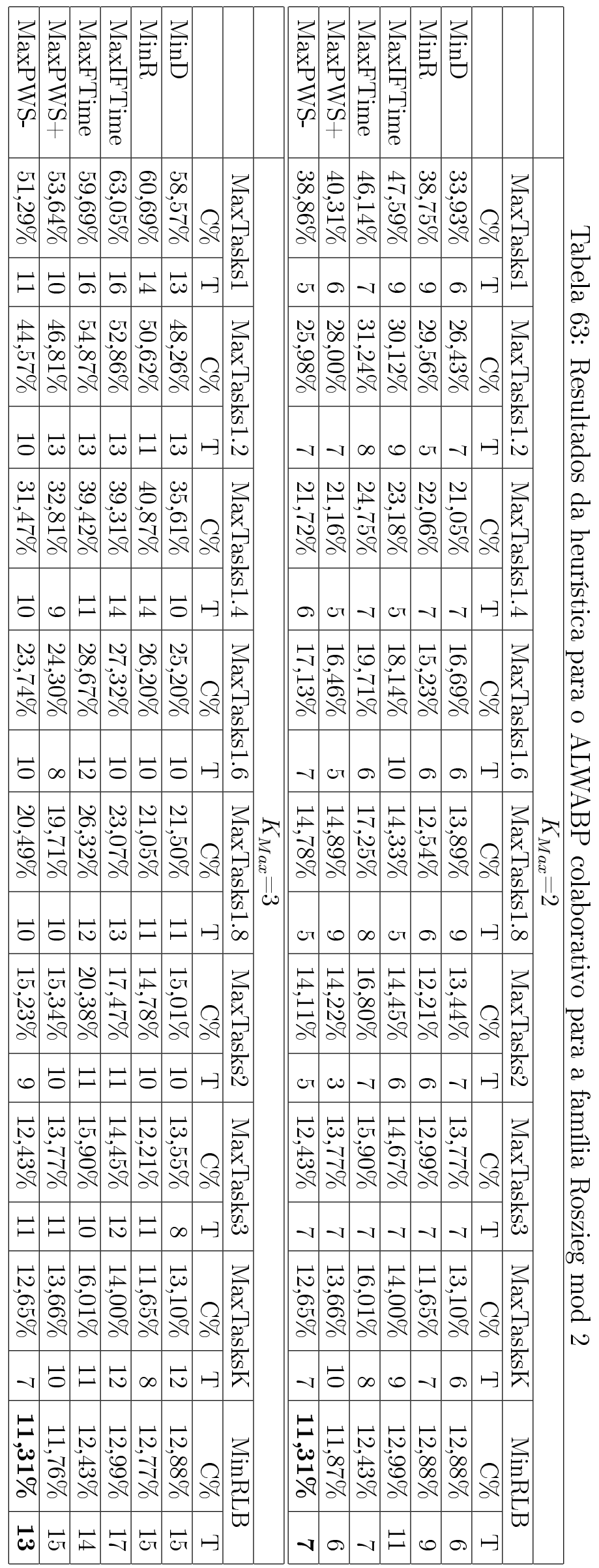




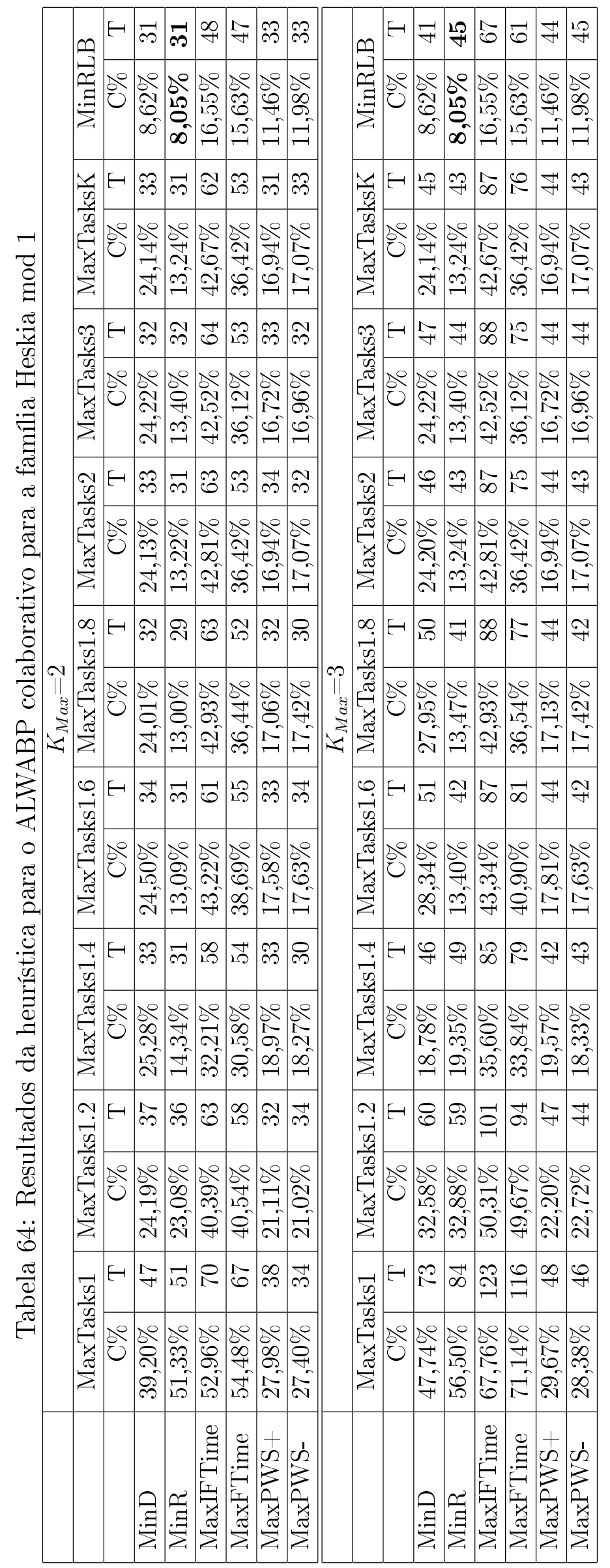




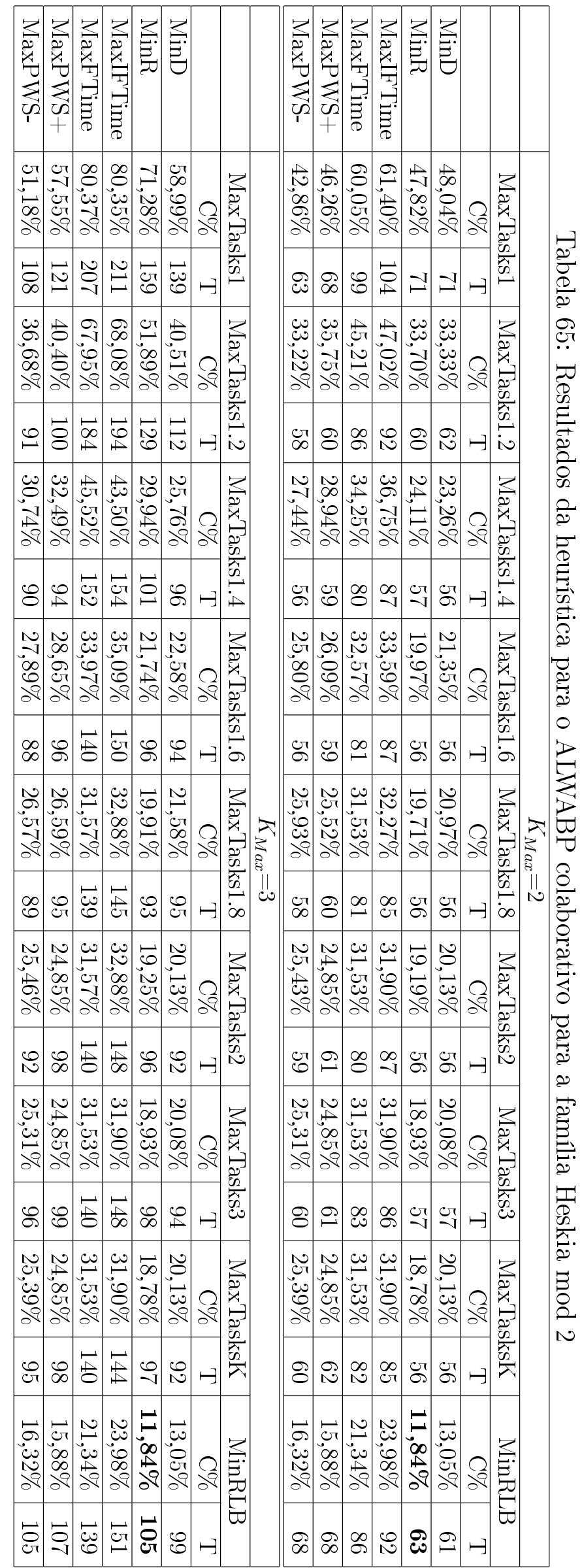


das soluções ótimas do ALWABP serial utilizando $K_{\text {Max }}=2$ e a 2,40\% utilizando $K_{\text {Max }}=$ 3. Em seis instâncias desta família, a heurística encontrou soluções melhores que as soluções ótimas do problema serial, sendo que em uma destas instâncias esta melhoria chegou a 43\%. A combinação das regras MinRLB e MaxPWS- obteve as melhores soluções em média para esta família.

As melhores soluções encontradas para a família Heskia estavam, em média, a 5,83\% das soluções ótimas para o ALWABP serial. A regra MinRLB, quando combinada com a regra MinR, apresentou as melhores soluções, em média.

Para família Tonge, as melhores soluções encontradas estavam, em média, a 22,05\% das melhores soluções conhecidas para o problema serial, utilizando $K_{\text {Max }}=2$, e a 23,19\%, utilizando $K_{\text {Max }}=3$. A regra MinR encontrou as soluções com os menores tempos de ciclo em média, especialmente quando combinada com as regras MaxTasks3, para $K_{\text {Max }}=2$, e MinRLB, para $K_{\text {Max }}=3$.

Para a família Wee-mag, as diferença entre as melhores soluções encontradas pela heurística e as melhores soluções conhecidas, em média, era de $26,77 \%$ para $K_{\text {Max }}=2$ e $27,46 \%$ para $K_{M a x}=3$. As melhores soluções em média foram encontradas pela regra MinR, combinada com as regras MaxTasks2 para $K_{\text {Max }}=2$ e MaxTasksK para $K_{\text {Max }}=3$.

Para a família Roszieg mod 1, as melhores soluções encontradas eram, em média, $3,09 \%$ melhores que aquelas encontradas pelo ALWABP serial para $K_{\text {Max }}=2$ e 3,12\% para $K_{\text {Max }}=3$. Seis instâncias desta família apresentaram soluções melhores que as respectivas soluções ótimas para o problema serial. Duas destas soluções representaram uma redução de $50 \%$ no tempo de ciclo, a maior melhoria encontrada pela heurística. A combinação das regras MinRLB e MinR retornou as melhores soluções em média.

As melhores soluções encontradas para a família Roszieg mod 2 estavam, em média, a $4,19 \%$ das soluções ótimas para $K_{\text {Max }}=2$ e a $4,55 \%$ para $K_{\text {Max }}=3$. As melhores soluções em média foram encontradas pela combinação das regras MinRLB e MaxPWS+.

Para a família Heskia mod 1, as melhores soluções encontradas estavam, em média, a $4,55 \%$ da soluções ótimas do ALWABP serial, tanto para $K_{\text {Max }}=2$ quanto para $K_{\text {Max }}=$ 3. As melhores soluções em média foram encontradas pela combinação das regras MinRLB e MinR.

Por fim, para a família Heskia mod 2, as melhores soluções encontradas estavam a $7,77 \%$ das soluções ótimas do ALWABP serial para ambos os valores de $K_{\text {Max }}$. A regra MinRLB, quando combinada com a regra MinR, encontrou as melhores soluções em média. 
Para as famílias Heskia e Roszieg, bem como para as quatro famílias de instâncias modificadas, a regra MinRLB encontrou as melhores soluções em média, especialmente quando combinada com as regras MinR, MaxPWS- e MaxPWS +. Para as famílias Tonge e Wee-mag, a regra MinR, quando combinada com as regras MaxTasks2, MaxTasks3, MaxTasksK e MinRLB encontrou as melhores soluções em média.

\section{A.2.1 Testes com as heurísticas modificadas}

As heurísticas C1, C2, CS e CW foram testadas utilizando as instâncias das famílias Roszieg, Heskia, Tonge, Wee-mag, Roszieg mod 1 e 2 e Heskia mod 1 e 2. As tabelas a seguir apresentam de forma resumida os resultados obtidos pelas heurísticas para estas famílias.

As tabelas 66, 67, 68 e 69 apresentam os resultados para a família Roszieg obtidos pelas heurísticas $\mathrm{C} 1, \mathrm{C} 2$, CS e $\mathrm{CW}$, respectivamente.

Assim como no caso em que forçamos paralelismo, forçar mais de um trabalhador em algum estágio para o ALWABP colaborativo pode resultar uma redução na qualidade da solução. Para a heurística $\mathrm{C} 1$, as melhores soluções encontradas para a família Roszieg estavam a 12,94\% das soluções ótimas do ALWABP serial, para $K_{\text {Max }}=2$, e a $13,8 \%$ para $K_{M a x}=3$. Esta heurística conseguiu encontrar cinco soluções melhores que as soluções ótimas das respectivas instâncias para o ALWABP serial. A combinação das regras MinRLB e MaxPWS- encontrou as melhores soluções em média.

Para a heurística C2, as melhores soluções encontradas estavam a 12,83\% das soluções ótimas do problema serial, para $K_{\text {Max }}=2$, e a $14,01 \%$, para $K_{\text {Max }}=3$. Cinco instâncias apresentaram soluções com tempo de ciclo menor do que os tempos de ciclo das soluções ótimas das respectivas instâncias para o problema serial. A regra MinRLB, quando combinada com a regra MinR, encontrou as melhores soluções em média.

As melhores soluções encontradas pela heurística CS estavam, em média, a 11,02\% das soluções ótimas para o ALWABP serial, utilizando $K_{\text {Max }}=2$, e a 12,29\%, utilizando $K_{M a x}=3$. Esta heurística também conseguiu encontrar soluções melhores que as soluções ótimas para o problema serial em cinco instâncias. Os melhores resultados, em média, foram encontrados pela combinação das regras MinRLB e MinD.

Para a heurística CW, as melhores soluções encontradas utilizando $K_{\text {Max }}=2$ estavam, em média, a 6,98\% das soluções ótimas para o problema serial e a $7,29 \%$ para $K_{\text {Max }}=3$. Em cinco instâncias, as melhores soluções encontradas pela heurística foram melhores que 

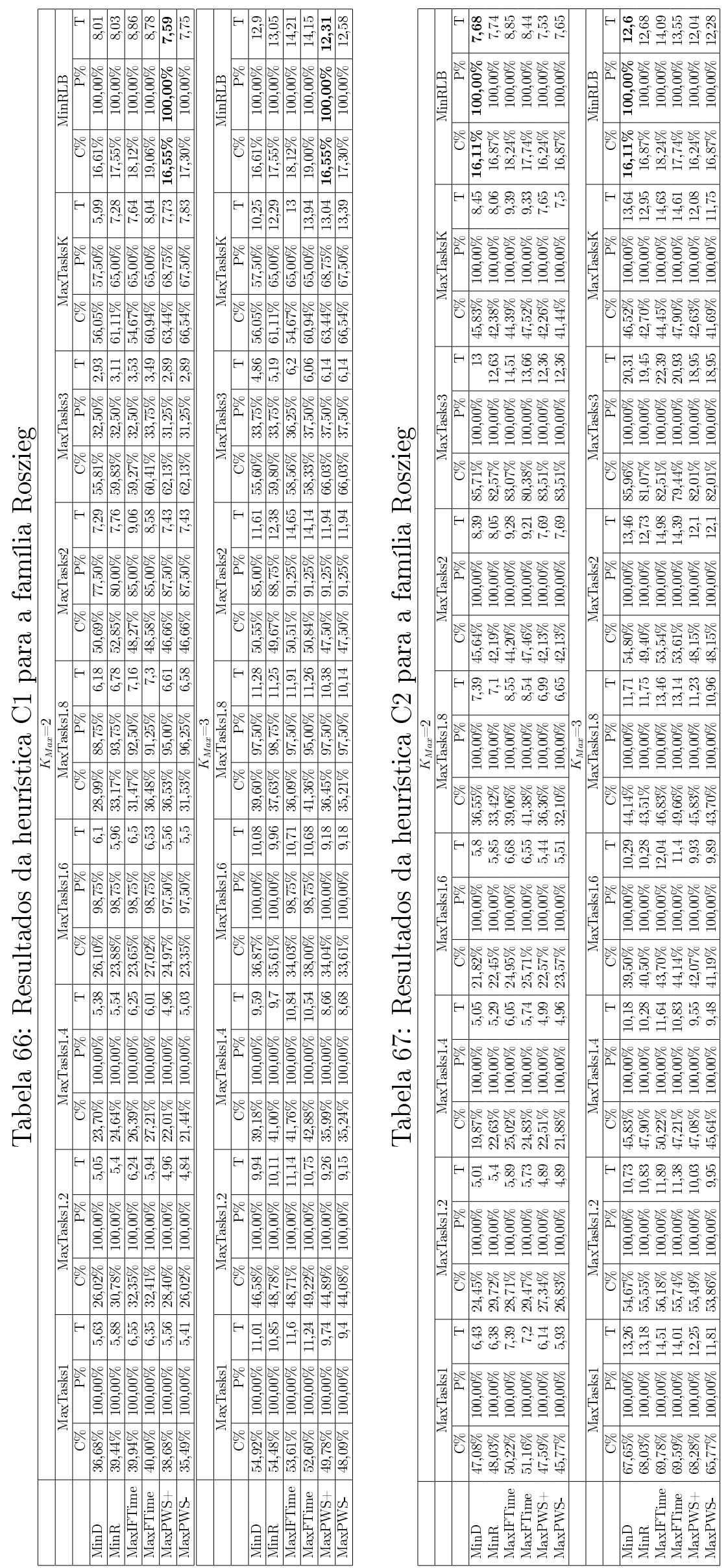


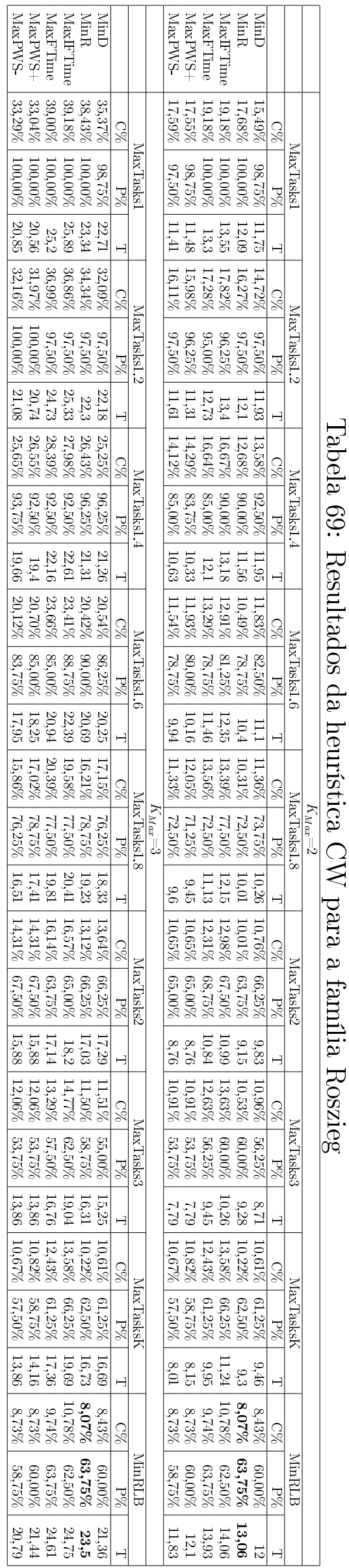

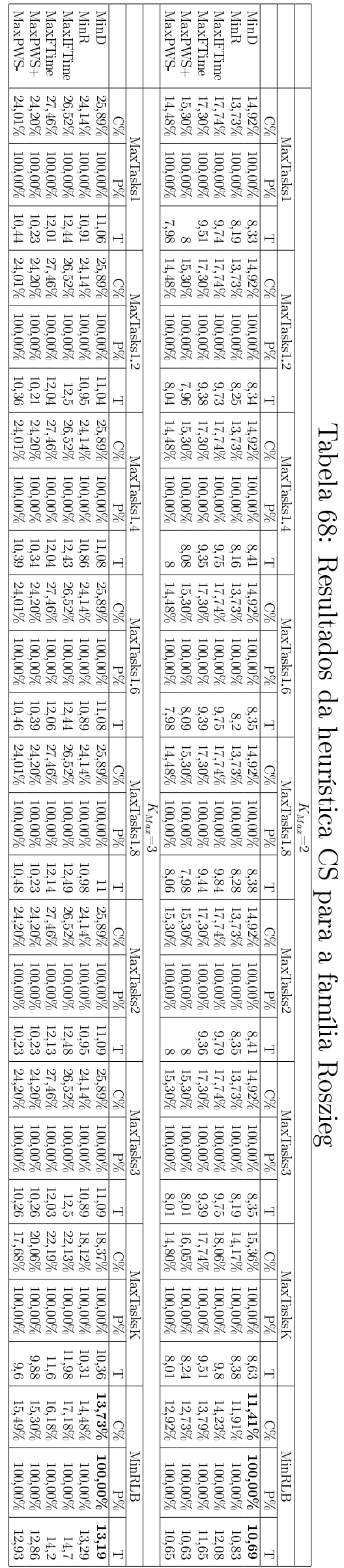


as soluções ótimas das respectivas instâncias para o ALWABP serial. A combinação das regras MinRLB e MinR encontrou as melhores soluções em média.

As tabelas 70, 71, 72 e 73 apresentam os resultados para a família Heskia obtidos, respectivamente, pelas heurísticas $\mathrm{C} 1, \mathrm{C} 2, \mathrm{CS}$ e $\mathrm{CW}$.

Para a família Heskia, as melhores soluções encontradas pela heurística C1 utilizando $K_{\text {Max }}=2$ estavam, em média, a $21,02 \%$ das soluções ótimas do problema serial e a 21,32\% para $K_{\text {Max }}=3$. Algumas combinações de regras não conseguiram encontrar soluções com mais de um trabalhador em um estágio, porém todas as instâncias foram resolvidas por pelo menos uma combinação de regras. A regra MinRLB, quando combinada com a regra MinR, apresentou as melhores soluções em média.

Para a heurística C2, a diferença entre as melhores soluções encontradas e as soluções ótimas para o ALWABP serial era de $19,06 \%$ para $K_{\text {Max }}=2$ e de $19,53 \%$ para $K_{\text {Max }}=3$. Apenas algumas instâncias não foram resolvidas por todas as combinações de regras, sendo que as regras MinRLB e MinR encontraram as melhores soluções em média quando combinadas.

Os melhores resultados encontrados pela heurística CS, estavam a 16,82\% das soluções ótimas para o problema serial, utilizando $K_{\text {Max }}=2$, e a $17,69 \%$, utilizando $K_{\text {Max }}=3$. A combinação das regras MinRLB e MinR encontrou as melhores soluções em média para ambos os valores de $K_{\text {Max }}$.

As melhores soluções encontradas pela heurística CW estavam, em média, a 10,23\% das soluções ótimas do ALWABP serial, para $K_{\text {Max }}=2$, e a $10,42 \%$, para $K_{\text {Max }}=3$. A combinação das regras MinRLB e MinD apresentou os melhores resultados, em média, para ambos os valores de $K_{\text {Max }}$.

Os resultados das heurísticas C1, C2, CS e CW para a família Tonge podem ser vistos, respectivamente, nas tabelas $74,75,76$ e 77 .

Para a família Tonge, a diferença entre as melhores soluções encontradas pela heurística $\mathrm{C} 1$ e as melhores soluções conhecidas para o ALWABP serial era de 25,28\% para $K_{\text {Max }}=2$ e $26,80 \%$ para $K_{\text {Max }}=3$. As regras MinRLB e MinR, quando combinadas, encontraram as melhores soluções, em média, para ambos os valores de $K_{\text {Max }}$.

As melhores soluções encontradas pela heurística C2 para estavam, em média, a $25,70 \%$ das melhores soluções conhecidas para o problema serial, utilizando $K_{\text {Max }}=2$, e a 26,16\%, para $K_{\text {Max }}=3$. A combinação das regras MinRLB e MinR encontrou as melhores soluções, em média. para ambos os valores de $K_{M a x}$. 


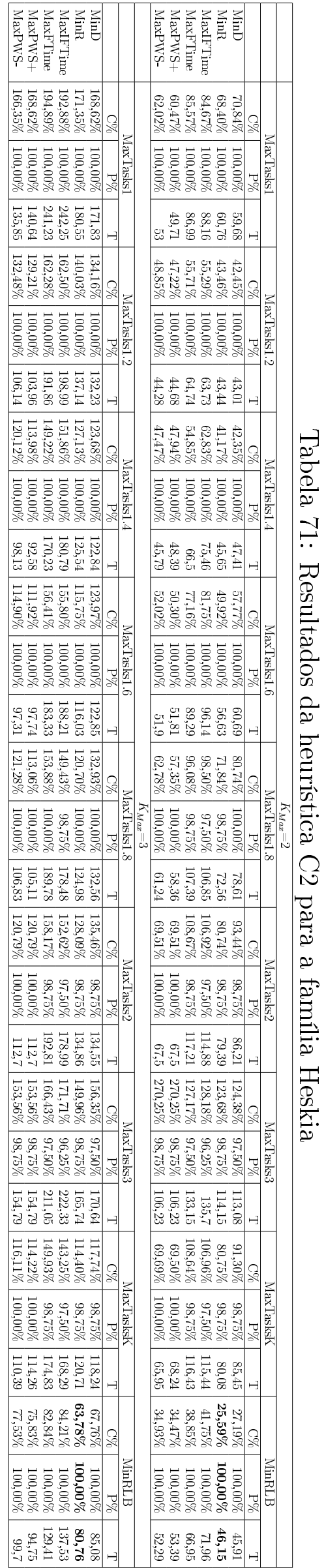

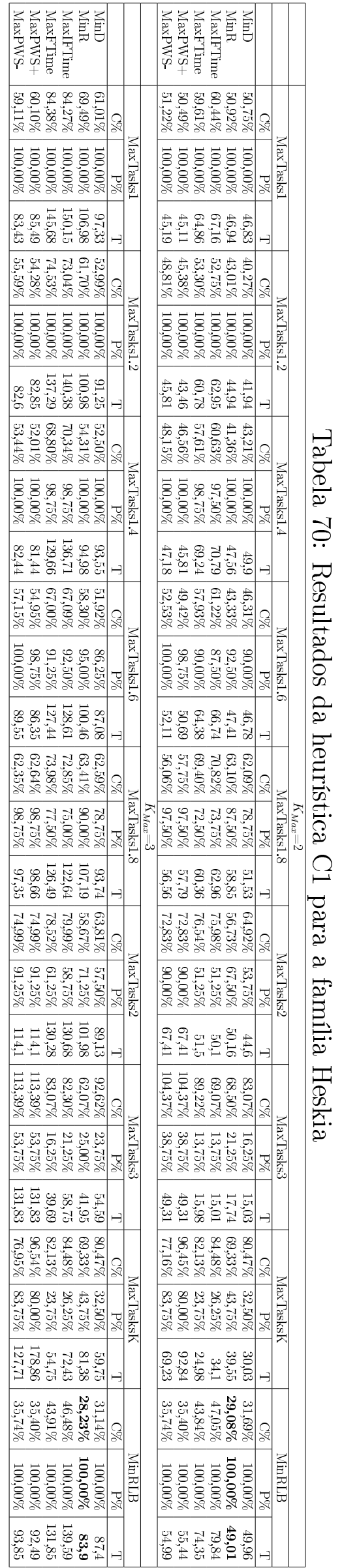



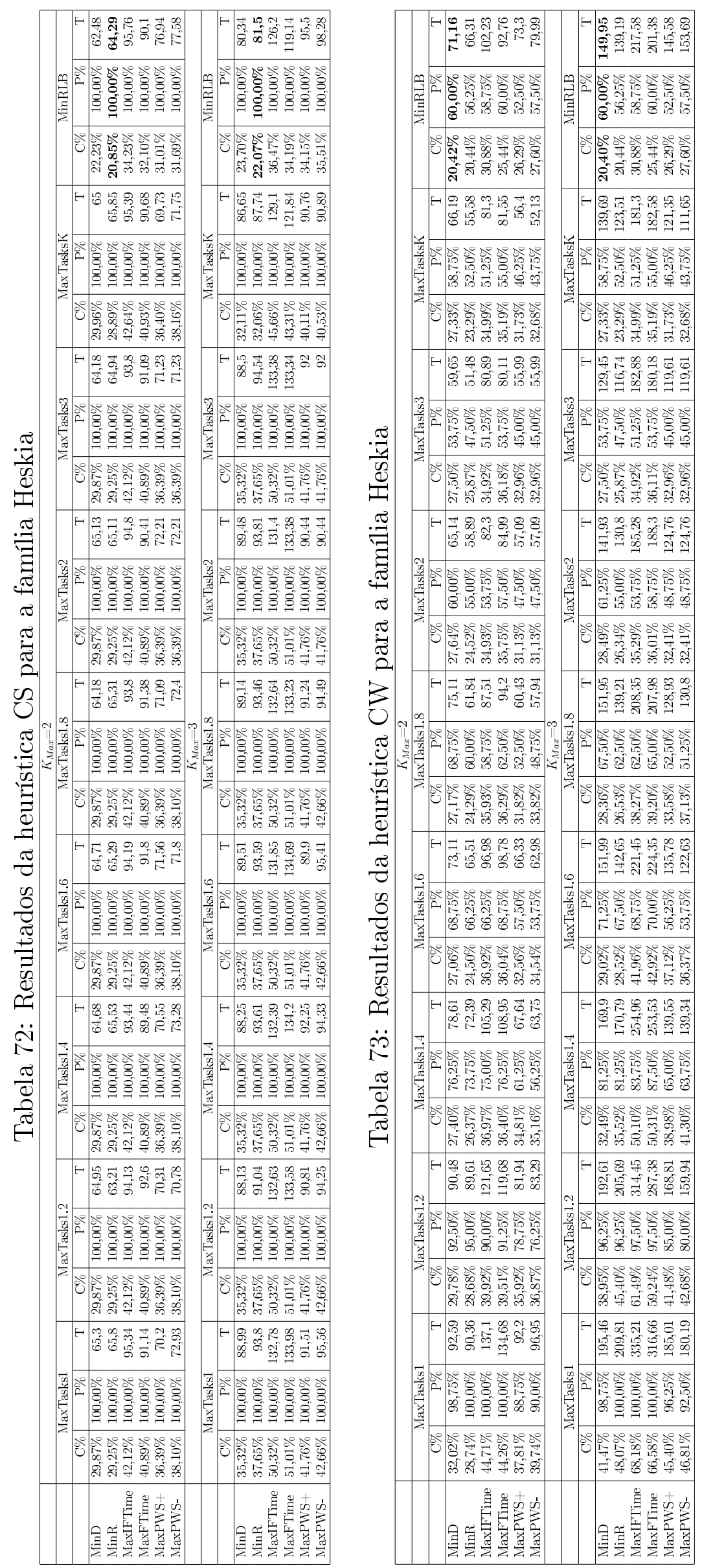


\begin{tabular}{|c|c|c|c|c|}
\hline 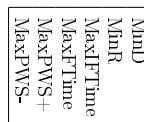 & & 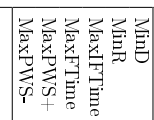 & & \\
\hline 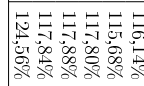 & & 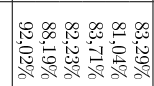 & & \\
\hline 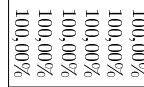 & & 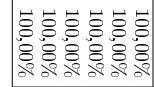 & 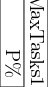 & \\
\hline 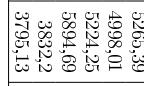 & & 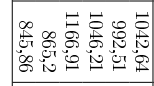 & & \\
\hline 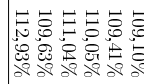 & 3 & 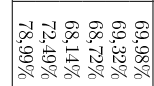 & & \\
\hline 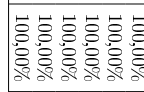 & & 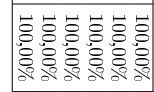 & 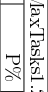 & \\
\hline 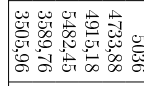 & -1 & 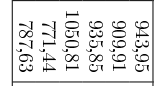 & $\dashv$ & \\
\hline 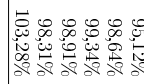 & & 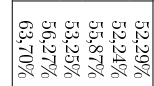 & & \\
\hline 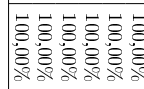 & & 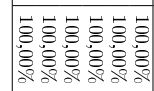 & & \\
\hline 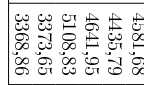 & & 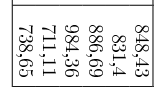 & ${ }_{-\rightarrow}^{-\infty}$ & \\
\hline 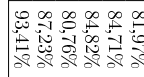 & & 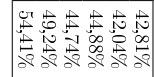 & & \\
\hline 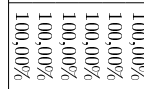 & & 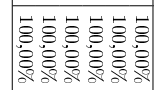 & & \\
\hline 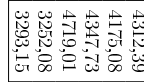 & -1 & 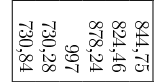 & - & \\
\hline 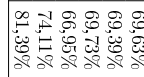 & & 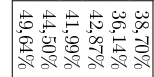 & & \\
\hline 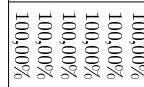 & $\checkmark)$ & 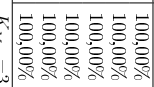 & & : \\
\hline 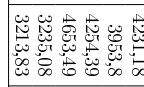 & $\rightarrow$ & 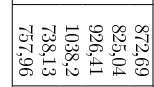 & - & \\
\hline 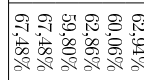 & & 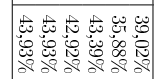 & & \\
\hline 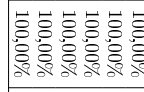 & 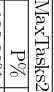 & 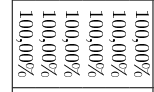 & 気 & \\
\hline 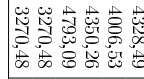 & & 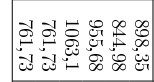 & & \\
\hline 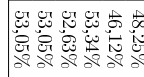 & & 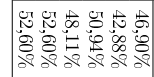 & & \\
\hline 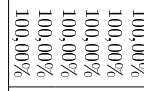 & 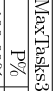 & 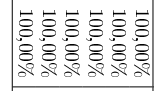 & 或窟 & \\
\hline 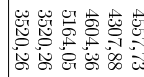 & & 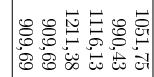 & $\dashv$ & \\
\hline 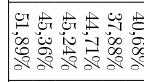 & & 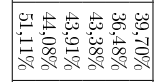 & & \\
\hline 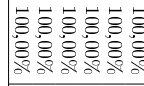 & 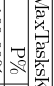 & 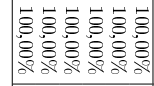 & 氙育 & \\
\hline 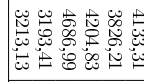 & -7 & 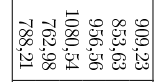 & & \\
\hline 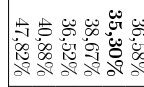 & & 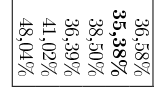 & & \\
\hline 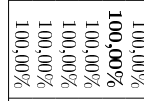 & 记 & 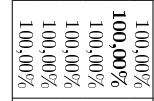 & 氙 & \\
\hline 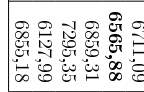 & $\rightarrow$ & 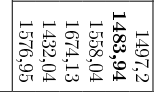 & & \\
\hline
\end{tabular}

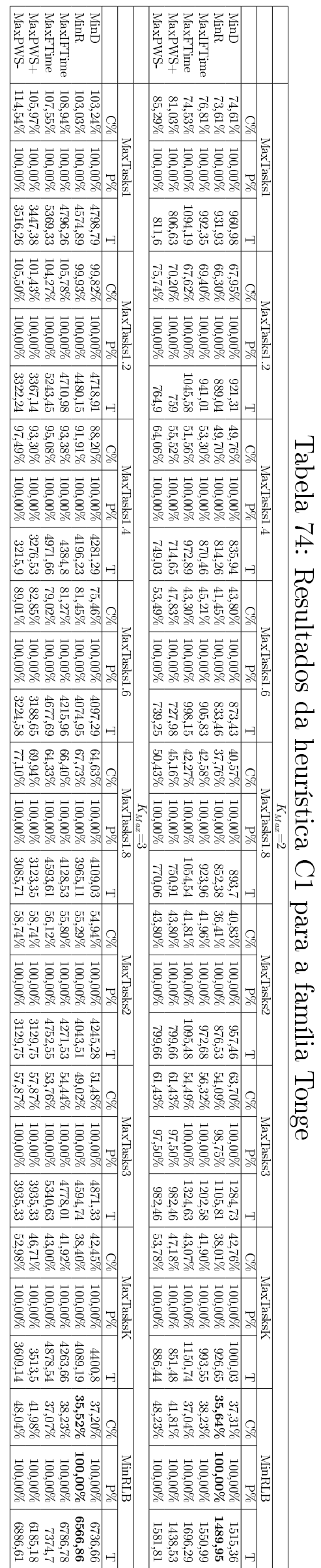



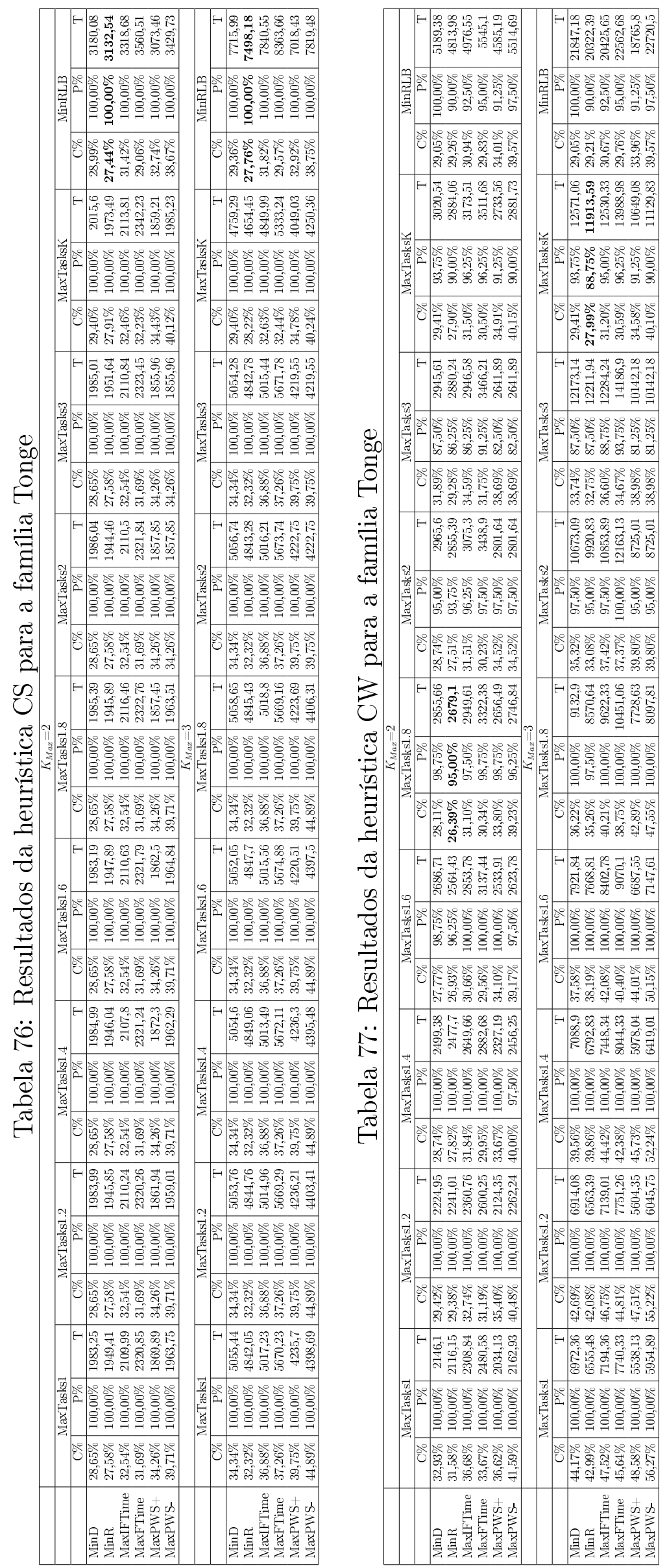
Utilizando a heurística CS, as melhores soluções encontradas estavam a 19,93\% das melhores soluções conhecidas para o ALWABP serial, para $K_{M a x}=2$, e a 20,04\%, para $K_{M a x}=2$. Para ambos os valores de $K_{\text {Max }}$, as regras MinRLB e MinR, quando combinadas, encontraram as melhores soluções em média.

A diferença entre as melhores soluções encontraras pela heurística CW e as melhores soluções conhecidas para o ALWABP serial era de $21,36 \%$ para $K_{\text {Max }}=2$ e de $23,14 \%$ para $K_{M a x}=3$. A regra MinR encontrou as melhores soluções em média, principalmente quando combinada com as regras MaxTasks1.8 (para $\left.K_{M a x}=2\right)$ e MaxTasksK $\left(K_{\text {Max }}=\right.$ $3)$.

As tabelas 78, 79, 80 e 81 apresentam, respectivamente, os resultados obtidos pelas heurísticas C1, C2, CS e CW para a família Wee-mag.

Para a família Wee-mag, as melhores soluções encontradas pela heurística C1 estavam a 31,21\% das melhores soluções conhecidas para o ALWABP serial, utilizando $K_{\text {Max }}=2$. Para $K_{M a x}=3$, as melhores soluções estavam a 33,92\% das melhores soluções conhecidas para o problema serial. A combinação das regras MaxTasks1.8 e MinR encontrou as melhores soluções em média para $K_{\operatorname{Max}}=2$, enquanto que, para $K_{\text {Max }}=3$, as regras MinRLB e MinD quando combinadas encontraram as melhores soluções em média.

As melhores soluções encontradas pela heurística C2 estavam, em média, a 31,59\% das melhores soluções conhecidas para o ALWABP serial, para $K_{\text {Max }}=2$, e a $32,32 \%$, para $K_{\text {Max }}=3$. Para $K_{\text {Max }}=2$, a combinação das regras MaxTasks1.8 e MinR encontrou as melhores soluções em média, enquanto que, para $K_{M a x}=3$, as melhores soluções em média foram encontradas pela combinação das regras MinRLB e MinD.

Para a heurística CS, as melhores soluções encontradas estavam a 23,03\% das melhores soluções para o problema serial, utilizando $K_{\text {Max }}=2$, e a $23,60 \%$, utilizando $K_{\text {Max }}=3$. A regra MinR encontrou as melhores soluções em média, especialmente quando combinada com as regras MaxTasks3 (para $K_{\text {Max }}=2$ ) e MaxTasksK (para $K_{\text {Max }}=3$ ).

As melhores soluções encontradas pela heurística CW estavam, em média, a 21,36\% das melhores soluções conhecidas para o ALWABP serial, para $K_{\text {Max }}=2$, e a $23,14 \%$, para $K_{M a x}=3$. As melhores soluções, em média, foram encontradas pela regra MinR, quando combinada com as regras MaxTasks1.8 (para $K_{M a x}=2$ ) e MaxTasksK (para $\left.K_{\text {Max }}=3\right)$.

As tabelas 82, 83, 84 e 85 apresentam os resultado obtidos pelas heurísticas C1, C2, CS e CW, respectivamente, para a família Roszieg mod 1. 

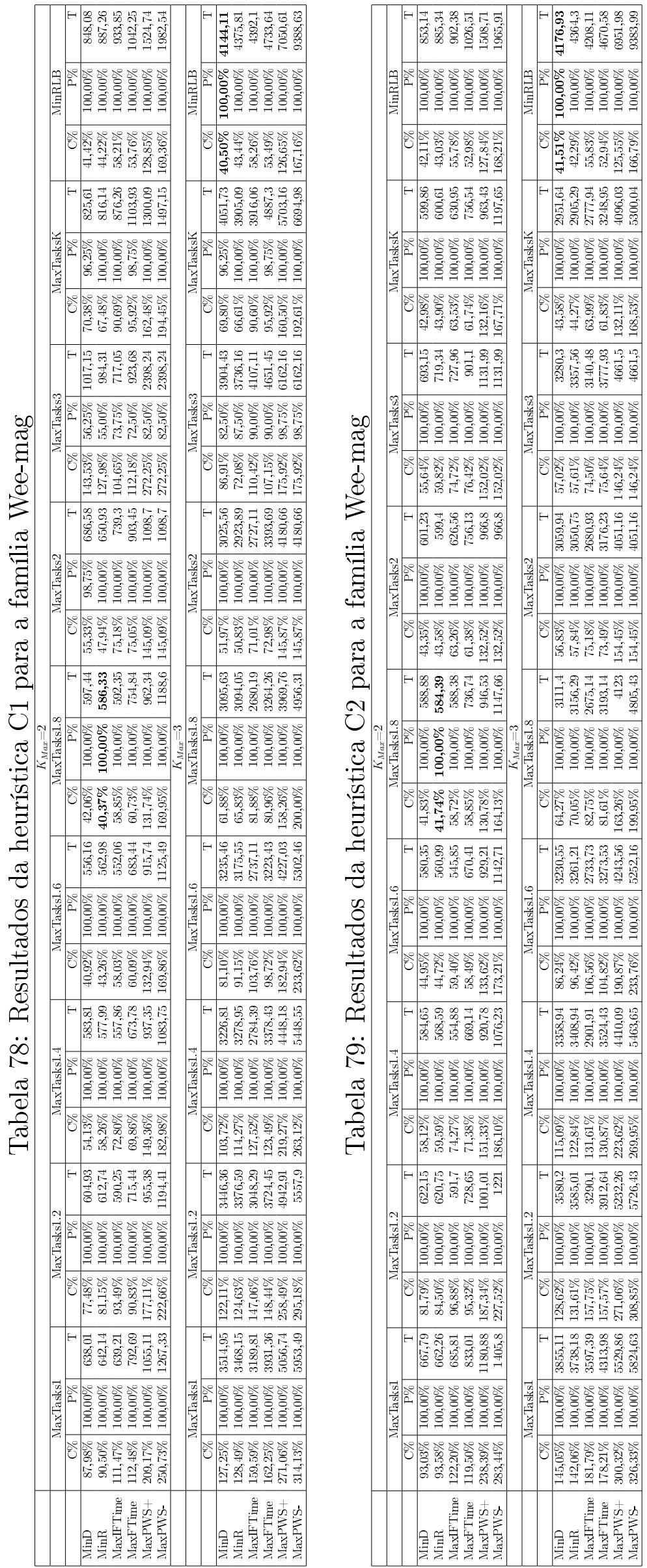

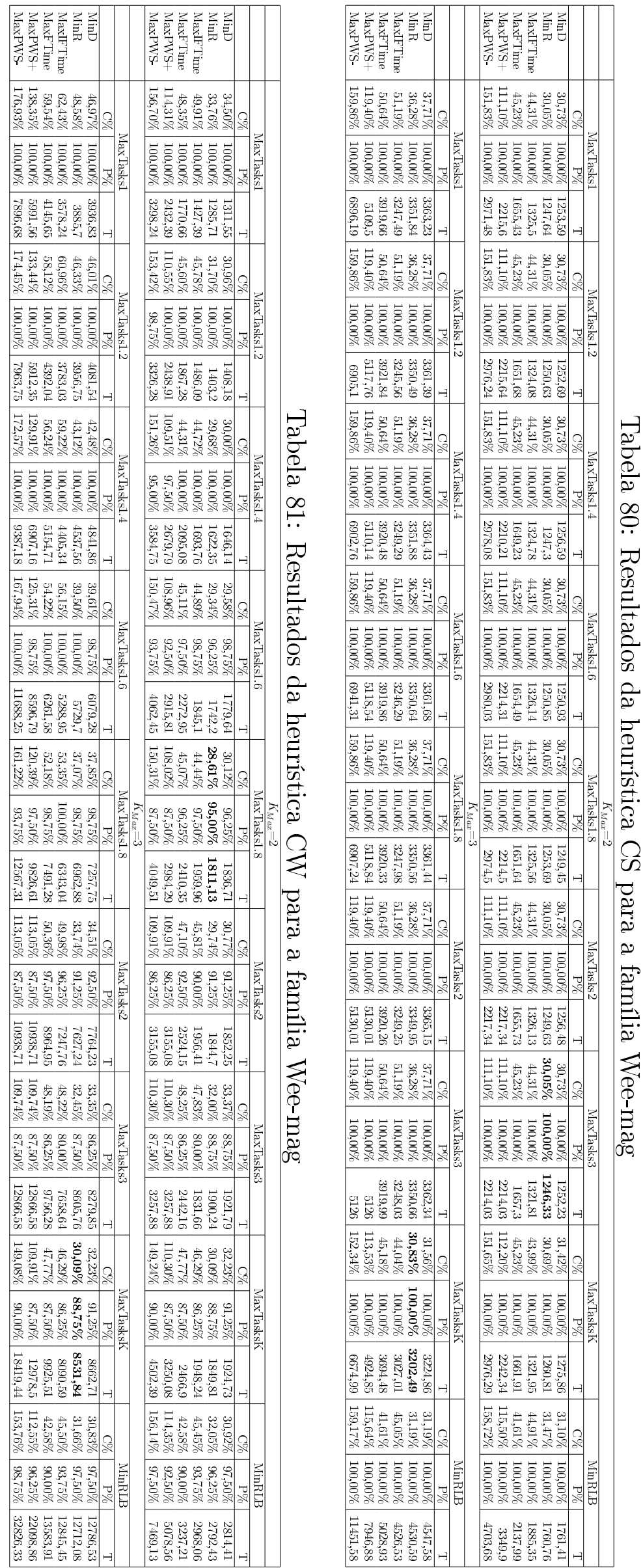

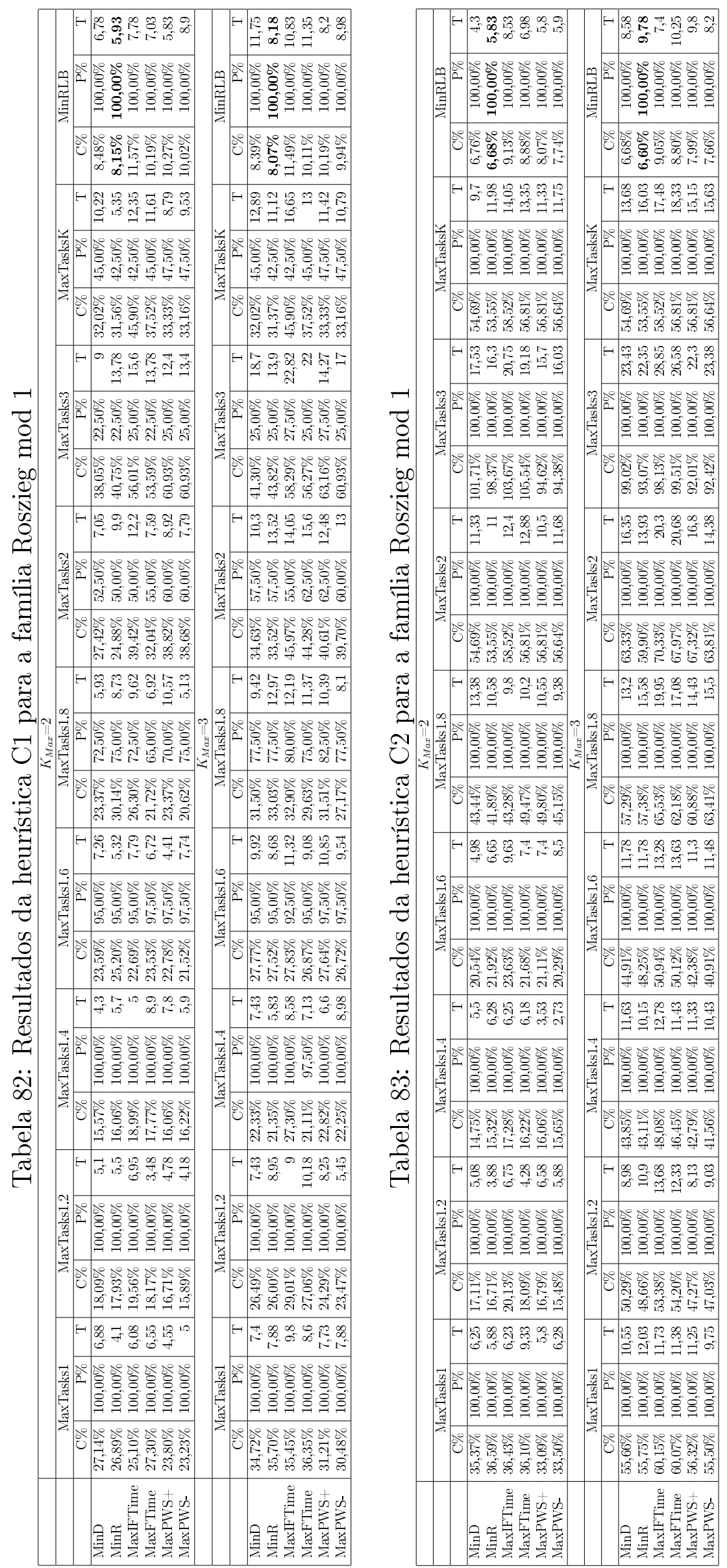

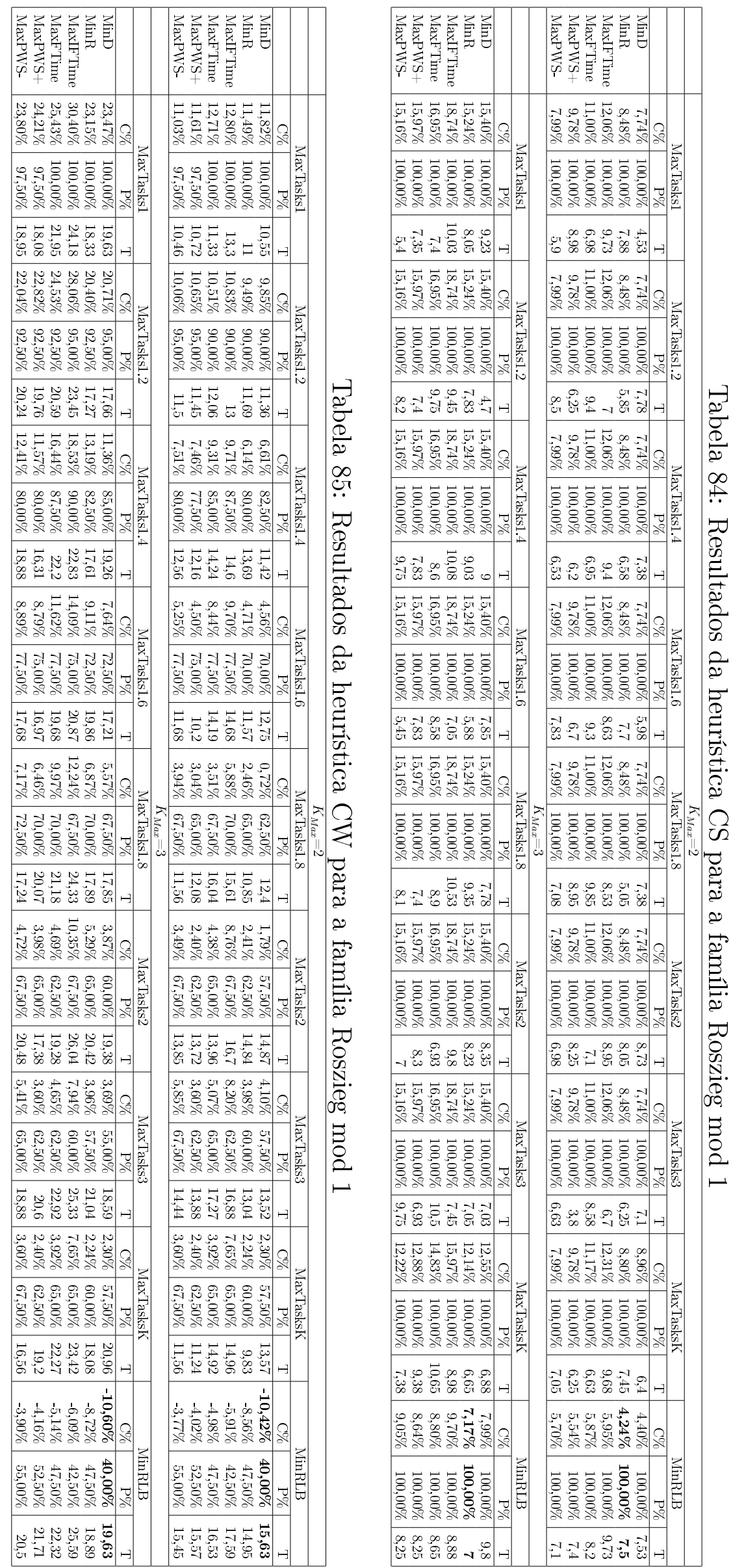
As melhores soluções encontradas pela heurística C1 para a família Roszieg mod 1 estavam, em média, a 9,03\% das soluções ótimas para o ALWABP serial, utilizando $K_{M a x}=2$, e a $9,22 \%$, utilizando $K_{\text {Max }}=3$. Algumas combinações de regras não conseguiram encontrar soluções para todas as instâncias, porém todas as instâncias foram resolvidas por pelo menos uma regra. Em seis instâncias, esta heurística conseguiu encontrar soluções melhores que as soluções ótimas das respectivas instâncias para o problema serial, sendo que em duas delas ocorreu uma redução de $50 \%$ no tempo de execução. A combinação das regras MinRLB e MinR conseguiu resolver todas as instâncias e encontrou as melhores soluções, em média, tanto para $K_{\operatorname{Max}}=2$ quanto para $K_{\text {Max }}=3$.

A diferença entre as melhores soluções encontradas pela heurística C2 e as soluções ótimas para o problema serial, em média, era de 8,95\% para $K_{\text {Max }}=2$ e 9,28\% para $K_{M a x}=3$. Esta heurística encontrou soluções para todas as instâncias utilizando todas as combinações de regras, sendo que em seis instâncias os tempos de ciclo das melhores soluções encontradas eram menores que os tempos de ciclo das soluções ótimas das respectivas instâncias para o ALWABP serial. As regras MinRLB e MinR, quando combinadas, apresentaram as melhores soluções, em média, para ambos os valores de $K_{M a x}$.

Para a heurística CS, as melhores soluções encontradas estavam, em média, a 8,15\% das soluções ótimas do problema serial, para $K_{\text {Max }}=2$, e a $9,91 \%$, para $K_{\text {Max }}=3$. Cinco instâncias apresentaram soluções melhores do que as soluções ótimas para o ALWABP serial. A combinação das regras MinRLB e MinR apresentou as melhores soluções, em média.

As melhores soluções encontradas pela heurística CW eram, em média, 1,02\% melhores que as soluções ótimas do problema serial, para $K_{\text {Max }}=2$, e 1,05\% melhores para $K_{\text {Max }}=$ 3. Em seis instâncias as melhores soluções encontradas possuiam tempo de ciclo menor do que as soluções ótimas para as respectivas instâncias para o problema serial. A combinação das regras MinRLB e MinD encontrou as melhores soluções, em média.

Os resultados das heurísticas C1, C2, CS e CW para a família Roszieg mod 2 podem ser vistos, respectivamente, nas tabelas $86,87,88$ e 89 .

Para a família Roszieg mod 2, a heurística C1 conseguiu encontrar soluções para todas as instâncias, apesar de que algumas combinações de critérios não conseguiram resolver algumas instâncias. A diferença entre as melhores soluções encontradas e as soluções ótimas para o problema serial foi de $18,8 \%$ para $K_{\text {Max }}=2$ e de $20,67 \%$ para $K_{\text {Max }}=3$. As melhores soluções, em média, foram encontradas pela combinação das regras MinRLB e MinR. 

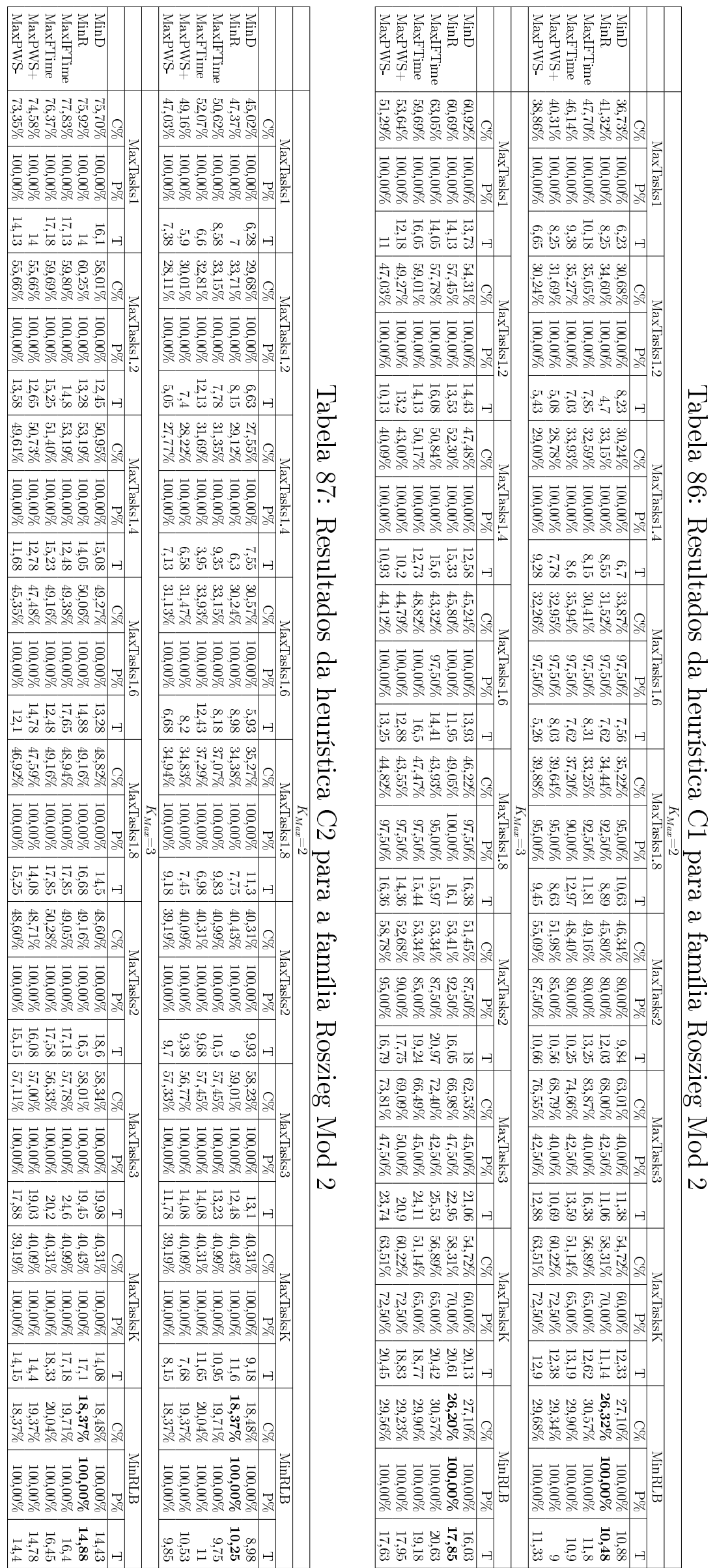

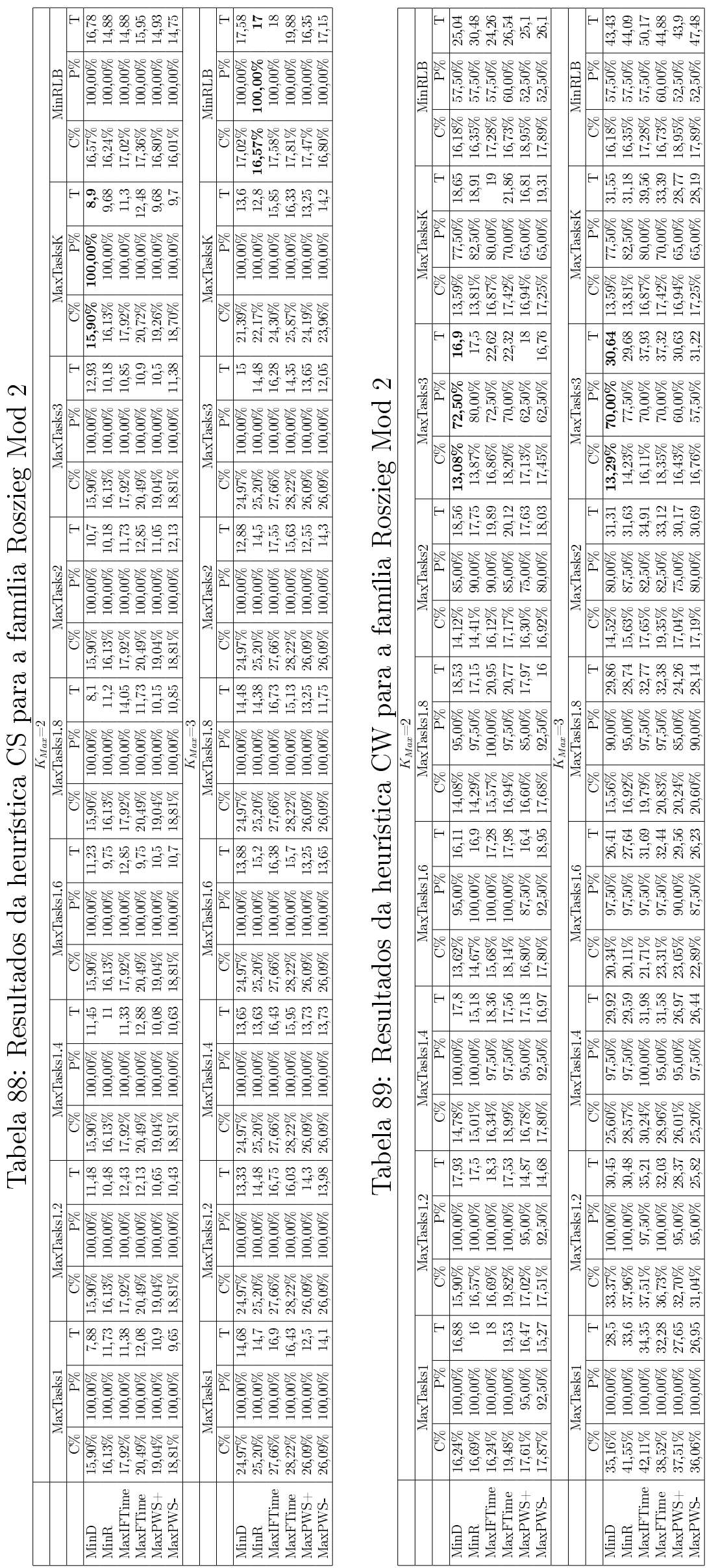
As melhores soluções encontradas pela heurística C2 estavam, em média a 22,33\% das soluções ótimas para o ALWABP serial para ambos os valores de $K_{\text {Max }}$. A combinação das regras MinRLB e MinR encontrou as melhores soluções em média.

A diferença entre as melhores soluções encontradas pela heurística CS e as soluções ótimas do problema serial, em média, foi de $12,18 \%$ para $K_{\text {Max }}=2$ e 12,90\% para $K_{M a x}=3$. Para duas instâncias, esta heurística encontrou soluções cujos tempos de ciclo eram menores que as soluções ótimas das respectivas instâncias para o problema serial. As melhores soluções, em média, foram encontradas pela combinação das regras MaxTasksK e MinD, para $K_{\text {Max }}=2$, e pela combinação das regras MinRLB e MinR, para $K_{\text {Max }}=3$.

Para a heurística CW, as melhores soluções encontradas estavam, em média, a 7,03\% das melhores soluções conhecidas para o problema serial, usando $K_{\text {Max }}=2$, e a $7,84 \%$, usando $K_{\operatorname{Max}}=3$. A combinação das regras MaxTasks3 e MinD encontrou as melhores soluções, em média, para ambos os valores de $K_{\text {Max }}$.

As tabelas 90, 91, 92 e 93 apresentam os resultados para a família Heskia Mod 1, obtidos respectivamente pelas heurísticas $\mathrm{C} 1, \mathrm{C} 2$, CS e CW.

As melhores soluções encontradas pela heurística C1 para a família Heskia mod 1 estavam em média, a 25,30\% das soluções ótimas do problema serial, para $K_{\text {Max }}=2$, e a 25,57\%, para $K_{M a x}=3$. Algumas instâncias não foram resolvidas por algumas combinações de critérios. Entre as soluções viáveis encontradas, a combinação das regras MaxTasksK e MinD encontrou as melhores soluções, em média. No entanto, esta combinação de regras conseguiu resolver poucas instâncias.

Para a heurística C2, as melhores soluções encontradas estavam, em média, a 25,37\% das soluções ótimas para $K_{\text {Max }}=2$, e a $25,85 \%$, para $K_{\text {Max }}=3$. algumas combinações de critérios não conseguiram resolver todas as instâncias. A combinação das regras MinRLB e MinR encontrou as melhores soluções, em média.

A diferença entre as melhores soluções encontradas pela heurística CS e as soluções ótimas para o problema serial foi de $24,26 \%$ para $K_{\text {Max }}=2$ e de $26,26 \%$ para $K_{\text {Max }}=3$. As regras MinRLB e MinR, quando combinadas, apresentaram as melhores soluções, em média.

Para a heurística CW, as melhores soluções encontradas estavam, em média, a 28,08\% das soluções ótimas para $K_{\text {Max }}=2$ e a $26,78 \%$ para $K_{M a x}=3$. Várias instâncias não puderam ser resolvidas por todas as regras. Apesar de as regras MaxTasksK e MaxPWSterem encontrado as melhores soluções em média, elas resolveram poucas instâncias. 

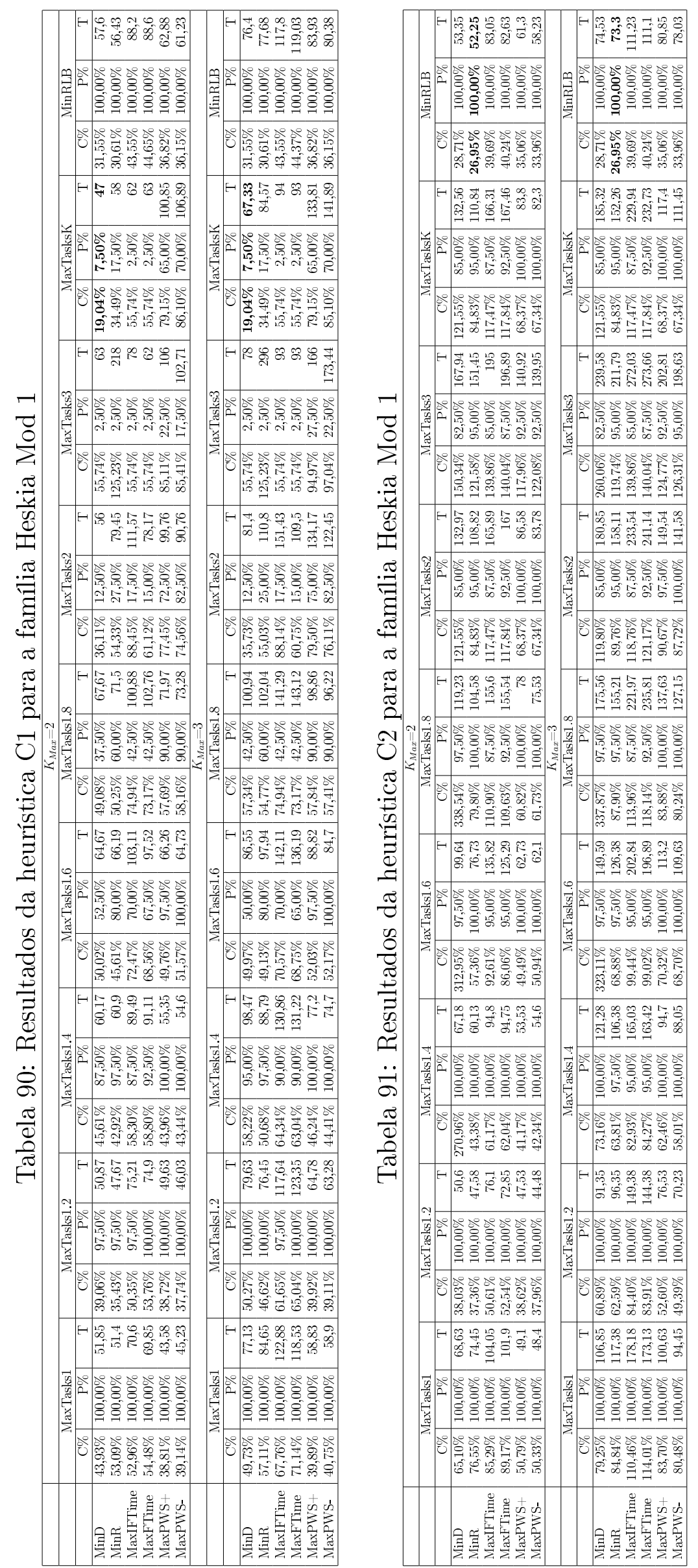


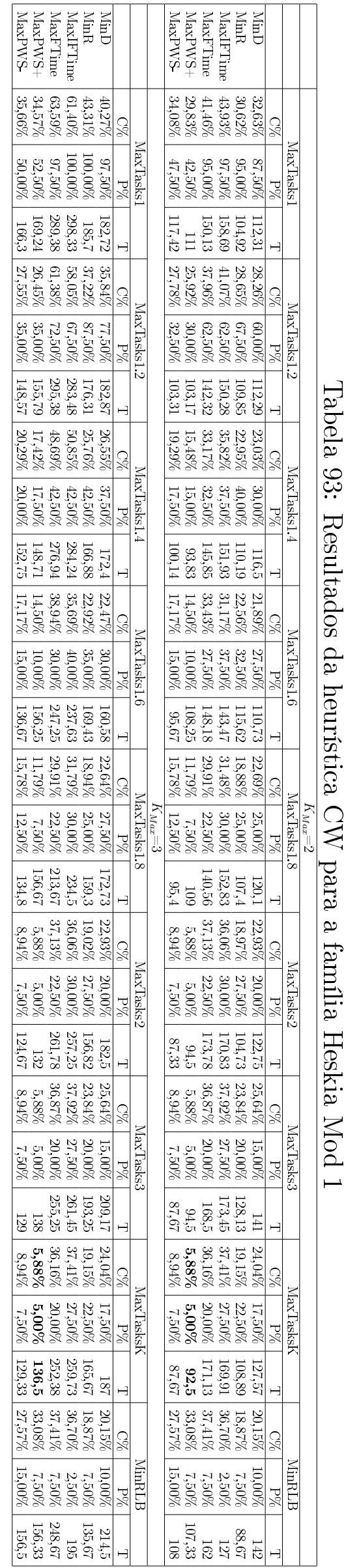

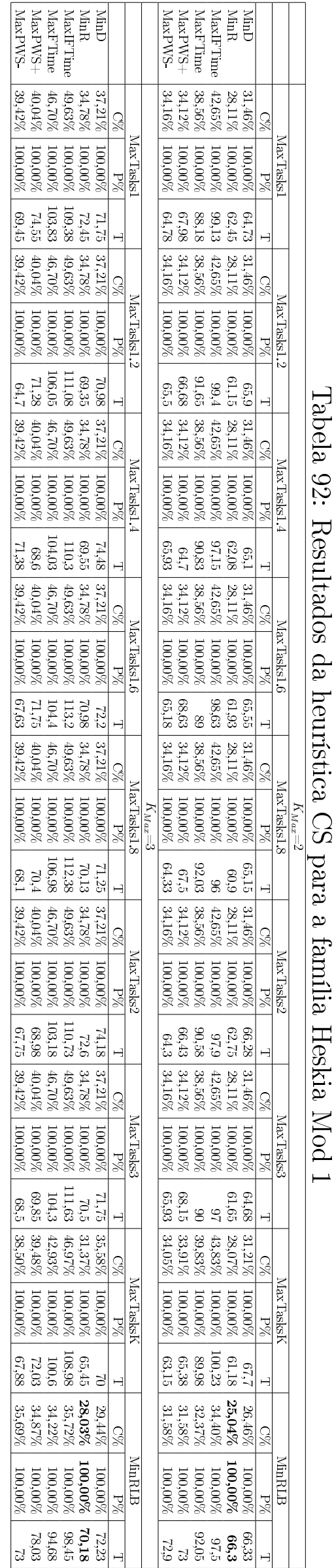


As tabelas 94, 95, 96 e 97 apresentam os resultados obtidos para a família Heskia mod 2 pelas heurísticas $\mathrm{C} 1, \mathrm{C} 2$, CS e CW, respectivamente.

Para a família Heskia mod 2, a diferença média entre as soluções encontradas pela heurística $\mathrm{C} 1$ e as soluções ótimas para o problema serial foi de $24,81 \%$ para $K_{\text {Max }}=2 \mathrm{e}$ de $25,30 \%$ para $K_{M a x}=3$. Nem todas as instâncias puderam ser resolvidas por todos os critérios. A combinação das regras MinRLB e MaxPWS+ encontrou as melhores soluções, em média.

As melhores soluções encontradas pela heurística C2 estavam, em média, a 10,12\% das soluções ótimas do problema serial, para ambos os valores de $K_{\text {Max }}$. As regras MinRLB e MinR apresentaram as melhores soluções, em média.

Para a heurística CS, as melhores soluções encontradas estavam, em média, a 9,13\% das soluções ótimas do ALWABP serial, para $K_{\text {Max }}=2$, e a $10,28 \%$ para $K_{\text {Max }}=3$. A combinação das regras MinRLB e MinR apresentou as melhores soluções, em média.

As melhores soluções encontradas pela heurística CW estavam, em média, a 9,57\% das soluções ótimas do ALWABP serial, para $K_{\text {Max }}=2$, e a $9,76 \%$, para $K_{\text {Max }}=3$. A combinação das regras MinRLB e MinR apresentou as melhores soluções, em média.

Desta forma, a heurística CW apresentou as melhores soluções, em média, para as oito famílias de instâncias. Entre as regras de prioridades para as tarefas, destacaram-se as regras MinR e MinD, enquanto que as regras MinRLB e MaxTasksK obtiveram as melhores soluções entre as regras de seleção de trabalhadores. 


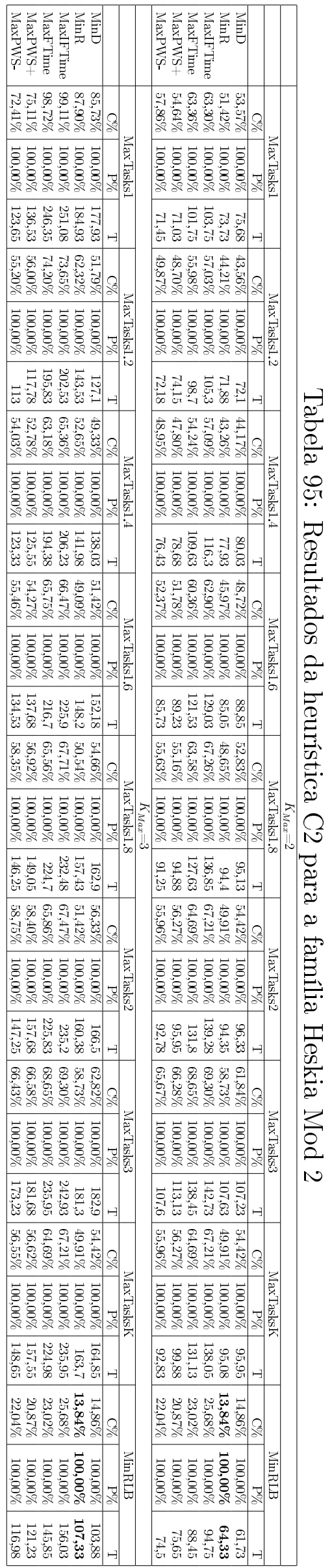

\begin{tabular}{|c|c|}
\hline 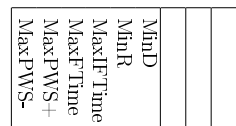 & 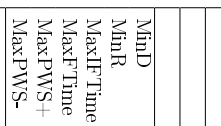 \\
\hline 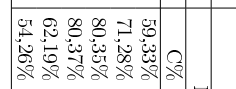 & 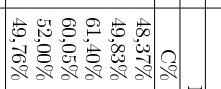 \\
\hline & 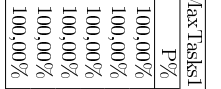 \\
\hline 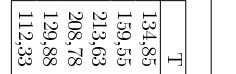 & 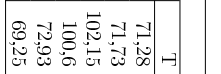 \\
\hline 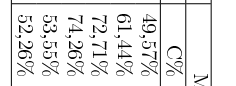 & 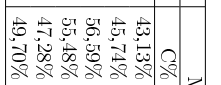 \\
\hline 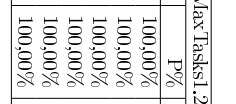 & 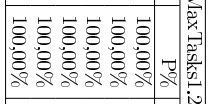 \\
\hline 吾 & 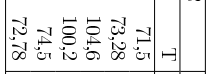 \\
\hline & \\
\hline & \\
\hline 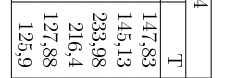 & \\
\hline & \\
\hline & $\begin{array}{lll}0 \\
0\end{array}$ \\
\hline & \\
\hline & \\
\hline & \\
\hline & \\
\hline & \\
\hline & \\
\hline 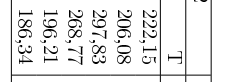 & \\
\hline & \\
\hline & \\
\hline | & \\
\hline 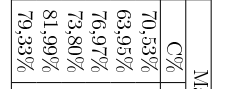 & 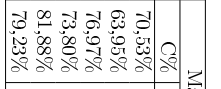 \\
\hline 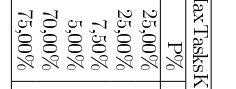 & $\mid$ \\
\hline 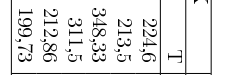 & 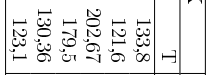 \\
\hline 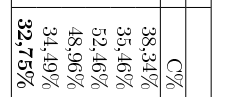 & 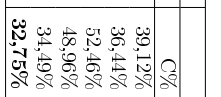 \\
\hline 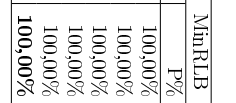 & 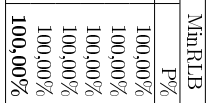 \\
\hline 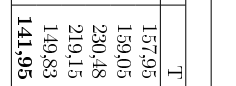 & 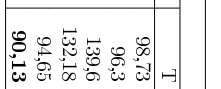 \\
\hline
\end{tabular}



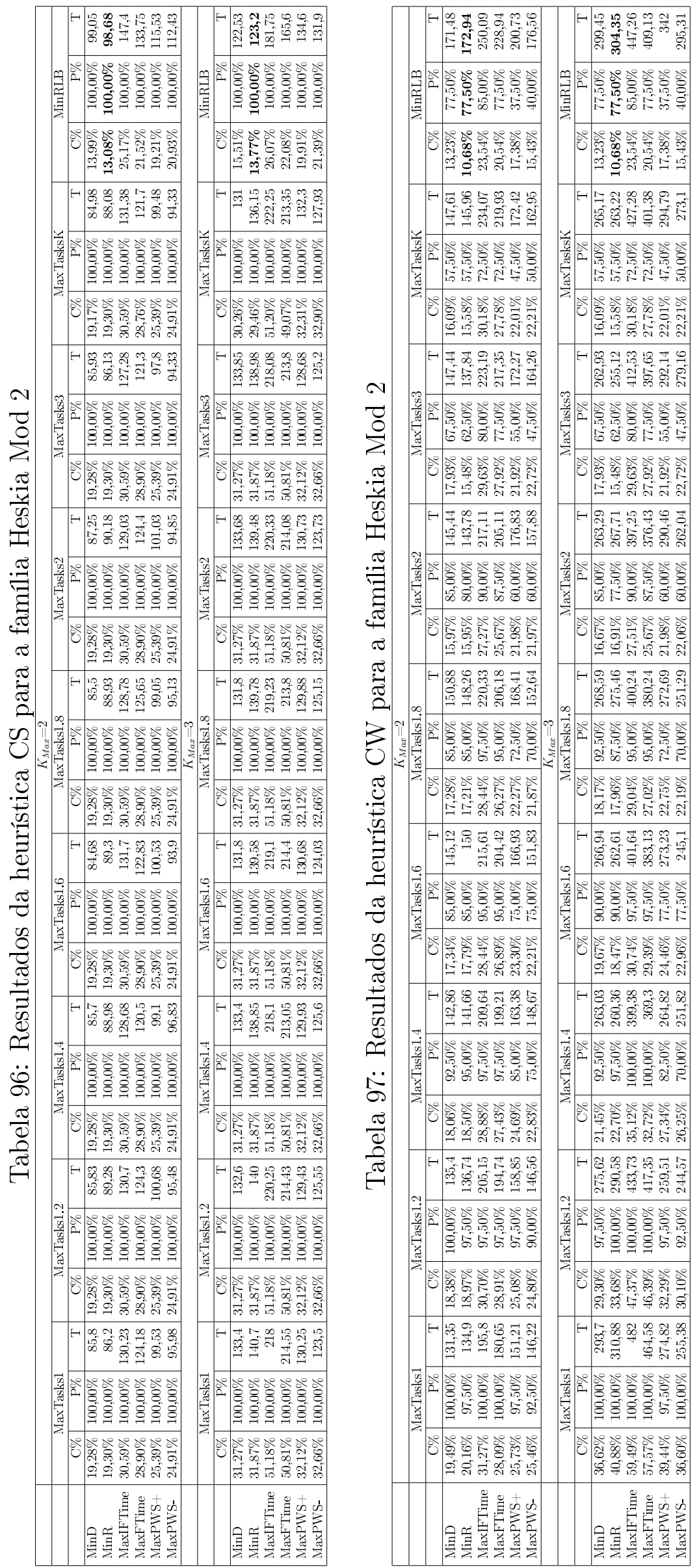